\title{
0.2390
}

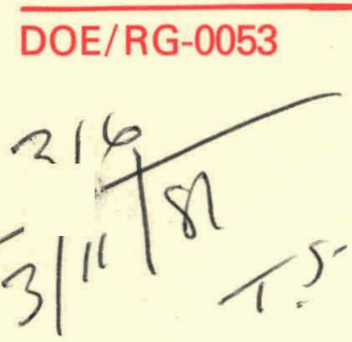

Prepared by:

February 1981

U.S. Department of Energy

Administrator Economic

Regulatory Administration

Division of Power

Supply and Reliability

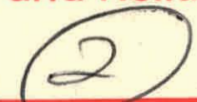

$R-2654$

\section{State Power Plant \\ Productivity Programs}

\section{MASTER}

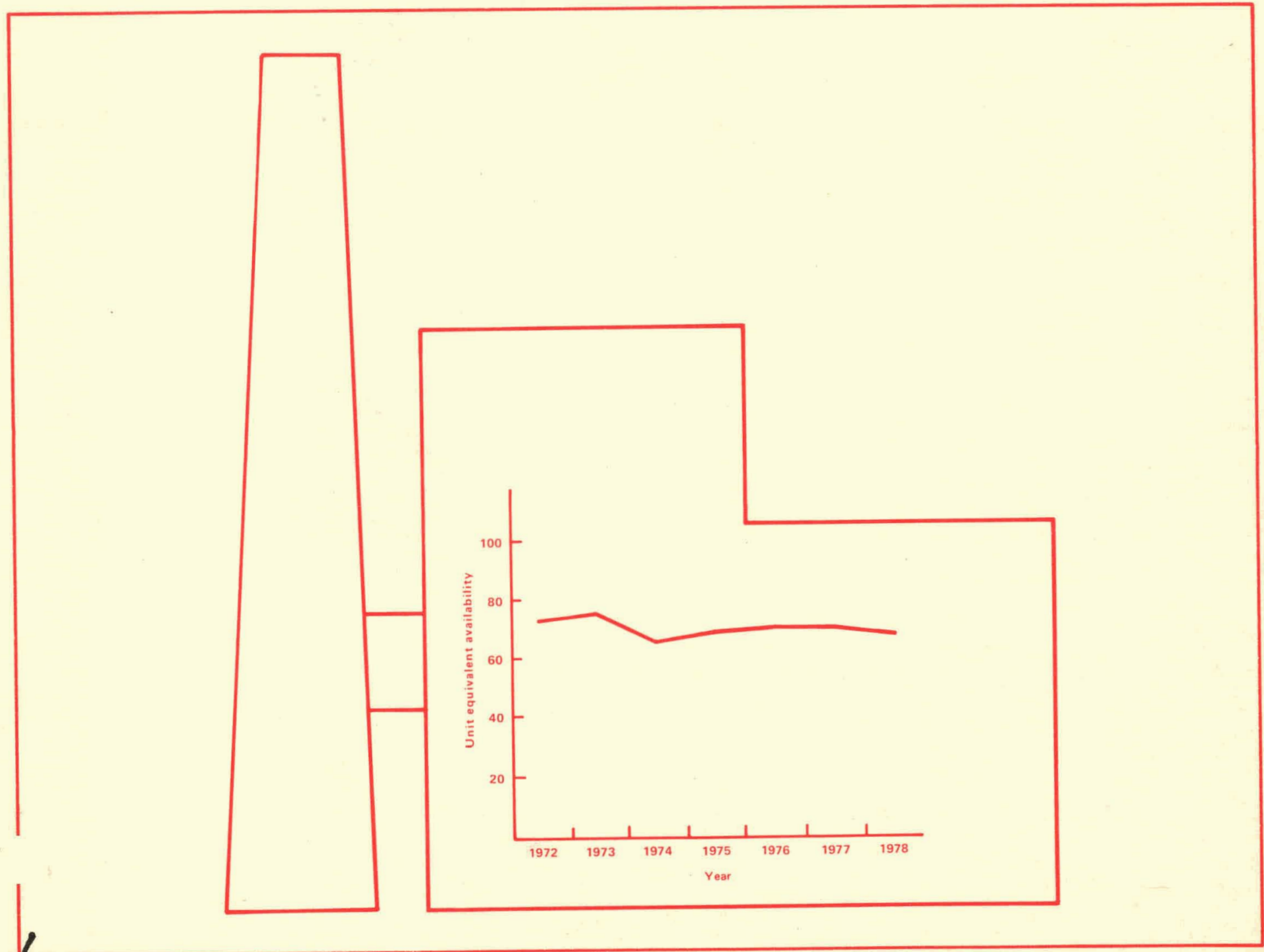




\section{DISCLAIMER}

This report was prepared as an account of work sponsored by an agency of the United States Government. Neither the United States Government nor any agency Thereof, nor any of their employees, makes any warranty, express or implied, or assumes any legal liability or responsibility for the accuracy, completeness, or usefulness of any information, apparatus, product, or process disclosed, or represents that its use would not infringe privately owned rights. Reference herein to any specific commercial product, process, or service by trade name, trademark, manufacturer, or otherwise does not necessarily constitute or imply its endorsement, recommendation, or favoring by the United States Government or any agency thereof. The views and opinions of authors expressed herein do not necessarily state or reflect those of the United States Government or any agency thereof. 


\section{DISCLAIMER}

Portions of this document may be illegible in electronic image products. Images are produced from the best available original document. 
Ava1lable from:

National Iechnical Information Service (NIIS)

D.S. Department of Commerce

5285 Port Royal Road

Springfield, Virginia 22161

Price: Printed copy: $\$ 11.00$

Microfiche: \$ 3.50 
DOE/RG-0053

Dist.Category 97b

\section{State Power Plant Productivity Programs}

February 1981

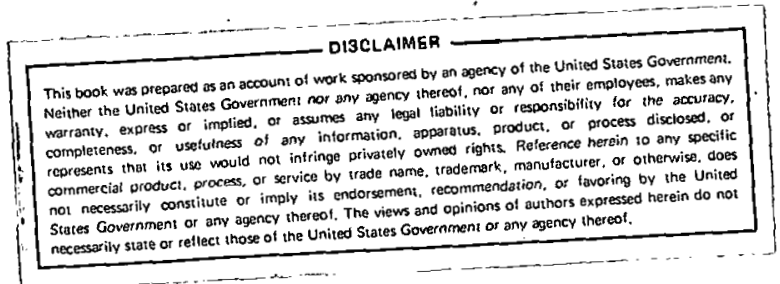

\section{Prepared by:}

U.S. Department of Energy

Administrator Economic Regulatory Administration

Division of Power Supply and Reliability

Washington, D.C. 20461

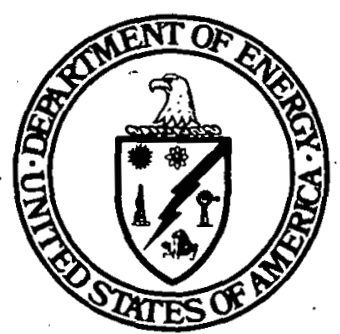


FOREWORD

This report presents the findings of a working group convened by the National Regulatory Research Institute (NRRI) and funded by the Department of Energy (DOE). This group was formed to review the status of efforts by utilities and utility regulators to increase the availability and reliability of generating units. The Working Group then developed findings and recommendations based on this review. Representatives from nine: state regulatory agencies, NRRI, and DOE, participated on the Working Group.

Funding for this project was provided by DOE as a part of its Power Plant Productivity Improvement Program. NRRI was the contractor. Considerable staff time was contributed to preparation of the report by the states represented on the Working Group.

DOE's Power Plant Productivity Improvement Program was begun by the Federal Energy Office in 1974. It was based on recognition of the important role that coal and nuclear generating units can play in conserving oil. The program was further cieveloped and expanded under the Federal Energy Administration and DOE. Throughout the course of this program, the Federal government has sought to act in a catlytic role, working cooperatively with utilities, utility organizations, and with regulators to encourage and facilitate improvements in power plant productivity. Cooperative projects have been undertaken with regulatory and energy commissions in California, Illinois, New York, Ohio, and Texas. Some of these efforts are described in this report along with those of other states, North Carolina and Michigan. Following initiation of these cooperative projects, DOE funded NRRI to conduct a survey to determine which states were explicitly addressing power plant productivity through the regulatory process. The working Group was formed following completion of this survey.

The report of the Working Group should serve as a valuable reference to those state regulators which are considering focusing special attention on the subject of generating plant performance. A number of alternative approaches for such performance evaluation have been implemented and other approaches are being considered. There is not likely to be only a single effective program to improve power plant productivity. The generic program presented should be viewed as a menu from which each state would choose those elements judged to best suit its available resources and potential for productivity improvement. The recommendations contained in the report are those of the working Group and may or may not represent the views of DOE.

The Department supports the emphasis that the Working Group has placed on the need for those power plant productivity improvements which are cost effective. The cost effectiveness of proposed availability improvement projects should be determined within the context of opportunities for operating and capital improvements available to an entire utility. Power plant productivity should not be viewed as an end unto itself.

In chapter 3, the Working Group also identified the need for:

"(1) allowing for plant designs that have a higher construction cost, but are also more reliable.

(2) allowing for recovery and reducing recovery lags for productivityrelated capital expenditures.

(3) identifying and reducing disincentives in the regulatory process. 
(4) ascertaining that utilities have sufficient money available to undertake timely maintenance.

(5) support of EPRI and NERC to develop a relevant and accurate national data base."

The Department views these as extremely important aspects of any regulatory program to improvie power plant productivity.

Finally, the Working Group noted in chapter 5 that the management responsibility of the utility and the oversight responsibility of Government "can be best discharged through a cooperative relationship." Power plant productivity is a complex subject, one in which. the adversarial process is not likely to yield the best solutions. Consumers and stockholders share a common interest in the economic operation of an electric utility. This interest can best be served through a cooperative approach to evaluating the opportunities for, and implementing actions to achieve increased, cost-effective power plant productivity.

This report supersedes an earlier report, "Recommendations for Regulatory Actions to Promote Power Plant Productivity Improvements" published by NRRI. Working Group I prepared the first version. Following substantlal review and comment frull stale alid. Federal agencies and industry spokespersons, working Group II prepared this final report. 
MEMBERS OF THE WORKING GROUP

ON POWER PLANT PRODUCTIVITY

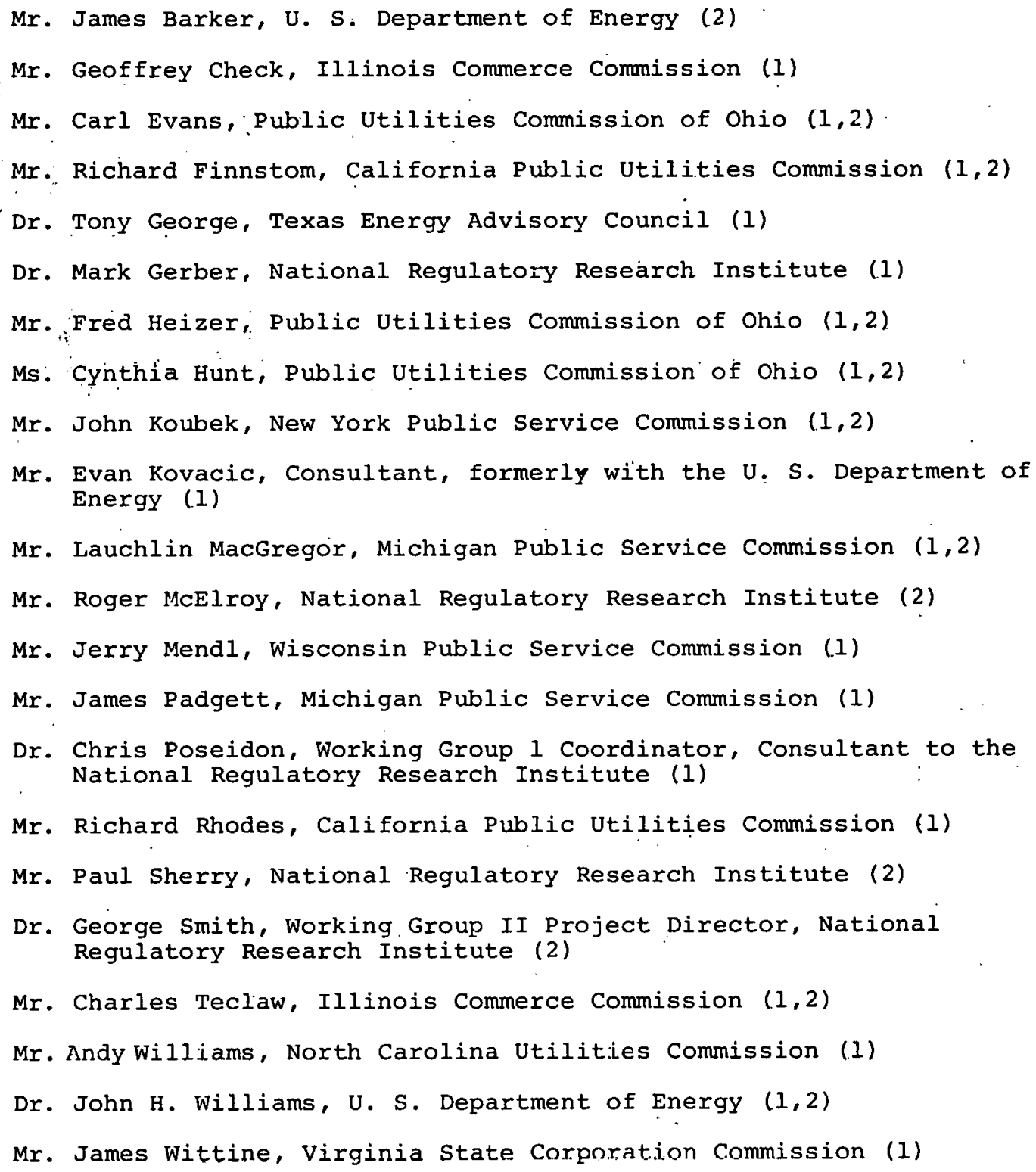

The National Regulatory Research Institute acknowledges the contribution of the members of the Working Group to this report. of the members of the Working Group, those representing state regulatory agencies volunteered considerable time and effort beyond their usual duties.

( 1 = Working Group I; 2 = Working Group II). 
TABLE OF CONTENTS

Page

Foreward. . . . . . . . . . . . . . . . . . . . . . . . . i

Members of Working Group on Power Plant Productivity. . . . . . . . . ii

Executive Summary . . . . . . . . . . . . . . . . . . . . . . 1x

\section{CHAPTER}

1

INTRODUCTION . . . . . . . . . . . . . . . . . . . . 1

1.1 Purpose ... . . . . . . . . . . . . . . . 1

1.2 Background. • . . . . . . . . . . . . . . . . . . 1

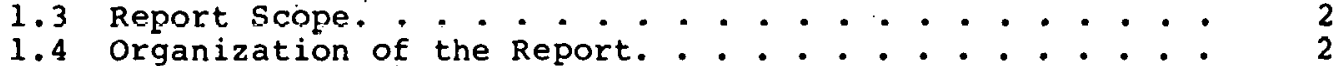

2 MECHANISMS FOR EVALUATING POWER PLANT PRODUCTIVITY AND BENEFITS FROM PRODUCTIVITY IMPROVEMENTS. . . . . . . . . . 5

2.1 Introduction. .. . . . . . . . . . . . . . . 5

2.2 Definition of Performance Indices............ 5

2.3 Existing Data Bases--Usefulness and Limitations . . . . 8

2.4 Analyses of Data. . . . . . . . . . . . . . . . . 10

2.5 Auditinq of Data. . . . . . . . ........... . . 11

2.6 Potential Benefits from Productivity Improvements. . . 11

3 OPPORTUNITIES FOR ENHANCING REGULATION REGARDING

POWER PLANT PRODUCTIVITY . . . . . . . . . . . . . . . . . 13

3.1 Introduction. . . . . . . . . . . . . . . . . 13

3.2 Elcmenta of a Program to Improve

Power Plant Productivity. . . . . . . . . . . . . 14

4 CURRENT ACTIVITIES AND PROGRAMS TO IMPROVE FOWER

PLANT PRODUCTIVITY . . . . . . . . . . . . . . . . . . 19

4.1 Introduction. . . . . . . . . . . . . . . . . . . . . 19

4.2 Industry Activities and Programs. . . . . . . . . . . . 19

4.2 .1 Data ...................... 19

4.2.2 Design Improvements. . . . . . . . . . . . . 22

4.2.3 Manufacture and Construction... . . . . . . . 23

4.2.4 Operations and Maintenance ............ 23

4.2.5 Diagnostic Instrumentation . : . . . ... . . . 24

4.2 .6 Fuel Quality.................. . . . . 24

4.2.7 Standardization. . . . . ........... . . . 24

4.2.8 Research Activities. . . . . . . . . . . . 24 
4.3 Feoleral Activities and Programs . . . . . . . . . 25

4.3.1 Power Plant Productivity Improvement

Program. . . . . . . . . . . . 25

4.3.2 Light-Water Reactor (LWR) Technology

Program. . . . . . . . . . . . . 27

4.3.3 Fossil Energy Programs . . . . . . . . . 28

4.3.4 Rural Electrification Administration

Activities . . . . . . . . . . . . . . 29

4.4 State Activities and.Programs . . . . . . . . . 29

4.5 Summary .................... 40

5

RECOMMENDATIONS. . . . . . . . . . . . .... 4 43

5.1 Introduction. . . . . . . . . . . . . . . . . 43

5.2 Discussion of Recommended Actions.......... 43

REFERENCES . . . . . . . . . . . . . . . . . . . 47

Appendix

A CURRENT ACTIVITIES RELATED TO IMPROVED POWER

PLANT PRODUCTIVITY IN THE STATE OF CALIFORNIA

(Power Plant Performance Analysis and

Guidelines Study). . . . . . . . . . . . . . . . 51

A.1 Introduction. . . . . . . . . . . . . . . . . 51

A.2 Results and Conclusions . . . . . . . . . . . . . . . 52

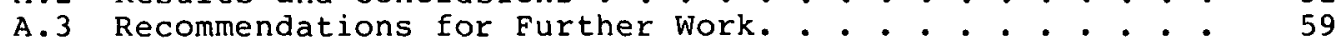

B CURRENT ACTIVITIES RELATED TO IMPROVED POWER

PLANT PRODUCTIVITY IN THE STATE OF ILLINOIS. . . . . . . . . . 63

B.1 Introduction. . . . . . . . . . . . . . . . . . 63

B. 2 Power Plant productivity Improvement Study. . . . . . . 64

B.3 Future Power Plant Availability Improvement

study . . . . . . . . . . . . . . . . . . 65

C CURRENT ACTIVITIES RELATED TO IMPROVED POWER

PLANT PRODUCTIVITY IN THE STATE OF MICHIGAN. . . . . . . . . . 67

C.1 Introduction. . . . . . . . . . . . . . . . 67

C.2 The Original Availability Incentive Provision. . . . . 67

C. 3 Proposed Modification to the Original System

Availability Incentive Provision. . . . . . . . . . . 67

C. 4 The Power Plant Availability Project. . . . . . . . . . 68

C.5 The Report on Power Plant Availability. . . . . . . . . 70

D CURRENT ACTIVITIES RELATED TO IMPROVED POWER

PLANT PROUUCTIVITY IN THE STATE OF NEW YORK. . . . . . . . . . 73

D.1 Introduction. . . . . . . . . . . . . . . . . . . 73

D. 2 State of New York Department of Public

Service Existing Procedures Related to

Power Plant Productivity Improvement. . . . . . . . . 74

D. 3 Power Plant Productivity Improvement Program $\cdot . . . \quad . \quad 75$

D.3.1 General. . . . . . . . . . . . . . . 75

D.3.2 Task 1 - Power Plant Outage Events

and Performance. . . . . . . . . . . . 75

D.3.3 Task 2 - Costs and other Impacts

Associated with Outage/Derating Events . . . . 76

D.3.4 Task 3 - Documentation and Development

of Regulatory Policies and Procedures. . . . . 77

4 
CURRENT ACTIVITIES RELATED TO IMPROVED POWER

PLANT PRODUCTIVITY IN THE STATE OF NORTH CAROLINA

(Description of North Carolina Power Plant

Performance Evaluation Mechanism). . . . . . . . . . . .

CURRENT ACTIVITIES RELATED TO IMPROVED POWER

PLANT PRODUCTIVITY IN THE STATE OF OHIO. . . . . . . . . . . . 83

F.1 Introduction. . . . . . . . . . . . . . . . . 83

F.2 The Fuel Cost Adjustment Clause . . . . . . . . . . . 83

F.3. PUCO/DOE Cooperative Agreement: The costs and Benefits of Improved Power Plant

Productivity. .... . . . . . . . . . . . . . . 83

F.3.1 Task I: Assessment of Power Plant

Perfurmance. . . . . . . . . . . . . . . 81

F.3.2 Task II: Costs/Performance Changes

Associated with Specific Productivity

Improvements .................... . 84

F.3.3 Task III: Benefits of Specific

Productivity Improvements. . . . . . . . . . . . 87

Task V: Impact of Load Shape Changes

on Benefits and Improved Productivity. . . . . . 87

F.3.4 Task IV: Incentives/Disincentives for

Power Plant Productivity Improvements. . . . . . 92

F.4 Current Action: Introducing Power Plant

Productivity into the Regulatory Process. . . . . . . . 92

G

CURRENT ACTIVITIES RELATED TO IMPROVED POWER

PLANT PRODUCTIVITY IN THE STATE OF TEXAS

(Power plant productivity study) . . . . . . . . . . . . 93

G.1 Introduction. . . . . . . . . . . . . . . . . . . 93

G.2 Performance Levels of Texas Utilities -
Preliminary Findings. . . . . . . . . . . . . . . . . 94

G.3 Long Term Impacts from Improved Power Plant

G.3.1 Scenarios of study . . . . . . . . . . . . . . 94

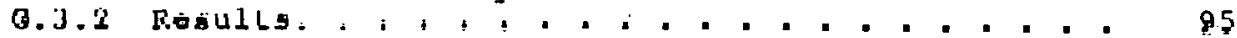

BIBLIOGRAPHY • . . . . . . . . . . . . . . . . . . . . . 
2.1 REPRESENTATIVE ENERGY COSTS BY FUEL TYPE IN $1979 . . . . .$.

4.1 ESTIMATED IMPROVEMENT IN EQUIVALENT AVAILABILTTY AND ASSOCIATED COST AND BENEFIT. . . . . . . . . . . . . . .

4.2 THE EFFECTS OF PRODUCTIVITY IMPROVEMENTS AND LOAD MANAGEMENT ON SYSTEM PARAMETERS OVER THE PERIOD 1979-1988 ASSUMING TIMELY CAPACITY ADDITIONS

A.1 RELIABILITY AND EFFICIENCY INDICES RECOMMENDED IN REF. [3]. . . . . . . . . . . . . . . . . .

A.2 ATTRIBUTES AND LIMITATIONS OF INDICES RECOMMENDED IN REF. [3]. . . . . . . . . . . . . . . . 55

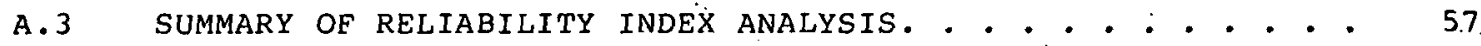

A. 4 SUMMARY OF EFFICIENCY INDEX RESULTS. . . . . . . . . . . . . . $\quad 58$

A. 5 KEY ISSUES - . . . . . . . . . . . . . . . . . . . . . . 60

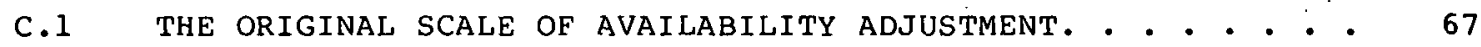

C.2 THE PROPOSED EXPANDED SCALE OF AVAILABILITY

ADJUSTMENT . . . . . . . . . . . . . . . . . . 68

C. 3 ORIGINAL SCALE OF AVAILABILITY ADJUSTMENT

INCLUDING PERIODIC MAINTENANCE FACTOR. . . . . . . . . . . . 69

C. 4 THE PROPOSED EXPANDED SCALE OF AVAILABILITY

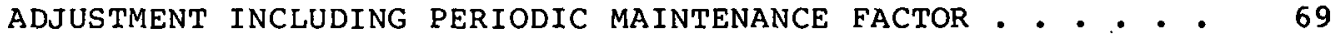

F.1 UNITS AND PROBLEM AREAS SELECTED FOR STUDY • • • • • • • • .85

F.2 ESTIMATED IMPROVEMENT IN EQUIVALENT AVAILABILITY

AND ASSOCIATED COST AND BENEFIT. . . . . . . . . . . . . . . . .

F.3 THE EFFECTS OF PRODUCTIVITY IMPROVEMENTS AND LOAD MANAGEMENT ON SYSTEM PARAMETERS OVER THE PERIOD 1979-1988 ASSUMING TIMELY CAPACITY ADDITIONS

F.4 THE EFFECTS OF PRODUCTIVITY IMPROVEMENTS AND LOAD MANAGEMENT ON SYSTEM PARAMETERS OVER THE PERIOD 1979-1988 ASSUMING ONE-YEAR DELAY IN ALL FUTURE CAPACITY ADDITIONS . . . . . . . . . . . . . . . . . . . 
F.5 THE EFFECTS OF PRODUCTIVITY IMPROVEMENTS AND LOAD

MANAGEMENT ON SYSTEM PARAMETERS OVER THE PERIOD

1979-88 ASSUMING TWO-YEAR DELAY IN ALL FUTURE

CAPACITY ADDITIONS . • . . . . . . . . . . . . . . . . . . 91

G.1 FIXED PLANNED CAPACITY EXPANSION - EROC REGION . • • . . . . 96 
EXECUTIVE SUMMARY

The National Regulatory Research Institute (NRRI), under contract from the U.S. Department of Energy, instituted a program to assist state regulatory agencies in the evaluation of power plant performance and the promotion of improved power plant productivity. The focus of this program has been based on state regulatory responsibilities to ensure adequate energy supply at reasonable cost to the consumer. The objectives in the following report have been to provide recommendations for regulatory actions to promote cost-effective power plant productivity improvements and to furnish appropriate state regulatory agencies with a reference document to assist in the evaluation of utility power plant productivity improvement programs.

Power plant productivity and performance improvements, as discussed below, refer to increasing the time that a plant is available for operation, reducing the time that a plant is not available at rated power, and improving plant on-line efficiency. This report was prepared by the Working Group on Power Plant Productivity organized by NRRI. The Working Group was comprised of representatives from regulatory agencies in California, Illinois, Michigan, New York, North Carolina, Ohio, Texas, Virginia, Wisconsin, from NRRI, and from the Department of Energy. Prior to organizing this Working Group, NRRI surveyed productivity related activities in forty states, finding ten states that are explicitly addressing the issue of power plant productivity. The initial Working Group report, "Recommendations for Regulatory Actions to Promote Power Plant Productivity Improvements," was issued Auguet 1979. NRRI and DOE distributed that report to state regulatory agencies and utility industry spokespersons for review and comment. An augmented subset of the original working Group reviewed the responses and produced this modified and updated final report.

The impetus for this report stems from DOE studies conducted in cooperation with state agencies, power pools, and utilities, showing that improved productivity can significantly reduce the cost of energy. These savings mainly result from more efficient utilization of baseload units.

The Working Group surveyed relevant data systems and the potential for utilization of those data systems and the existing mechanisms for evaluating power plant productivity and the potential for improvements.

Working Group findings include:

- Current industry efforts promise to.improve the availability of productivity data greatly. A cooperative effort between government and industry could greatly enhance this important aspect of the productivity improvement agenda.

- A number of factors have adversely affected power plant productivity. Among them are (1) deteriorating fuel quality; (2) a regulatory climate and/or a utility manageinent strategy which may have encouraged a lower first cost at the expense of future performance; (3) a prevailing economic climate which has radically altered the feasibility of earlier decisions; (4) power plant equipment design and manufacturing decisions; power plant design and construction decisions, and plant operating and maintenance practices; and (5) regulatory requirements related to environmental and health safety issues (i.e., emission levels, pollution abatement). 
- No single index is sufficient to assess plant productivity. The commonly used terms such as capacity factor, forced outage rate, equivalent availability, and operating availability are individual performance measures which must be considered together to assess productivity. Furthermore, even though multiple indices are monitored, in-depth analyses must be performed to identify root causes of low productivity.

- The major existing data bases are the Generation Availability Data System (GADS) operated by the National Electric Reliability Council (NERC), the Gray Book, published by the Nuclear Regulatory Commission (NRC), and the Nuclear Plant Reliability Data Systems (NPRDS) of the American National Standards Institute (ANSI).

- Even though existing data bases are imperfect, comparisons of performance by unit size, type, and vintage can be made from the existing data bases. Such analyses have been made by EEI, the U.S. Department of Energy (DOE), the Eiectric Power Research Institute, and NRC. However, these analyses should be tempered by an understanding of the shortcomings of the data and the differences between generating units of like fuel and size.

- Cooperative studies conducted by DUE ana state duencirs have demongtrated that the expected benefits of improved power plant productivity are substantial. Such benefits include reduction in fuel or (more expensive) purchased power costs, oil and gas conservation, possible deferral of capacity additions, and rcduced overall system rnst.s.

- The opportunities for actions by state regulatory agencies may be $11 \mathrm{~m} 1$ ted by technical and statutory constraints. These constraints and the cost-effectiveness of potential improvements may vary from state to state.

\section{Recommendations}

The Working Group recognizes that power plant productivity is principally the responsibility of the utility industry. However, the Working Group believes that state regulators should be committed to a cooperative undertaking with industry in order to assure ratepayers that this responsibility is properly discharged. At this time (September 1980), only a small number of states have implemented productivity improvement programs. There is a need to continue existing regulatory programs to encourage productivity improvements, and for additional states to implement appropriate programs. To accomplish this, the Working Group recommends that regulatory agencies implement elements of the programs suggested in this report, including taking the following actions to promote cost-effective power plant productivity improvements:

- Develop a commission position or policy statement to encourage productivity Improvellents by utilities;

- Coordinate state efforts with ongoing industry and goverument programis lo improve the acquisition of power plant performance data and the maintenance of quality information systems;

- Acquire the capability to perform independent analyses of power plant productivity;

- Direct the establishment of productivity improvement programs, including explicit performance objectives for both existing and planned power plants, and a performance assurement program;

- Establish a program of incentives to motivate productivity improvement activities; and

- Participate in ongoing efforts at all levels and initiate new actions to promote productivity improvements. 
Chapter 1.

\title{
Introduction
}

\author{
1.1 Purpose
}

The purpose of this report is to provide state regulatory agencies with a reference document to assist in the evaluation of power plant productivity and in the promotion of improved power plant productivity. Several reports in this area have shown that improvements in power plant productivity are possible, cost-effective, and beneficial $[13,27,34-36]$. This report identifies current regulatory activities related to power plant productivity improvement, describes elements of a model program for power plant productivity improvements, and recommends regulatory actions that would motivate utilities to increase the productivity of their generation units, their power plants, and ultimately their power-generating systems. The underlying premise of the report is that there is an appropriate role to be played by state regulatory agencies in motivating cost-effective productivity improvements by the utilities. That role should be an active one, recognizing the variety of working relationships that exist between state agencies and the utilities that they regulate.

In the discussions that follow, productivity is viewed as an aggregate concept that cannot be captured adequately by a single index. It is appropriate, then, to speak of a vector of performance measures or indices, all of which relate to some aspect of total productivity. In all, there are some seven measures of performance that are generally recognized in the industry. Not all of the measures are independent; however, each highlights some aspect of productivity.

\subsection{Background}

Unprecedented cost increases for fossil fuels and greatly increased. lead times and costs for adding new generating capacity have made improving power plant productivity an important issue for utility managers and state regulators [15, 20, 29, 37]. Simultaneously, oil supply disruptions and the nation's growing dependence on oil imports have led to federal policies that set high priority on reducing oil and gas consumption by utilities. Reduced oil and natural gas consumption can be achieved in part through improved production of coal and nuclear units. Recent studies conducted by the U.S. Department of Energy in cooperation with state regulatory agencies, power pools, and utilities have shown that improved productivity can yield substantial benefits at the utility, state, and regional levels [34-36].

Beginning in the early 1970s, and continuing for several years, there was a gradual decline in power plant productivity in the United states, followed by a recent leveling off and possible upturn [32]. Generally, on the average, the nation's nuclear and large coal-fired units are unavailable for service 15 percent of the time due to unscheduled full outages, are available for service 75 percent of the time; and operate at about 60 percent capacity factor [37]. These levels of performance are

*Numbers in brackets refer to the list titled "References" on page 47 of this report and not to the "Bibliography." 
considerably below previous experience and far below those anticipated by utilities and vendors alike.

\subsection{Report Scope}

This report was prepared as part of a project by The National Regulatory Research Institute (NRRI) under contract to the U.S. Department of Energy (Economic Regulatory Administration, office of Utility systems). The goal of this project has been to identify current state programs related to improving power plant productivity and to outline activities that promote power plant productivity for the consideration of state regulatory commissions.

In the first phase of this project, NRRI contacted 40 of 50 state regulatory agencies to gather information on their activities and practices that are aimed at improving power plant productivity. The results of the first phase revealed that there is concern over the issue of productivity among state regulators, but only a small number of states are actually involved in programs to improve power plant performance.

In the second phase of the project, NRRI organized a Working Group on Power Plant Productivity to prepare a reference document on power plant productivity for state regulatory agencies and to develop recommendations for such agencies to initiate programs directed toward improving power plant performance. The Working Group is comprised of members of those state regulatory agency staffs where efforts toward improving power plant productivity have been evident through regulation, hearings, and special studies. Regulatory agencies from nine states are represented on the working Group. * In addition, representatives from NRRI and the Department of Energy, office of Utility systems, participated.

Although the working Group devoted considerable attention to the matter of load management, the consensus was that load management is an inappropriate means for improving power plant productivity as defined in this report. However, the Working Group recognized that if productivity is high, the benefits of load management may be substantially increased.

\subsection{Organization of the Report}

opportunities for regulatory initiatives vary among states. A diversity of factors, including among others, enabling legislation, historical-working relationships between the commission and the utilities, capability of the commission staff, philosophy of the utility managers and the regulatory commissioners, utility plant characteristics, and system load characteristics interact to produce unique circumstances. In recognition of this, the Working Group has prepared a generic program consisting of a number of different commission actiyities and programs. Farh commission should consider its present situation, establish a policy to guide and direct future initiatives, select from these recommended steps, or others, and begin to implement a program to enhance power plant productivity.

The report is organized as follows:

Chapter 2 contains background information in the area of power plant performance. It includes definitions of the most commonly used power plant performance measures, a discussion of available data bases and their limitations, and a discussion of data analysis efforts. Some of the potential costs and benefits of productivity improvements, and the need for such improvements, are also discussed.

Chapter 3 presents a generic program of suggested regulatory activities to improve power plant productivity. This program includes the development of productivity goals and suggested monitoring and enforcement activites. These suggested

*States represented include California, Illinois, Michigan, New York, North Carolina, Ohio, Texas, Virginia, and Wisconsin. California, Illinois, Michigan, New York, and Ohio participated in drafting the final report. 
activities are supported by descriptions of actual state programs that appear in the appendixes.

Chapter 4 contains a description of current activities by the federal government, the state governments, and the industry to improve plant performance. Such activities include studies and implementation of measures to improve plant performance. This chapter identifies the types of programs being conducted and cites the experience from the outcomes of these programs.

Chapter 5 presents specific recommendations for state regulatory agencies wishing to undertake initiatives to enhance power plant productivity improvement programs. These recommendations are based on the experience gained from programs and activities that have been implemented (Appendixes A through G), the program of regulatory activities presented in Chapter 3, and the review of mechanisms for measuring various aspects of power plant productivity found in Chapter 2 .

Appendixes A through G contain the details of specific state programs. Descriptions of state activities in California, Illinois, Michigan, New York, North Carolina, Ohio, and Texas are included.

A bibliography of available literature on power plant performance follows the appendixes. The purpose of the bibliography is to provide the reader with background information on power plant productivity beyond the scope of this report. (Numbers in brackets throughout the text do not refer to the bibliography but to the 1 ist of references that follows chapter 5.) 


\section{4}

THIS PAGE

\section{WAS INTENTIONALLY LEFT BLANK}


Chapter 2.

\section{Mechanisms for Evaluating Power Plant productivity and Benefits from Productivity Improvements}

\subsection{Introduction}

This chapter presents background information on power plant performance indices, data bases of measures of power plant performance, and discusses the potential benefits from power plant productivity improvements. The data base status is described as it exists currently. The data base deficiencies as described herein are recognized by the industry and in fact have been identified substantially through industry efforts. As discussed in section 4.2, the industry has a wide-ranging effort aimed at correcting the data base deficiencies.

A number of indices are being used to measure overall power plant performance. The most widely recognized and publicized are the forced outage rate, operating availability, equivalent availability, and capacity factor. others in use include heat rate, equivalent forced outage rate, and scheduled outage rate.

Power plant performance data are collected by many organizations. The major sources of published data are the following:

(1) The Edison Electric Institute (EEI) Report of the Equipment Availability Task Force of the Prime Movers Committee. (Effective January 1, 1979, the responsibility for data collection was transferred to the National Electric Reliability Council [NERC].) There is a quarterly report for $600 \mathrm{MW}$ and larger units ${ }^{\star}$ and an annual report for all unit sizes. The data base includes fossil-fired units.

(2) The Nuclear Regulatory Commission (NRC) "Operating Units Status Reports" commonly known as the "Gray Book" (and referred to as such in this report). The Gray Book is published monthly. The data include only nuclear units.

(3) The American National Standards Institute (ANSI)-sponsored "Nuclear Plant Reliability Data System" (NPRDS). This data system covers only safety-related equipment in nuclear power plants.

In section 2.2 , the most widely recognized indices are defined and discussed. In section 2.3, the usefulness and limitations of existing data bases are discussed, analyses performed using such data are reviewed, and the methods of data collection are evaluated. The benefits from productivity improvements are discussed, and the immediate need for productivity improvements is demonstrated in section 2.4 .

\subsection{Definition of Performance Indices}

The following definitions of performance indices are those used in the Edison Electric Institute data base [5]. (Note: As discussed in section 4.2 there is an

\footnotetext{
*In the future, the quarterly report will include $200 \mathrm{MW}$ and larger units.
} 
industry effort to propose national standard definitions. The proposed standard definitions differ somewhat from the EEI definitions.)

The fraction of time that a plant is available for operation is called "Operating Availability" (OA). This parameter is defined by:

where

$$
\mathrm{OA}=\frac{\mathrm{AH}}{\mathrm{PH}} \times 100
$$

$\mathrm{AH}=$ service hours + reserve shutdown hours,

"service hours" is the number of hours a unit was in the in-service state, "reserve shutdown hours" is the number of hours a unit was in the economy shutdown state, and

$\mathrm{PH}=$ the number of hours in the period of measurement.

A unit is not considered "available" when it is forced out of service or is down for planned maintenance. 'l'he number of service hours includes the number of hours that a plant operates at rated capacity and at derated capacity due to planned or unplanned partial outages. The operating availability measures the percentage of time that a unit is capable of producing power at any power level.

In order to account for the effects of partial outages in the measurement of availability, the parameter "Equivalent Availability" (EA) has been defined. This parameter is defined by

$$
\mathrm{EA}=\frac{\mathrm{AH}-(\mathrm{EFOH}+\mathrm{ESOH})}{\mathrm{PH}} \times 100
$$

where

$$
\begin{aligned}
& \text { EFOH }=\frac{\text { Forced Partial Outage Hours } x \text { Size of Reduction in MW, }}{M D C} \\
& \text { ESOH }=\frac{\text { Scheduled Partial Outage Hours } x \text { Size of Reduction in MW, }}{M D C}
\end{aligned}
$$

and

MDC = maximum dependable capacity in MW. (EEI and NERC use the lowest of the two seasonal rates. Misinterpretation could occur.)

The equivalent availability is a measure of the unit's true ability to produce power, since it takes into account partial outages. This index is important, since it is possible to have a unit with 100 percent availability but with less than 100 percent equivalent availability. Operating availability can be used to indicate the percentage of time the unit is fully out of service. When compared to operating availability, equivalent availability can be used to indicate the additional loss in production capability due to partial outages.

The "Capacity Factor" is a measure of the actual output (MWh) of a unit within a specified time period relative to its potential output.

$$
\begin{aligned}
& \text { The "Capacity Factor" (CF) is defined by } \\
& C F=\frac{\text { Total Gross Generation in MWh }}{(\mathrm{PH}) \times(\mathrm{MDC})} \times 100
\end{aligned}
$$

The "Total Gross Generation," equation (2.3), can be affected by factors other than forced or scheduled outages. Such factors include economy dispatch and regulatory deratings. If there is no economy dispatch (baseloaded plants) and no deratings other than those due to forced or scheduled partial outages, then the capacity factor approaches the equivalent availability. 
The "Heat Rate" is a measure of the thermal efficiency of a generating unit. It is defined by

$$
\text { Heat Rate }\left(\text { Btu/kWh) }=\frac{\text { (Btu Fuel) } \times \text { (Heat Input) }}{\text { kWh Output }}\right.
$$

and it represents the fuel-heat input required to generate a kWh and deliver the generated power to the transmission line leaving the station. The heat rate is inversely proportional to the unit's efficiency. Equation (2.4). is not included in the EEI definitions of reference [5].

A parameter used to express a plant's total unavailability due to full forced outages (that is, unscheduled outages) is the "Forced Outage Rate" (FOR).

This parameter is defined by

$$
\mathrm{FOR}=\frac{\mathrm{FOH}}{\mathrm{SH}+\mathrm{FOH}} \times 100
$$

where

$$
\begin{aligned}
\text { FOH } & =\text { full forced outage hours, and } \\
\text { SH } & =\text { service hours. }
\end{aligned}
$$

Partial forced outages are taken into account by defining an "Equivalent Forced Outage Rate" (EFOR).

This parameter is defined by

$$
\text { EFOR }=\frac{\text { FOH }+ \text { EFOH }}{\text { FOH }+ \text { SH }} \times 100
$$

A parameter used to express a plant's unavailability due to planned and scheduled outages (such as maintenance and nuclear refueling) is the "Scheduled Outage Rate" (SOR).

This parameter is defined by

$$
\mathrm{SOR}=\frac{\mathrm{SOH}}{\mathrm{SH}+\mathrm{SOH}} \times 100
$$

where

SOH $=$ scheduled outage hours.

Each of the indices measures one specific aspect of the performance of a unit or a plant. None of them really can be assessed in the absence of a knowledge of the behavior of at least some of the others. When taken in the aggregate, however, they provide an extremely good indication of the productivity of a unit or a plant. The individual performance measures are useful in directing an investigator's attention toward particular weaknesses in a unit and suggest targets for improvement.

A more detailed discussion of the usefulness and limitations of performance indices can be found in appendix $A$, section $A .2$. 


\subsection{Existing Data Bases--Usefulness and Limitations}

Three major plant performance data bases are the National Electric Reliability Council's (NERC) Generation Availability Data system (GADS), that was transferred from the Edison Electric Institute; the Nuclear Regulatory Commission's (NRC) "Operating Units Status Reports" (commonly known as the "Gray Book"); and the American National Standards Institute's (ANSI) "Nuclear Plant Reliability Data System" (NPRDS)

All three data bases contain data for nuclear power plants, but only NERC/GADS includes data for fossil-fired plants.

In addition to the three data systems mentioned, some major equipment manufacturers maintain unit performance data that are used for improving and tracking the performance of their equipment. Generally, these data are not available to the public.

The above three data bases have been studied in great depth by DOE, EPRI, ANSI, and other governmental, industrial, and professional organizations. Existing data bases are inadequate for satisfying the needs of either government or industry for timely, accurate, and useful performance data. Eurthermore, there is a high level, of artivity under way at this time to remedy this particular problem.

Participation in the NERC data base is voluntary; hence, the data base does not include all units. Also, reporting is often very slow.

Studies sponsored by DOE and. EPRI have identified anomalies and errors in the EFI data. Data anomalies include inconsistencies among the equivalent availability factor, availability factor, and forced outage rates.

One of the most revealing studies sponsored by DOE was performed by the Oak Ridge National Laboratory and titled, "An Assessment of Anomalies in the EEI Data Base on Power Plant Performance" [30]. "This study evaluated raw data supplied by EEI on four units (three coal, one nuclear) for one year of operation for a total of four unit-years of operation. The analysis uncovered anomalies such as the following:

(1) double reporting of forced outages;

(2) double reporting of forced outages with planned outages;

(3) double reporting of maintenance outages with planned outages; and

(4) overlapping outages.

A rough check showed that 20 to 25 percent of the unit-year data are suspect because service hours exceed available hours, or capacity factor exceeds operating availability or equivalent availability.

NERC has undertaken a large effort to improve the quality and timeliness of. generating unit performance data. Error checking is built into GADS. Consequently, it is believed that the data published by NERC beginning with the first quarter of 1979 represent an accurate measure of generating unit performance.

Another problem with the EEI data base is in the area of component outage causes that was analyzed by Stone \& Webster for EPRI [6]. Stone \& Webster's findings are as follows:

(1) Equipment covered by the cause codes are not described adequately by the deșign data.

Only major outage causes are required to be reported. When a unit experiences an outage where several components from different major equipment groups are being repaired, only one cause code from each group needs be selected to cover them all. This method of reporting outages affects the recording of the frequency of failure of components, since necessary maintenance and repair that are done while the unit is out of service for some other cause are not reported. 
(3) The duration of component outages that occur during nonoperating system tests in which a component failure is revealed cannot. be determined. The reason is that only the start date of the system test is recorded unless the entire system failed. The end date is omitted per instructions.

(4) Specific cause codes are applied to broad descriptions of equipment components, events, and combinations thereof. They do not distinguish precise items of equipment that have experienced outages. Examples are: Safety system Valves and Piping (Cause Code 229), Operating Training and License Testing (Cause Code 290), and Auxiliary or Standby Feedwater Supply System Malfunction (Cause Code 220).

(5) Neither cause codes nor equipment design data are provided for some important components and systems. This is especially true for instruments, controls, and station electrical systems. A few generalized codes in the 900 series must be used.

NERC is revising the cause codes and the guldelines for reporting data in an effort to eliminate some of these deficiencies.

Stone \& Webster under the same EPRI contract performed a similar analysis for nuclear unit outage data and derived the following limitations to data reported in the Gray Book [6].

(1) Significant reductions in power level (those of greater than 20 percent reduction in average daily power level for the preceding 24 hours) do not list the elapsed time, the cause, or the amount of reduction. In fact, the instructions direct the reporter to enter "0" in the DURATION column and to list the METHOD as "9" (Other). Data on these periods of reduction would be useful for analysis if information on duration, cause, and amount of reduction were included. These would permit computation of the previously mentioned major productivity indices.

(2) The numbering of shutdowns and reductions is to be assigned sequentially for the year by the reporter. However, the instructions are not clear in the use of the same number for a shutdown or reduction that is continued into the next report period, whether the following month or year. Because the instructions are not explicit on this desired procedure, there are many instances of dual or different numbering of the same shutdown in the monthly reports. processed for the Gray Book's file.

(3) As with the numbering of shutdowns, the instructions similarly do not specify carrying over the data of the start of each shutdown or power reduction that is continued into the following report. This is implied, but the number of cases where this is not practiced shows that it is ambiguous.

(4) Many reporters gave the cumulative time of a shutdown from its start in the monthly reports rather than the actual time for that month, though the instructions appear clear on this point.

(5) Although the instructions are explicit on the use of the REASON code, reporters have erred many times in their selection. This can be detected from the narrative identifying the cause of shutdown. REASON code "H" (Other) appears to be the catchall reason to use and seldom are even brief comments given to explain its usage.

(6) As with the numbering and dates of continued shutdowns, the number designation used for the METHOD OF SHUTTING THE REACTOR OR REDUCING POWER is not carried over into succeeding reports of a continuation. The instructions are lacking here because they do not tell the operator to use the same METHOD number in the following reports for a continued shutdown. 
The COMMENTS, given in narrative form, are intended to explain what caused the shutdown and the corrective action taken. The reports are rarely explicit in identifying the specific equipment that caused shutdowns and power reductions. A SUMMARY block is provided on the reporting form for recording the highlights of unit operation for the month. This was found to be helpful whenever it was filled in. However, the summary was not always provided. (Recent changes to instructions provide for equipment identification.)

The Nuclear Plant Reliability Data System (NPRDS), unlike the EEI and NRC data systems, does not provide data on overall power plant performance. Rather NPRDS provides engineering and reliability information on safety classes 1 and 2 equipment for nuclear power plants. (Classes 1 and 2 refer to engineered safeguard systems in nuclear power plants; class 1 equipment is the most critical, while classes 2 and 3 are less critical.) It is the only major file in use that has been specifically structured to classify and summarize data to determine system and component failure rates. The reporting system consists of four kinds of data: nuclear unit information, engineering data, quarterly operating data, and failure reports. The failure report is an attempt to describe the failure with codes for type, mode, cause, and effect of a failure, as well as for failure detection, action taken, and licensee event report submittal date. Fáilure types are identified as mechanical, electrical, and other. Selections for a mode are derived from a table 1 isting 18 possibilities such as "crack," "won't start," and so forth. Failure is represented by two groups: category (A) cause and (B) description. The category section typically is denoted by items such as manufacturing, operating error, and so forth. The description section contains 28 selections of which typical descriptions.are weld related, abnormal flow, open circuit, and excess vibration.

The NPRDS comes closest to a data system that permits the calculation of reliability parameters such as failure rates, mean time to repair, and so forth.

There is one inherent limitation to data base analyses, and that is they cannot be used to determine the root causes of plant outages. Root-cause analysis, if performed by government agencies, would require background and training found in few requlatory agencies. In addition, the on-site inspection normally required could be extremely costly.

\subsection{Analyses of Data}

This section contains a description of data analyses performed by the National Electric Reliability Council (NERC), the U.S. Department of Energy (DOE), the Electric Power Research Institute (EPRI), the Nuclear Regulatory Commission (NRC), and the Edison Electric Institute (EEI).

EEI analysis has been on a macroscopic level. Performance indices (for example, CF, FOR, OA) are reported based on grouping fossil units into various capacity ranges [5]. EEI has made individual-generating unit data available on request for more specific analysis (for example, for comparing units by similar design, vintage, size). NERC conducts similar analyses on request.

DOE analysis has compared large nuclear and coal units utilizing EEI and Gray Book data. A 1979 report on "The Performance of 400 Megawatt and Larger Nuclear and Coal Fired Generating Units," utilizing performance data up to 1976, categorizes units by size, vintage, and primary fuel capabilities [12]. This report focuses attention on the annual performance of generating units aggregated by state and utility. Capacity factors, availability factors, equivalent availabilities, and forced outage rates are the parameters 1 isted. Such data can be used by utilities and state regulatory agencies for comparison purposes. An updated report using 1977 and 1978 data will be released at the end of 1980 .

Another type of analysis has been reported in "Use of Nuclear Plant Operating Experience to Guide Productivity Programs" [21]. This reference presents the results 
of an extended evaluation of the operational performance of light water reactor nuclear-generating units whereby relevant operating and outage data have been compiled and analyzed.

This evaluation isolated component outage causes indicating durations of outages as well as failure rate per component year. For example, steam turbines were shown to have the highest failure rate of all plant equipment and had a failure rate of 1.5 incidents per turbine year for the period studied. A frequency/intensity plot for turbines indicated outage durations ranging from 1 hour to almost 3,000 hours with more than 50 percent of the incidents being 10 hours or less. Investigation of these low-duration outages shows that they are typically associated with the turbine control subsystem or with seal leakage. Durations in excess of several hundred hours imply turbine casing removal and extensive repair or replacement of low-pressure turbine blading or rotors. Examination of both the frequency of failure and frequency/ intensity information show that the manufacturer has improved blading through corrective design and field-fix programs. Thus, this EPRI paper serves as a model for examining the productivity of existing nuclear units using a systematic analysis technique for eveluating outage causes and contribution to lost productivity as well as identifying $f_{2} x$ programs to increase the component's productivity. With this information high-payoff areas can be identified, and determinations can be made in terms of cost benefits.

The NRC in its monthly Gray Book publication compares performance of nuclear units on a monthly and yearly basis, primarily for trending of capacity factors, availability, and forced outage rates. It also compares these indices with the performance of large fossil units.

\subsection{Auditing of Data}

The most prevalent data indices and data systems used by the utility industry and their limitations were discussed in previous sections. The industry is well aware of these limitations and is attempting to improve the accuracy, usefulness, and timeliness of its data systems through EPRI, NERC, and industry task forces $[25,38]$. To accomplish these improvements, EPRI is undertaking the development of a national data system. This system will complement GADS and provide an improved basis for the design and operation of generating units. It may enable consolidation of the various existing data systems into one comprehensive data base. The centralized data base is, of course, one of several approaches to data collection and management. Decentralized collection at the power pool or utility level is also a viable approach.

In addition, NERC has developed verification procedures to avoid repetition. of previous problems of duplicate reporting, overlap, and so forth. When the data are received from the utilities, they are manually screened for obvious errors before entering a data bank. After the screening, the data are edited and analyzed through computer programs. Acceptable data are stored in the data base; data that do not clear the editing programs are returned to the submitting utility for correction and resubmittal. NERC is also working toward a common data base to avoid duplication among utilities, manufacturers, and regulators. It is anticipated that this concept will take two or three years to implement.

In the final analysis, the utilities themselves must be dedicated to accomplishing the goal of developing an effective, accurate, and useful data base by ensuring that data are accurately reported at the source (in the power plant).

\subsection{Potential Benefits from Productivity Improvements}

Data inadequacies notwithstanding, the available data establish that there is substantial potential for productivity improvements. Average values stated in section 1.2 support this statement as evidenced by availabilities and capacity factors listed here. 
Numerous studies by the Department of Energy (and previously by the Federal Energy Administration) and state agencies have demonstrated significant benefits from productivity improvements. Government studies have been reported in references $[6,33-36]$, and state-agency studies in references $[22,27,28]$ and in appendixes of this report. Specifically, a study [37] sponsored by the Department of Energy indicates that approximately $54 \mathrm{million}$ barrels of oil could be saved in the northeast and east central regions of the U.S. if a 10-percent-point improvement in availability could be attained for large-coal-fired and nuclear units. Savings from this improvement could be well over $\$ 1$ billion per year. Although these estimates were based on load, supply, and oil price forecasts that have changed substantially, their essential thrust remains valid. The magnitude of the potential savings for a utility and its consumers suggests that immediate steps be taken to establish programs to promote productivity improvements. In pursuing improved power plant productivity, additional capital and operations and maintenance expenditures may be required. In most cases, however, the magnitude of the potential savings is expected to overshadow such expenditures.

Benefits from productivity improvements will be manifested in the form of reduced fuel costs and improved system reliability. Reductions in fuel cost will occur because a greater portion of the energy generation will come from the less expensive to operate plants. The cost differential between these types of electricity generation can be seen in table 2.1 that shows the cost of energy conservation $\left(\$ /\right.$ Btu $\left.\times 10^{6}\right)$ for different fuels.

Concurrent with the savings in the cost of fuel is the added advantage of decreasing the use of oil and thus the dependence on oil imports. Improved reliability and improved opportunities for effective load management activities for a given system promise additional benefits. These latter benefits, while important for a given system, offer still more potential cost savings in the longer term. Improved performance of existing units and increased system reliability may provide the opportanity to defer or cancel additional new units that may otherwise be required. It should be noted that while improved performance of existing units tends to

TABLE 2.1

REPRESENTATIVE ENERGY COSTS BY FUEL TYPE IN 1979

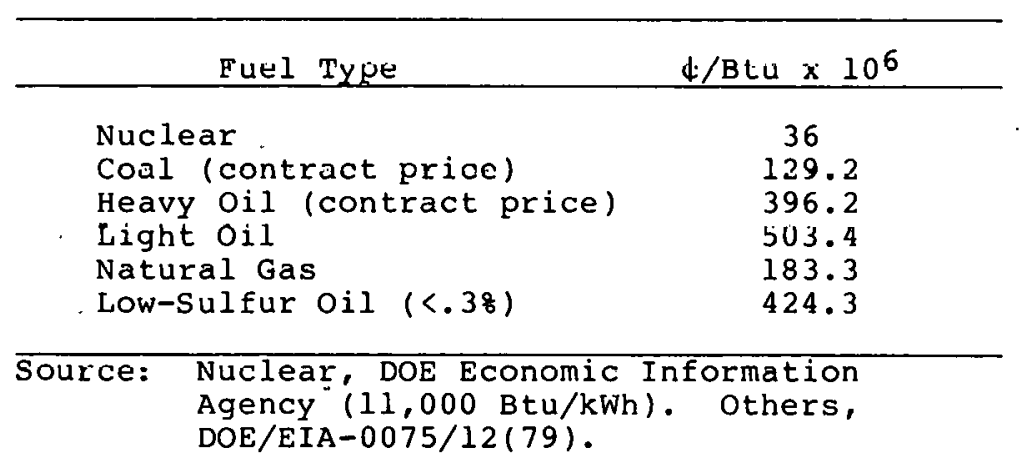

mitigate the need for new units, it could also prove to be detrimental to some degree in oil dependent areas where delay of new units results in less new nuclear and coal generation being made available to displace oil. The overall savings potential, however, both in the short and long term is significant and should be aggressively pursued. 
Chapter 3.

\title{
Opportunities for Enhancing Regulation Regarding Power Plant Productivity
}

\author{
3.1 Introduction
}

In the period 1950-70, impressive advances in the public utility sector. resulted in declining rates to consumers. Given these advances of the industry during this period, the question of regulatory incentives to improve productivity was seldom raised. However, low-power-plant productivity experienced by electric utilities in the 1970s and spiraling inflation in the cost of fuels and new construction have sparked a review of the adequacy of the traditional regulatory role. Recognizing that the level of return on investment is the direct result of the efficiency of the production process in the competitive market, regulators are searching for methods to simulate competition in an effort to improve utility productivity. This position was summarized by Alfred Kahn in his foreword to public Utility Productivity:

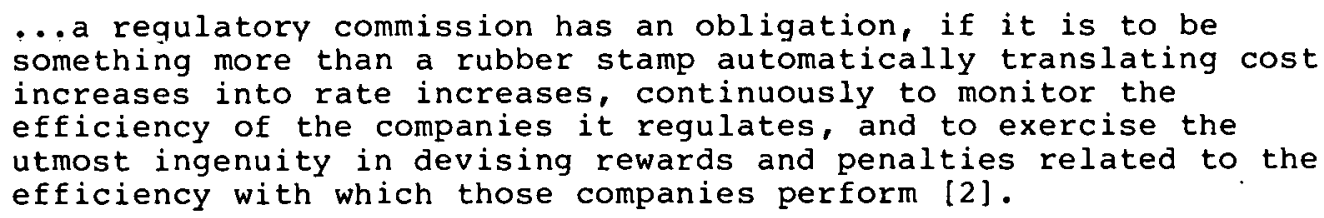

Regulatory actions that can lead to improvements in plant performance are described in this chapter. Historically, plant performance has been adversely affected by the following factors:

(1) deficiencies in design, manufacturing, and construction of plant components;

(2). utility specifications in the procurement process that minimize plant cost at the expense of plant reliability;

(3) deficiencies in operating and maintenance practices;

(4) deteriorating fuel quality; and

(5) regulatory requirements related to environmental and safety issues (for example $\mathrm{SO}_{2}$ removing equipment, emission levels).

However, the search for mechanisms to motivate productivity improvements is still a search. Some state regulatory agencies order specific actions. Others monitor performance and encourage utility action, still others have no immediate concerns about productivity. The approach is experimental. Trial and evaluation of those trials is a hallmark of the productivity improvement effort. Always, there remains the goal of finding the optimal cooperative arrangement between the regulatory agency and the regulated utility. 
In addition to state agencies, other agencies whose actions affect productivity through regulation are the Nuclear Regulatory Commission (NRC), the Federal Energy Regulatory Commission (FERC), the U.S. Department of Energy (Economic Regulatory Administration), and the Environmental Protection Agency (EPA). Organizations that affect productivity through technology development are DOE, EPRI, EPA, and the research departments of the industry.

As was indicated earlier, the opportunities for actions by a state regulatory agency may be limited by either technical or statutory constraints or both. Technical constraints refer to the lack of funds, personnel, and electronic data-processing capabilities. Statutory constraints refer to the lack of legislative authority to implement certain parts of a productivity improvement program. These constraints may vary among states. Also, the need for plant improvements may differ among states. For this reason, the following generic approach is described. It consists of a step-by-step development of the elements of a productivity improvement program. The intention is for state regulatory agencies to select those activities that are applicable and feasible. There are five major parts of this program:

(1) collect plant performance data;

(2) undertake studies to assess the need for productivity improvements and demonstrate the gross benelils fïiö piuduclivily impruventent prograns ins.luring rost-effertive produrtivity improvement goals;

(3) monitor plant productivity and the status of productivity improvement programs;

(4) facilitate the attainment of higher productivity;

(5) enforce the attainment of higher productivity.

The preliminary parts of the program such as data analyses, assessment of the need for productivity improvements, and associated gross benefit estimation can, in many cases, be accomplished by a few staff members who should become intimately familiar with the factors that affect power plant productivity. However, depending upon the scope and maturity of the program, the services of a consultant, or the creation of a special group within the agency may be required. That group should have access to computer facilities and personnel who can monitor plant performance, develop/maintain computer programs and system simulation techniques, and ultimately establish mechanisms for facilitating and enforcing the attainment of improved productivity.

Before proceeding with specific statements on each of the program elements, it is important to recall that the primary responsibility for providing service to the customer resides with the utility. Reliable service at the lowest possible cost is the common goal of the utility, and the regulatory agency and power plant productivity improvement is a means to that end.

\section{$\frac{3.2 \text { Elements of a Program to Improve }}{\text { Power plant Productivity }}$}

Part 1: Collect Performance Data to Initiate the Program

In the initial phases of this program, data must be collected to assess the potential for productivity improvements and to estimate gross potential benefits from productivity improvements. The potential for improvements may be assessed by comparing the performance of units under consideration with that of similar units nationwide. Suitable performance indices have been discussed in chapter 2 . They are Operating Availability, Equivalent Availability, Capacity Factor, Heat Rate, Forced Outage Rate, Equivalent Forced Outage Rate, and Scheduled Outage Rate. The gross potential benefits from productivity improvements may be measured by the effects of a specified percent-point improvement in selected performance indices on system fuel and construction expenditures, and system reliability. Historical 
values of these indices can be obtained from various national data bases and clarified by the utilities as needed. When comparisons are made, care must be exercised to ensure comparability and to avoid misinterpretation of transient or cyclical conditions.

Part 2: Undertake Studies to Assess the Potential for Productivity Improvements and Demonstrate the Gross Potential Benefits

Once the potential for productivity improvements has been assessed, the gross benefits from such improvements can be estimated by using simulation techniques of system planning and operations. System planning techniques may be used to generate the optimum expansion plan of the utility. The operations techniques may be used to estimate the fuel cost, reliability, and purchase power under hypothetical scenarios of improved indices of performance. Certain existing simulation techniques are described in references $[26,34]$.

Part 3: Ascertain Existing Productivity Improvement Programs and Direct Utilities to Develop Productivity Improvement Programs Including Cost-Effective Productivity Improvement Goals

Productivity improvement programs may be developed by the utilities at the direction of regulatory agencies. Prior to establishing. such programs, a regulatory agency should request the utilities to identify factors contributing to productivity loss, evaluate the feasibility of improvements, and analyze the costs and potential benefits of corrective actions.

Factors contributing to the productivity loss may be specific equipment problems, poor coal quality, and inefficient management/operating/maintenance procedures. Problems of a technical nature can be identified by inspecting outage records. "Root-cause" analysis is a technique by which plant breakdowns can be traced back to their source, and this method might be used as needed to suggest effective corrective actions. Management and operating practices, while extremeiy difficult to identify, should be recognized when they affect production.

The first step in estimating the benefits from a corrective action is to estimate the corresponding percent-point improvement in equivalent availability (or other suitable parameter). This can be done by finding the plant outage time (and/or partial outage time) attributed to the particular factor from the plant's outage records. Such an approach was developed for the U.S. Department of Energy [33]. In cases of organizational or procedural changes, such a quantification of benefits may be difficult. However, tracing the effects of such changes to specific causes of equipment failure should be attempted. As discussed in part 2, the second step in evaluating the benefits from a corrective action is to calculate the effects on system cost and reliability.

These studies must be validated by paying particular attention to whether all important factors contributing to productivity loss have been identified correctly, to the reasonableness of data used, and to the accuracy of methods used for cost and benefit estimation. The availability of accurate data is an important prerequisite in estimating changes in productivity resulting from specific factor improvement. However, the fact that such data may not be available at the present time should not necessarily prevent the identification of factors contributing to lost productivity and the establishment of corrective actions.

Based on the analyses mentioned above, the regulatory agency and the utility should cooperate in assessing existing productivity improvement programs and in developing new programs as needed. Such programs must include specifications of activities, explicit goals, timetables, budgets, and management organization and responsibilities. Typically, activities may include personnel training, data-gathering programs, procurement of computerized maintenance-scheduling systems, changes in management/operational practices, and management reorganization. Goals 
for existing plants may be the replacement or repair of specific components and/or the attainment of specific levels of performance (such as EA $=80$ percent) with a graduated schedule of incentives for achieving the goal. For new plants, goals may be established to meet specific levels of performance and the requirement for such levels to be stipulated at the time of procurement.

Goals that are set should recognize the interactive nature of various performance measures. For example, single-minded attempts to improve capacity factor could actually lead to a non-optimum-loading order.

Part 4: Monitor the status of Productivity Improvement Programs

A system of productivity monitoring should accomplish the following:

verify adherence to the timetable set for performance improvements;

(2) verify the annual maintenance plan and budget;

(3) document actual maintenance activities (dates, budget differences, timetable, man-hours, spare parts);

(4) assess contingency plans (how the utility. is planning to handle certain types of outages including timetable, man-hours, spare parts);

(5) document outages (dates, cause, duration, corrective actions taken, expenditures, cost-of-replacement power).

Attention to the above could lead to recommended changes in planning and recommended appropriate improved outage management practices.

Part 5: Facilitate the Attainment of Higher Productivity

The information submitted regarding performance problems may be useful to other. utilities. Therefore, information on equipment problems, corrective actions, and outage management procedures should be disseminated. This can be accomplished through publications, workshops, and related activities. Regulatory agencies should encourage utilities to fulfill their responsibilities in this area.

There are other possible productivity-related measures that require cooperation among utilities. Such measures might include increased coordination between utilities of generation dispatch, common spare-parts inventory, personnel training; and maintenance coordination (possibly establishing rotating maintenance teams). None of these is inherently cost-effective, and specific analyses must be conducted before any is undertaken.

Many states have several agencies involved with different aspects of electric utility regulation (typically, a power siting commission, an environmental protection agency, a department of energy, and/or a public utilities commission). The policies and actions of all such agencies in a state can affect plant productivity. For example, certain environmental/safety regulations may require plant retrofit and modifications of existing plants. Such modifications may contribute to a decline in certain measures of performance. The regulatory agency with the responsibility to ensure high-plant productivity may require the evaluation of proposed regulations and environmental and safety measures for their impact on productivity and require debating the issue and an assessment of the trade-offs before such measures are adopted.

Many outages in coal-fired power. plants are due to equipment breakdown related to poor quality. In many cases, poor coal quality is due to moisture, rock, and ash content. Standards for the quality of delivered coal ought to be reviewed as part of a productivity improvement program. 
One possible productivity improvement program would facilitate the licensing of replicate-design plants. Replicating design features that have a history of performance should improve the reliability of plants. Also, the availability of spare parts should be enhanced significantly. On the other hand, special circumstances dictate special designs that might be significantly more productive than a replicate plant. In addition, design innovation requires introduction of "nonstandard" features. Design innovation is another means for improving power plant productivity.

Finally, there are some actions specifically regulatory in nature that are productivity related. They include the following: (1) allowing for plant designs that have a higher construction cost but are also more reliable; (2) allowing for recovery and reducing recovery lags for productivity-related capital expenditures; (3) identifying and reducing disincentives in the regulatory process (for example, Does the particular formulation of the fuel adjustment clause remove incentive for productivity? Do expenditures to improve heat rate detract from availability improvement?); (4) ascertain that utilities have sufficient money available to undertake timely maintenance; (5) support EPRI and NERC to develop a relevant and accurate national data base. (This includes adopting compatible formatting and reporting requirements and perusal and verification of data sent from utilities to these agencies.)

Part 6: Enforce the Attainment of Higher Productivity through Regulation

State regulatory agencies have the option of utilizing a number of possible mechanisms to encourage and enforce power plant productivity improvement. The issue can be reviewed in a rate or fuel adjustment proceeding, or in a procedure outside the province of traditional rate base regulation, such as in a generic investigation or an independent hearing.

Rate case hearing. In a rate proceeding, the issue of power plant productivity can be examined within each of the three major components of the revenue requirements equation: rate base, rate of return, and expenses.

The rate base represents the net-capitalized investment the utility has in plant, materials, supplies, and other assets that are used and useful in providing service to the utility's consumers. Adjusting a company's rate base as a result of a power plant productivity assessment is theoretically valid; it is an adjustment of the value of the plant for a portion of the plant that cannot be utilized. However, the long-term impact of adjusting the utility's rate base should be measured against the record of the plant in question. Poor power plant productivity, as measured by a performance index such as operating availability factor or capacity factor, is often a short-term effect and can vary significantly on a monthly or yearly basis. (For example, in generator turbine overhaul, a five-year horizon might be necessary to detect trends.)

In a more positive sense, the rate base component can also be used to reflect a utility's increased investment in spare-parts inventory for its existing plants or in capital improvements to existing plants or those under construction.

An incentive for power plant productivity improvement can also be incorporated into a regulatory body's evaluation of a utility's rate of return. The rate can be adjusted to reflect the positive or negative difference in a utility's system (or unit) performance when compared with a target set by the regulatory agency. This type of adjustment is probably the easiest to implement, since the rate-of-return valuation is the most judgmental element in the revenue requirement equation. $A$ target mechanism also has the advantage of having a potentially significant impact on the utility; a small percent change in the rate of return will affect the utility's entire rate base return.

The appropriateness of incorporating power plant productivity considerations into the rate-of-return calculation is not clear. Since a regulatory agency's role, in economic terms, is to simulate competition for a utility, the efficient operation 
of that utility could be considered a valid criterion for adjustment of the rate of return. Certainly, the inefficient operation of a utility is reflected in an increased cost of capital for that utility. However, the concept of economic efficiency is usually applied in more general terms than specific power plant performance. Some economists believe that adding a specific power plant productivity incentive to the rate-of-return calculation is inappropriate because the rate is designed to reflect only the cost of capital to the utility, and because the efficiency factor is implicit in that cost. However, this is not necessarily a universally accepted. premise.

The expense component of the revenue requirement equation is composed of expenses incurred in furnishing service to the utility's consumers. The regulatory agency could permit the inclusion of a specific (or system-based) corrective action or preventive maintenance expense, either recurrent or nonrecurrent, based on the results of a cost-benefit calculation. The predicted benefits could be monitored, either through examination in the subsequent rate case or through a shorter term proceeding such as a fuel adjustment clause hearing. Such a mechanism is justifiable on the grounds that the money expended on a corrective action, preventive maintenance. or spare parts can be classified as an operations and maintenance expense.

A major problem with this type of adjustment is that current methods might not be sufficiently refined to accurately quantify potential benefits to support a dollar adjustment. Also, commission proceedings have been traditionally based on historical information, and this type of forward-looking adjustment could be limited or prohibited by statute.

Fuel cost and purchased power adjustment hearing. Power plant productivity improvement could also be encouraged in a fuel cost adjustment clause proceeding. An adjustment to the fuel and purchased power recovered by the utility, perhaps through a target mechanism, would have an immediate impact and could be reevaluated on a regular, more frequent basis than in the rate case proceedings.

Independent hearing. Assuming that a regulatory agency has, or can obtain, the authority to require utilities to improve their performance, the issue of power plant productivity can be considered outside traditional regulatory procedures.

Careful examination of any target incentive program, whether it is based on a systemwide index or on the performance of a specific unit, is necessary to avoid compounding the adverse effect of a substantial outage. In addition, outages must be examined carefully to avoid penalizing the company for factors not within its control.

In most of these examples, the potential for a positive as well as a negative adjustment reflecting the status of power plant productivity exists. In the development of an enforcement mechanism, each regulatory agency should evaluate the potential impact of a positive incentive against the concept that a utility should not earn more than it has expended. In addition, each agency must evaluate existing statutes; they may limit or prohibit adjustments such as those described above. 
Chapter 4.

\section{Current Activities and Programs to Improve Power Plant Productivity}

\subsection{Introduction}

Before 1970, little attention was given to formal industrywide programs to improve availability, design, reliability, maintenance, and operation of generating facilities. However, since the 1973 oil embargo and the increasing tide of inflation in recent years, the need for cost-effective power supply planning has become increasingly important. Significant increases in the cost of oil have resulted in major increases in the cost of generation when nuclear and coal units are down. The availability and reliability of these units are becoming critical path items in the wake of the nation's petroleum shortfall and regulations prohibiting the use of oil or gas for generation. In addition, the cost of constructing and operating new. facilities are, in many instances, more cost-effective than adding new capacity.

No determinations have been made with regard to the extent that improved productivity programs are national in scope. The following discussion, taken from the available literature, represents industrial, federal, and state activities directed toward improving power plant productivity.

\subsection{Industry Activities and Programs}

\subsubsection{Data}

Industry efforts to assess and upgrade existing data bases have accelerated greatly since 1975 when the Federal Energy Administration (FEA) Task Force on Improving Power Plant Productivity concluded that existing sources of data on power plant performance were inadequate [14]. Numerous industry initiatives in the area of performance data have been taken that are responsive to the FEA Task Force recommendation for a coordinated industry effort for the collection, storage, analysis, verification, and dissemination of power plant performance and reliability data.

As a follow-up to the FEA Task Force recommendation, the American National Standards Institute (ANSI) established the Ad Hoc Steering Committee on Power Plant Data Systems in May 1976 [1] for the purpose of obtaining a national consensus on what data are needed and how best to obtain them. The committee, made up of representatives from industry and government, held a series of meetings with various sectors of industry and with various federal agencies to obtain a comprehensive assessment of the following questions: What data are needed and how are they used? What are the recommended actions for establishing an adequate national data base? $A$ total of 59 industry organizations and 8 federal agencies responded to these questions. This comprehensive assessment led to the following key findings and conclusions:

(1) Data reporting already is a major effort and represents an increasing burden of concern to utilities. 
(2) No one system can satisfy all power plant reliability data and problem-solving needs without becoming unwieldy and unworkable.

(3) A national, industry/government-supported, unified, centralized information system is needed for key performance and reliability data.

(4) Existing data systems are inadequate, do not meet any of the needs of industry and government, and have not been readily accessible.

(5) Improved communications and educational programs are needed to put power plant performance and reliability in the right perspective.

(6) Root causes and corrective actions for generic problems must be determined to achieve widespread improvements in power plant reliability.

(7) Standardized uniform terminology and definitions are needed in the reporting of performance and reliability data.

(8) An early-alert-reporting system is needed for generic equipment problems.

The committee recommended the following industry/government actions:

(1) A unifled, centralized infurllatiun sysleil un puwei plaril performance and reliability should be established with the cooperation of industry and government.

(2) Industry should continue to improve existing industry data systems to increase their usefulness while a unified, centralized information system is being established.

(3) Industry and government should adopt standard definitions and terminology in using existing systems and in a unified, centralized information system.

(4) Industry should establish an early-alert-reporting system to be adopted on an industrywide basis for reporting generic equipment problems that have a high probability for cásing unie unavallability.

(5) Industry should improve its problem analysis and solution efforts with a coordinated plan of action involying utilities, arrhitect/engineering companies, steam system suppliers, and manufacturers.

(6) Industry should implement reliability-engineering methods in the design, construction, operation, and maintenance of power plants, beginning with plant cpeoifications and continuing thrnugh nperatinns.

(7) Industry should clarify the confusion over power plant performance through improved communication of performance and reliability data and their interpretation.

(8) Industry and government should establish a joint committee on data activities in order to continue and consolidate ongoing fragmented efforts to coordinate data collection.

(9) Industry and government should eliminate redundant information systems and should utilize the unified, centralized system.

In parallel with the broad-based assessment of the ANSI Committee, the Electric Power Research Institute (EPRI) conducted a l6-month investigation of the data needs of the industry [8] together with recommended actions [9]. These investigations essentially confirmed the committee's findings and conclusions and resulted in recommended actions 
that were consistent with the committee's recommendations. Most of the recommendations of the ANSI Committee are in the process of being implemented.

(1) Development of a national data system is under way at EPRI. Initially, EPRI studied the experience of a number of large organizations, both inside and outside the utility industry, with the collection of data related to equipment performance in large complex systems and assessed the feasibility of consolidating power plant data bases [7]. The study concluded that a consolidated data system would be cost-effective and should be developed. In October 1978, EPRI conducted separate studies, one aimed at component failure data, to establish data requirements for such applications, the data collection/reporting methods, and the data system scope. In April 1979, EPRI issued Request for Proposal to do Phase II of the national data base development. In Phase II, a set of detailed specifications for the data base will be developed covering the reporting procedures, computer system, and computer software requirements. Bids were received in July 1979. Due to the higher priority of work associated with the Three Mile Island accident, the Phase II effort has been suspended temporarily. Current plans are to complete a revised Phase II effort by March 1982 and then to begin a demonstration program that includes interfaces with power plant in house data systems. After final evaluation and upgrading, completion of an operational data system (NDS) is scheduled for 1984.

(2) In parallel with development by EPRI of a national data system, which will take several years, the industry is taking new initiatives to improve the accuracy, timeliness, and availability of the existing systems. Responding to the ANSI Committee's specific recommendations, the Edison Electric. Institute (EEI) has released its data base to all interested parties and has developed and begun implementation of a data quality assurance system. To improve the timeliness of the data as well as its accuracy, the industry has greatly increased the resources being applied to the EEI data base. Effective January 1 , 1979, the responsibility for the data base was transferred to the National Electric Reliability Council (NERC). Whereas the total manpower assigned to the data base at EEI had been less than one full-time professional, the industry has now provided sufficient funding such that at NERC a staff of five is already at work, an in-house computer has been procured, and a substantial amount of contract support is authorized. To strengthen NERC's efforts further, a Joint Advisory Committee on the Generating Availability Data System (GADS) was established in MaY 1979 made up of representatives from EEI, EPRI, NERC, and DOE. The committee provides advice and consultations to the NERC staff, interfaces with EPRI on development of the national data system, encourages industry and government use of the central data systems, and works to eliminate duplicative data collection efforts. DOE and its contractor, the Oak Ridge National Laboratory (ORNL), has conducted a detailed assessment (on a small sample) of data accuracy, and NERC is currently applying the tools developed therein to check the data currently being received from utilities. A detailed, comprehensive description of NERC's data base rebuilding program is included in a paper given at the April 1979 Reliability Conference for the Electric Power Industry [25].

(3) An ad hoc committee made up of industry and government representatives, . under the auspices of the EEI Equipment Availability Task Force, has prepared a draft standard of terminology relevant to power plant productivity and of standardized definitions for power plant performance indices. Under the sponsorship of the Institute of Electrical and Electronics Engineers (IEEE), this standard is currently in the process of being published as an IEEE standard that will be submitted to ANSI for approval as an ANSI national standard.

In the past year, the Power Generation Committee of the Power Engineering Society, IEEE, established the Ad Hoc Working Group on Availability of Generating Units to develop recommended guidelines for recording and 
presenting in narrative form the failures that occur in power plants. The Working Group has drafted its recommendations and will present them to the industry in a paper at the winter meeting of the Power Engineering society.

(4) Through EPRI, the industry has initiated action to establish an early-alert problem-reporting system. The scope and proposed operating methodology for the system have been developed [10]. As proposed, the system would become an integral part of the national data system.

(5) Although the industry still lacks a coordinated plan of action for problem analysis and solution, it has taken several initiatives that constitute a significant progress in that direction. EPRI has conducted industry workshops on its own in September 1977 [11], November 1977 [12], and Auqust 1978. In addition, in september 1976, EPRI and the American Nuclear Society cosponsored an Executive Conference on Improving power Plant Availahijity.

(6) Significant steps have been taken leading to increased implementation by all sectors of the industry of reliability-engineering methods in the design, construction, operation, and maintendnce of power plants. In June 1978, EPRI, EEI, NERC, and DOE cosponsored three seminars for top utility management on Availability Engineering and Power Plant Productivity

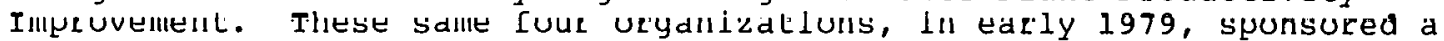
series of five workshops on Availability Engineering and Productivity Improvement for staff and project personnel from utilities, architect engineers, and equipment manufacturers. These three-day workshops provided in-depth demonstrations and practice of various availability and productivity improvement methods that have been developed by industry and the DOE in recent years. In addition to the coordinated, industrywide efforts described above, numerous utilities, some equipment suppliers, and the steam system suppliers have initiated in-house efforts to improve the collection and use of power plant performance data.

\subsubsection{Design Improvements}

A major element in the improvement of design activities to achieve better productivity has been the establishment of high productivity as an explicit requirement in the design process. 'l'o bring this about, Combustion Engineering has formed a standing committee on availability and reliability of the steam supply system. The committee is usually charged with the regular analysis of operating experience data and its responsibilities may include the publication of alert notices for design improvements, or ensuring that design, manufacturing, and operating problems that affected initial reliability are corrected.

The feedback of operating experience data to the design process is an effective means for improving productivity in component and system design. Most organizations involved in design use feedback in one form or another, and significant design accomplishments have been achieved. Testing to support design efforts is being used by several companies. As an example, Combustion Engineering has carried out an extensive field test program to broaden the data base on coal-fired units. These data provide the basis for upgrading performance prediction tools to deal with current design deficiencies and set the foundation for handing new unit designs.

Boston Edison used models in a study of reactor refueling, while in the design stage, to improve efficiency and reduce outage. The study concentrated on activities and equipment inside the reactor containment structure. The study was used to analyze the critical path in refueling to provide a basis for cost-benefit analysis of improvements. It was established that implementation of certain findings would cut an estimated 5 days off of a 42 -day refueling outage.

Present actions to improve the productivity aspects of design may be summarized as establishment of productivity in policy and organizational arrangements, use of 
operating experience including both data and participation of operating personnel, feedback, testing and laboratory research to verify designs, and use of models to evaluate design. These actions have already led to important improvements and offer potential for even greater ones with wider implementation to the utilities themselves.

\subsubsection{Manufacture and Construction}

Quality assurance during manufacture and construction of components and units is vital to the reliability and productivity of power plants. The use of models of parts of a plant is helpful in understanding each step in the construction sequence, thereby improving the quality of construction and helping to ensure that construction activities do not cause problems that will ultimately reduce power plant productivity.

An example of the use of models for design and construction is found in the Standard Nuclear Power Plant system (SNUPPS) project, where a set of models, including a construction sequence model, was used for design and construction. The set included the entire power block and associated excavations and yard facilities. The construction sequence model was used by a group of experienced construction field supervisors as a means for providing early input to the engineering design effort. It has been used to develop a civil-structural sequence and schedule for important construction operations. The engineering and construction personnel have made use of the model to create particular construction situations in advance of detailed design portions under construction.

\subsubsection{Operations and Maintenance}

The technical skills of the operations and maintenance staff are very important to the overall productivity of power plants. To achieve a high level of technical skill, most utilities operate a training program for personnel. Vendors also support training by establishing and operating training programs and by providing special capabilities such as training simulators. Some utilities have established training units and formal training programs within their organization. In most cases, the programs address the training requirements of both management and technical personnel, though the scope, level of implementation, and participation vary widely throughout the industry.

One of the highest payoff areas for investment in productivity improvement is initial path maintenance and outage planning. Analysis of activities during outages can lead to significant reductions in the time required and resulting outage duration. Development and documentation of procedures for preventive maintenance and outage activities will improve performance and achieve planned outage goals.

Adherence to planned maintenance schedules will reduce forced outage rates. some utilities, maintenance guidelines are developed and followed to the fullest extent possible. For example, turbine generators are being maintained on the basis of planned inspection and repairs rather than on a breakdown basis. More attention is given to improving outage schedules and to expediting equipment and materials during overhauls. Also, it may be less costly to make greater use of company personnel in place of contract labor.

As part of a concerted effort to reduce fuel use and energy purchases, San Diego Gas and Electric (SDGE) has developed a computerized optimization technique for the overhaul of major generating units. By proper scheduling of maintenance, downtime is minimized, and the complete system is operated at the best average efficiency. $A$ series of computer programs is used iteratively to select the most economical overhaul schedule. By using these programs in conjunction with an overall heat rate improvement program, the utility's system heat rate improved from $11,206 \mathrm{Btu} / \mathrm{kWh}$ in 1973 to $10,390 \mathrm{Btu} / \mathrm{kWh}$ in 1979; a rise from 73rd to 29 th place in a survey of heat rates among other utilities. Additional methods used to obtain the improvements included replacement of 20-year-old heat exchangers, improved fuel oil burner equipment, improved condenser cleaning techniques, and computer dispatch of SDGE steam plants. 
The availability of spare parts during maintenance outage is of particular importance. Several organizations have addressed this issue. Stone and Webster developed a comprehensive procurement and inventory control program for a reactor that included steps to improve its equipment specification preparation procedures so that spare-parts requirements are anticipated and specified, developed a system for evaluating the spare parts needed to support plant equipment, established the procurement control necessary for effective quality assurance and accurate cost accounting, and determined the scheduling required to ensure timely order placement and delivery.

Performance goals have been established by many utilities as targets and measures of success for improved power plant productivity. As reported to the Federal Energy Administration's 1975 regional meetings on power plant productivity, the goals vary widely in level of detail. In some cases, vague general goals were reported; in others, very specific goals related to several aspects of individual units with accompanying accomplishment plans were presented. Together with an improved data collection system, there is a need for more consistency in utility operation and maintenance programs in order to improve power plant productivity.

\subsubsection{Diagnostic Instrumentation}

Recently, significant advancement in the technology and use of diagnostic instrumentation techniques in electric generating plants has resulted in early prediction or detection of imminent equipment failure. This type of early-warning system can be of great benefit for prevention or minimization of unplanned unit outages, or the shortening of planned outages, thereby accomplishing two very important and worthwhile objectives--namely, reduction of production maintenance expenditures and increased power plant productivity.

Most diagnostic instrumentation programs include, as a minimum, provisions for comprehensive vibration analysis to diagnose the cause of a machine failure or high-vibration incident and can be applied equally well to detect many machine faults in their formative and developing stages, before equipment failure occurs. Many experts feel that the new analysis equipment that is available and the experience of the utility personnel make it functionally and cost justifiable to provide such equipment condition monitoring of machines that can cause loss of generation capability. The information from such vibration analysis would provide equipment operators . with advance warning of developing equipment malfunctions so maintenance can be performed or scheduled in advance, thereby improving the reliability of equipment and overall power plant productivity.

4.2.6 Fuel Quality

Several equipment breakdown problems have been attributed to low-coal quality. The rock ash content of coal has, in many cases, caused coal-handling equipment breakdowns, and moisture and ash content in coal have been affecting boiler performance. The ability of a boiler to handle a wide range of coals has become a crucial design consideration. There are active programs currently under way (some in conjunction with the U.S. Department of Energy) to promote design improvements and for fuel treatment to prevent such equipment problems.

\subsubsection{Standardization}

Standardization based on reliable designs is still another step toward improving productivity. Few projects designed for standardized plants have been achieved; however, the thrust toward more efficient power plant operation and performance has been increasingly lent to standardized design of nuclear and coal-fired units.

\subsubsection{Research Activities}

The Electric Power Research Institute has a number of projects specifically aimed at improving the productivity of fossil and nuclear power plants under way. The following are the objectives of the fossil program: 
(1) Within five years provide the capability for a 5 percent-point improvement in large fossil plant reliability and a 0.5 percent-point improvement in plant efficiency;

(2) Identify and investigate the factors affecting reliability and performance of both power plants and plant components;

Initiate projects that will improve plant reliability by providing a better operating environment for critical components, better inspection and quality control in plant design, improved operating conditions and control techniques, and improved materials and equipment designs; and

Develop standards of performance for use as a basis for generating plants and components specifically by the utility industry.

This fossil program has been put into place within the last two years. A comparable nuclear program has been in existence for a longer period of time. In general, EPRI has increased its efforts substantially to obtain the maximum productivity from existing units and is initiating projects with a near-term payback.

\subsection{Federal Activities and Programs}

Energy programs in the federal government relating to power plant productivity are generally diverse in scope with specialization in several cases. Most of the studies originated in parent agencies (Energy Research and Development Administration, Federal Energy Administration, Federal Power Commission, and so forth) but have since been incorporated into functions of the Department of Energy. This section focuses on three major programs sponsored by the U.S. Department of Energy: the Power Plant Productivity Improvement Program, the Light water Reactor Technology Program, and the Fossil Energy Programs. At the end of this section, three projects sponsored by the Rural Electrification Administration are also cited.

\subsubsection{Power Plant Productivity Improvement Program}

This program was initiated with the Federal Energy Administration in 1974 and continued by the U.S. Department of Energy. The objectives of the program are to increase productivity awareness, encourage productivity improvement programs, highlight the cost-effectiveness and benefits of improved productivity, and publicize examples of improvements that are well documented. Activities to meet these objectives include power plant performance data analysis, documentation of model methodologies for improving power plant productivity, assessments of potential benefits and cost-effectiveness of improved power plant productivity, workshops and seminars to disseminate and exchange information, and cooperative projects with states to demonstrate analytic techniques for performance evaluation and to develop regulatory mechanisms for productivity improvement. This report on regulatory mechanisms was funded by DOE as a portion of the ongoing effort of the Power Plant Productivity Improvement Program.

The FEA program began with a comprehensive assessment by an interagency task force of the status of power plant productivity. The results of this assessment, including the task force conclusions and recommendations, were published in 1975 [14] and were mailed to the heads of all utilities and state puCs.

An in-depth assessment of the status of efforts within the utility industry, conducted in late 1975 and early 1976 in a series of nine regional meetings, showed growing utility awareness of the increasing economic value of improved power plant productivity but revealed a very wide disparity among individual utilities in actions being taken to improve productivity. The results of their assessment also were mailed to all utilities and PUCs [15]. 
In parallel with this assessment, three separate investigations were made on a total of 12 large power plants to determine the underlying causes of poor productivity. These studies revealed that the actions of utility management, regulatory commissions, and the impacts of legislation to preserve the environment were affecting productivity as much or more than equipment failures.

The importance of systematic, in-depth assessments of the root causes of plant outages and derates was made vividly clear by these investigations; yet, at the same time, they revealed a serious lack of reliable up-to-date information on equipment performance and the causes of outages as well as the absence of proven analytical methods and tools for conducting rigorous engineering economic evaluations of poor productivity and productivity improvement projects [16]. To overcome these deficiencies, the FEA/DOE program includes extensive efforts to develop, document, and publicize analytical methods for assessing the potential benefits of productivity improvements and for evaluating their cost-effectiveness.

Under contract to the General Electric Company and in cooperation with several utilities, DOE assessed the potential benefits of improved productivity in terms of fuel and capital cost savings, reduced use of oil and gas, and reduction in needed capacity [33-35]. Although the benefits estimated are only about 40 percent of the theoretical estimates on a nationwide basis, they still are significant. For example, at the time the study was performed, increasing the average capacity factor of 400 megawatts and larger coal and nuclear units by 10 percent points between now and 1990 on an industrywide basis would, in the year 1990, reduce fuel costs by over 8 billion dollars (current dollars), reduce oil and gas consumption by 870,000 barrels a day, and reduce capacity requirements by more than 30,000 megawatts. Substantial changes in demand, supply, and fuel price forecasts since this study was conducted would change the estimated benefits. DOE judges, however, that the thrust of the results is still valid.

In parallel with the development of the GE methodology for assessing potential benefits, methodologies were developed under contract to Mechanics Research Inc. (now Systems Development Corporation) for systematically tracing plant problems back to their root cause. Under the same contract, an analytical method, which makes use of conventional reliability analysis, was developed that can be used to predict the effect of changes in improved power plant component reliability upon overall power plant availability. Approaches also were described and demonstrated for evaluating the cost-effectiveness of specific improvement projects. All of this work has been done with the cooperation and participation of three major utilities [33].

Following development of the above-mentioned analytical methods, the DOE entered into cooperative projects with the PUCs of ohio and Illinois to demonstrate their usefulness and validity. These projects are described in section 4.4 of this report. The application of these methods was introduced in 1979 to hundreds of utility staff and project engineers through the DOE/EPRI/NERC/EEI-sponsored workshops on Availability Engineering and Productivity Improvement. (See section 4.2.1, item 6.:)

Since testing the DOE/MRI methodology and discussing its application with other utilities, DOE has initiated a project to produce a simplified version expressly designed for application by utilities with relatively small engineering staffs. This manual for prioritizing potential productivity improvement projects will be published in 1981 .

Recognizing that policies and regulations of state pucs may contribute to poor productivity, the DOE has undertaken cooperative projects with the ohio and Illinois PUCs and the Texas Energy Advisory Council for an assessment of such policies and regulations and for identification and development of alternative actions that might be feasible at the state level for motivating utilities to improve productivity. These projects are described in section 4.4 of this report.

Over the past several years, the FEA and DOE have taken a variety of actions aimed at the establishment of an accurate, timely, and accessible data base on power plant performance. The FEA and DOE policy has been to improve and make more effective 
use of the existing industry data systems rather than have the government get into the data-collecting business. Consistent with its overall position that the industry has the load responsibility for improving power plant productivity, the FEA and DOE have encouraged and supported the industry data efforts described in Section 4.2 .1 .

DOE is represented on the Joint Advisory Committee to NERC's Generation Availability Data system. It is also represented on the EPRI Reliability Data Subcommittee that oversees the development of the National Data System.

While the industry's upgrading efforts are going on, DOE has compiled productivity data from available sources and has performed analyses of power plant performance through its contractor, ORNL. Since 1978, DOE has published and distributed a statistical summary of the performance of nuclear and coal units 400 MW and larger to industry and the states [32]. With the EEI and NRC Gray Book data bank on file, DOE has an in-house computer capability that has been used to fulfill many requests from state PUCs and other agencies for power plant performance information. DOE also has conducted special investigations including a statistical analysis of the effects of various power plant design parameters on productivity [24] and an investigation into the causes of widespread anomalies in the EEI data base [30].

DOE has stepped up the efforts begun by FEA to contact utilities throughout the U.S. so that outstanding examples of programs to improve power plant productivity can be located. Pertinent details of these programs are noted, and information is provided through a clearinghouse type of function to utilities searching for new ideas to improve power plant availability.

DOE is also developing a manual to aid utilities in achieving the maximum cost-effective reliability when converting their units from oil to coal firing. This manual will be published in 1981 .

\subsubsection{Light-Water Reactor (LWR) Technology Program}

The Department of Energy's LWR technology program is directed toward providing technology developments that are beneficial to the public interest and not likely to be accomplished without federal initiatives [40]. Consistent with the President's National Energy Plan, DOE's technology program is aimed at endorsing the role of light-water reactors in the nation's energy economy.

The objective of the LWR technology program is to develop and demonstrate technology that can improve LWR plant productivity in existing reactors and enhance the evolution of light-water-reactor technology and economics without increased regulation.

Efforts conducted under the productivity improvement element involve the following: (1) analyzing LWR industry experience to identify problem areas; (2) evaluating the potential for improvement in these areas and the proper roles of government and industry in seeking improvements; (3) selecting those technical improvements to be developed under DOE sponsorship; and (4) developing and demonstrating the technology for productivity improvements. The scope of this program element ranges from treating known problems in present LWR components and systems to technology development for diagnosing and minimizing the impact of future problems that may develop.

The objective in the treatment of known problems is to develop and demonstrate the technology to resolve those problems that currently limit LWR productivity, as well as those problems that will decrease plant productivity if unresolved. A wide range of problem areas has been identified and will be considered in this task effort.

Some of these problems are as follows:

- PWR Steam Generator Denting--In several operating PWRs, corrosion products have built up in the annulus between the steam generator tubes and tube support plates to the point where an inward force is exerted on the tube, causing it to dent. Progressive denting requires replacement of the steam 
generator, resulting in plant outages exceeding six months. Commonwealth Edison is the prime contractor for a project to prevent denting in PWR steam generators.

- Flow-Induced Vibration (FIV) Failures--FIV-induced-fatigue failure and excessive wear of reactor components have resulted in lengthy plant shutdowns for repair and extended periods of restricted power level operation. General Electric is the prime contractor in a project to eliminate FIV failures.

- Excessively Long Plant Refueling/Maintenance Outages--LWR refueling/maintenance outages represent the largest single increment of lost plant productivity.

There are two program thrusts: (1) to develop in-plant maintenance and repair technologies to reduce the impacts of these problems on productivity, and (2) to develop techniques to expedite the changeout of components when necessary.

Some effort has been devoted to the development of methods for preventing and for alleviating steam-generator-denting efforts; further work will be conducted in this area. Consideration will be given to the need to develop a milder cleaning technique that could be applied periodically during plant operation to avert denting. In addition to developing chemical means of arresting corrosion damage, future program tasks will address new methods for steam generator inspection, remote steam generator tube repair methods, and other technologies that can be used to extend the life of steam generators.

The objective of minimizing future problems is to develop and demonstrate the technology for early detection and diagnosis of future problems as well as to minimize the impact of these problems as they occur.

The program thrust is to develop techniques for detecting these problems at an early stage, to identify their root cause, and to conduct developmental efforts to resolve them. All activities will begin with an assessment of LWR industry experience in the subject area. This will lead to the selection of technical areas for development and demonstration projects.

Entitled Productivity Improvement Technology, the above-described programs accompany other objectives in the areas of uranium utilization, radiation dose reduction, and safety technology in the implementation plan. It is generally assumed that these policy objectives are all in the interest of improving performance and. supporting technical advances in reactor operations.

\subsubsection{Fossil Energy Programs}

The Department of Energy's Fossil Energy Program began in 1977 and has experienced a stronger thrust toward developing solid fuel-related strategies in recent months [39]. This has been due, in part, to the need to develop domestic supplies and use the nation's coal supply.

The objectives of the Fossil Energy Program, relative to power plant productivity, encompass the need to assure that current and proposed facilities be able to burn coal in an economically viable and environmentally acceptable manner, as well as to create a more efficient and economically attractive option for utilities in the choice of fuel. In order to develop a strong technology base for further development, these objectives are sought through a wide range of basic and applied research activities.

Coal-cleaning tests are directed primarily toward desulfurization technologies. six basic processes, that remove pyritic and organic sulfur from coal, presently are being performed and tested to determine commercial feasibility. Eventually, coal-cleaning processes will aid utilities by reducing the need for scrubbers and increasing boiler efficiency by furnishing a higher Btu content in treated coal. coal-cleaning techniques are differentiated between physical and chemical processes 
under the umbrella of coal preparation technologies. The amount of impurities has increased in recent years, and there is a need for greater uniformity in coal feedstocks, particularly for power plant use. Unlike chemical cleaning, as found in desulfurization techniques, physical cleaning is less expensive and more environmentally acceptable. Physical-cleaning methodologies are particularly important for western coal with specific attention to the lignites. As the nation relies on greater coal utilization in the years ahead, the development of methods for coal cleaning will play an important economic and environmental role. Evaluation studies by the DOE for physical-cleaning techniques cover a time frame between Fiscal Year 1979 through Fiscal Year 1983. Schedules for chemical-cleaning studies' completion and commercial application range between Fiscal Year 1982 for some cleaning procedures to Fiscal Year 1987 for others that have serious technical and economic issues to be resolved. DOE demonstration projects for more promising techniques can begin as early as Fiscal Years 1981 and 1982. Over the long run, the advent of coal-cleaning technology should lend significant help in improving power plant performance.

Environmental standards created a severe constraint on the direct combustion of coal as an energy source by electric utilities. New technologies are needed in order to maintain these standards with increasing use of coal to displace imported oil. One avenue being pursued, allowing higher environmental standards to be met by coal boilers, is the improvement of flue gas cleanup processes to remove pollutants from stack gases of conventional combustion units. The Fossil Energy program includes an Advanced Environmental Control. Technology program that addresses means by which cleanup systems can be developed and integrated into power generation. The flue gas cleanup activity includes examination of 1 ime/1imestone scrubber performance, advanced flue gas desulfurization systems, and advanced nitrous oxide and particulate control systems. Given that poor scrubber availability in the past few years has resulted in plant shutdowns, this work is particularly important. In addition, the New Source Performance standards now in effect require that the most advanced technology available be utilized in conventional combustion to achieve long term cost-effective production of electrical power.

The status of the flue gas cleanup program is detailed in the Fossil Energy Program Summary Document [39]. Initiated in Fiscal Year 1979, the program has seen expanded efforts in Fiscal Year 1980 and will use cooperative efforts of other organizations including industry, associations and federal power systems, and other federal agencies.

\subsubsection{Rural Electrification Administration Activities}

The Rural Electrification Administration (REA) of the U.S. Department of Agriculture has determined that a need existed within the generation and transmission cooperative electrical-generating stations for detailed guidelines pertaining to preventive maintenance, operations, and quality assurance. To fulfill this need, U.S.D.A. Bulletin Nos. $163-2,3$, and 4 were planned [31]. These three manuals address preventive maintenance management for fossil fuel steam electric power plants, operational aspects, and quality assurance during design, procurement, and construction.

The preventive maintenance management manual has been published and distributed while the other two proposed manuals are planned for distribution late in 1980 .

REA initiated this effort to enhance the opportunity of its generation and transmission borrowers to capture the benefits of improved power plant productivity, availability, and efficiency.

\subsection{State Activities and Programs}

The extent to which state regulatory agencies have concerned themselves with power plant productivity has been identified by The National Regulatory Research Institute in a series of interviews with state agency staff and a review of available 
1iterature published by state agencies. The interviews revealed that most state regulatory agencies do address the issue of productivity in either rate cases, fuel adjustment clauses, or in power-plant-siting proceedings. One state, Michigan, addresses productivity through a separate availability hearing.

Seventeen state regulatory agencies reported being involved in projects aimed at improving power plant productivity--the projects having been either funded by the Department of Energy or by state grants. The most widely used measures of productivity were availability factor, capacity factor, equivalent availability, equivalent forced outage rate., forced outage rate, and heat rate, though not necessarily in that order or priority. It was found that many state agencies recognize that the primary benefit from improved power plant productivity would be savings to the ratepayer. However, most states were not considering plant performance as a determining factor in fuel adjustment clauses, nor did they employ financial incentives to compel utilities to improve power plant productivity.

This section summarizes activities and programs to improve power plant productivity in California, Illinois, Michigan, New York, North Carolina, Ohio, Texas, and Virginia. More detailed descriptions of the activities and programs can be found in appendixes $A$ through $G$.

\section{California}

California is pursuing improved power plant productivity along two fronts: new power plants and energy cost adjustments. The California Public Utilities Commission is responsible for obtaining the most cost-effective level of reliability and productivity for existing power plants through utility regulation, while the California Energy Commission (CEC) is principally responsible for the same activity for new plants through its power-plant-siting authority.

Energy Cost Adjustment. In order to reduce utility risk due to widely fluctuating fuel prices, the Public Utilities Commission instituted an Energy Cost Adjustment Clause (ECAC) that provides a cost adjustment mechanism. Under the ECAC procedure, the staff is responsible for investigating the utility's energy costs and recommending an adjustment factor.

A recent decision by the public Utilities commission indicates that both productivity improvement and a system of incentives to stimulate improvement by the utility can be a part of the ECAC. Orders Nos. 4 and 5 of Decision No. 90488, July 3, 1979, of Southern California Edison's Application No. 90488 state as follows:

(4) Edison shall prepare as a part of its ECAC application for rates to become effective November 1,1979 , a proposed system of incentives for improved operation of its coal-fired power plants and shall recommend standards of performance for these plants on which to base incentives.

In cooperation with the staff, Edison shall select and retain an independent expert consultant to assess, evaluate and report on Edison's coal plant operating practices and the standard performance that can be expected of these plants.

The consultant selected was system Development Corporation. After an extensive study in which both the utility and the staff participated, the consultant developed both performance standards and a formula for calculating incentives. In this study, capacity factor and heat rate were chosen as the appropriate indices for the development of the performance standards and incentives. Also, the concept of rewards as well as penalties was included in the incentive program.

The recommendations resulting from the consultant's study were presented by the staff at commission hearings in May and June 1980 during which the consultant, the utility, and the public participated. The commission's decision is now pending. 
New Power Plants. The California Energy Commission (CEC) is responsible for the siting of new power plants within the state. A recent commission study of power plant reliability and efficiency has established guidelines, indices, and ranges of reliability and power plant performance to be used in assessing the productivity of proposed new generating stations [3]. A two-part guideline has been developed to assure that the most cost-efficient levels or ranges of reliability and efficiency will be obtained by plants to be sited in California. The first part addresses the utilities' establishment of the most cost-effective range of reliability for new plants within the power system. The second part ensures that specific actions will be taken by the utility to achieve established ranges of efficiency in the most cost-effective manner. There is a standard agenda in the guidelines in the form of a list of key issues for use by the utility and CEC to assess the cost-effectiveness and attainability of reliability levels.

Indices of power plant performance have been recommended for the CEC's and utilities' use in assessing reliability and efficiency for new power plants: (1) operating availability, (2) equivalent availability, (3) capacity factor, and (4) heat rate. These indices have been suggested because they may be used individually and in combination to assess the cost-effectiveness of a proposed facility. The analysis of historical power-plant-reliability data acts as a guide in formulating meaningful questions on the ability of new facilities to achieve desired levels of reliability and efficiency. While the data are useful in this manner, they are not proposed as standards for predicting future performance of new units. A more comprehensive description of the guidelines study can be found in appendix $A$.

\section{Illinois}

Prior to its current study with the U.S. Department of Energy, the Illinois Commerce Commission took note of power plant productivity only when the issue arose on a case-by-case basis. In 1976, the commission ordered a management audit of one utility. One of the recommendations emerging from this audit was to establish a productivity strike force at a certain plant. Improved maintenance practice and the setting of availability progress goals were also encouraged. The management audit report acknowledged the complexity of the problem and the efforts undertaken by the utility but stated that the approach has been fragmented and lacked direction and force. The commission monitored the activities of the utility in carrying out the recommendations.

Power plant productivity became an issue during a rate case with another Illinois utility during 1976. The utility petitioned the commission for a purchased power adjustment clause due to low productivity at a nuclear plant. The utility was a joint owner of the facility and needed expensive purchased power when the reactor was out of service. The commission recognized the disincentive effects of such a clause in this case and rejected the petition.

Cases such as these have served to sensitize the commission and staff to the growing importance of power plant productivity. This realization led to involvement in the joint study with DOE that is scheduled for completion in the near future. The goals of the DOE project were to increase staff expertise in the area, examine current levels of power plant productivity in Illinois, and to study possible methods of encouraging improvements where they would be cost beneficial.

Preliminary observations from the study suggest the need for increased commission staff monitoring of productivity figures. The monitoring will most likely be based on EEI data with backup from data furnished by utilities. After the establishment of a data base, it is recommended that such information be introduced into the rate case forum. With regard to comparison of productivity figures, this may be done using statewide and national data. Also, comparison could be made by life-year and generating unit and size. Where low productivity could not be justified by the utility, adjustments might be made to replacement power expense or to the allowed rate of return. 
The commission is also just now embarking on a study of what might be the appropriate level of productivity for future generating stations in Illinois. This study will attempt to establish groundwork for determining how much reliability should be anticipated in the design for new facilities. Information in this regard will be used in future plant certification proceedings. A more comprehensive description of the activities related to productivity improvements in Illinois is included in appendix $\mathbf{B}$.

\section{Michigan}

The Michigan Public Service Commission has established a system availability incentive provision for the state's two major utilities that rewards or penalizes the companies financially, based on a scale of rate of return on common equity and system availability [22].

To date, five availability incentive provision cases have been decided. In three cases, the commission determined that the utility had qualified for a bonus return on common equity based on the system availability achieved for a previous calendar year.

In December 1977, the commission staff formed an availability task force to identify contributory causes of power plant availability decline within the industry and also within the regulatory structure. In March 1979, the task force issued a paper entitled, "Report on Power Plant Availability" that defined power plant availability problems in Michigan and the industry as a whole. presently, the group is developing recommendations aimed at improving system availability levels in the state and also suggesting revisions in the existing availability incentive plan. Further details of the Michigan Public Service Commission programs are available in appendix $\mathrm{C}$ of this report.

In addition, the task force is pursuing a project with the purpose of developing regulatory techniques to improve power plant availability. These goals are: (1) establishing baseline data on the performance of power plants in Michigan; (2) evaluating the current production maintenance process for the two major Michigan utilities; (3) evaluating the commission's present regulatory policies and techniques as they impact power plant productivity; (4) analyzing the impact of major productivity improvement projects for large baseload power plants in Michigan; and (5) developing recommendations for improvement in present regulatory policies and techniques and developing new policies and techniques that could be implemented by the commission to improve power plant availability further.

As a further incentive to improving power plant availability, the commission has disallowed purchase power expenses in certain purchase power adjustment clause hearings where it was determined that the utility was at fault for a particular plant outage that had resulted in increased purchase power.

\section{New York}

The objective of the state of New York Department of Public Service's Power Plant Productivity Improvement Program is to encourage the state's utilities to develop a systematic permanent reliability program based on sound engineering and cost-effective principles. In order to realize accomplishments in this objective, the department has established a power plant productivity Working Group comprised of department staff and utility personnel. This Working Group serves as a vehicle for obtaining information as well as for discussing and evaluating information obtained and suggestions made for future improved procedures concerned with productivity.

Fundamentally the program consists of four parts:

(1) compilation and analysis of performance data;

(2) evaluation of utility response to outage/derating events;

(3) cost-benefit analysis; and

(4) evaluation of procedures and policies. 
The first part, compilation and analysis of performance data, is designed to obtain data for individual units from the separate utilities. Categories for data acquisition include planned maintenance, forced and partial outages; additional information is gathered from other sources such as EEI, EPRI, and DOE. Efforts are devoted to distinguishing basic, generic problems from random malfunction problems and to avoiding masking of singularities in the data. Data are organized by utility, fuel type, and unit size. In addition to gathering the statistical data, the working Group reviews maintenance and outage practices at similar plants. Where differences are observed, reasons behind the alternative procedures are examined to determine if these may lead to improved procedures at similar plants.

One of the reasons for gross data compilation is to compare the performance of generating units; for example, how well are specific New York coal and nuclear units performing relative to each other and how well are they performing relative to comparable units in the United States, begging the question: "Why the difference?"

While the gross performance indices are very useful for comparison and measuring overall performance, they are somewhat limited in that they do not identify equipment component outage causes that are the basis of determining root causes, alternative corrective actions, and cost-benefit analysis. Therefore, an outage/derating-reporting system has been instituted under which every outage or derating of every unit involved in this program is reported. Such items as duration, size, and root cause (as best as can be determined) are recorded by station personnel, in handwriting, on a one-page form. The root-cause analysis focuses on causes of outages, solutions, similar outages at various plants, and corrective actions and policies of each utility for preventing outages.

The second part deals with utility response to outage/derating events. Under this action, the Working Group reviews procedures for responding to outages. Attention is given to variations in these responses as a function of time-of-day, time-of-year, and so forth, and to the differences between average response and reeponee at crucial times. In addition, the Workinq Group also reviews procedures for deciding scheduled maintenance outages. In effect, the utility response to instrumentation signals is considered as important as response to actual outages when they occur.

Obviously, the Department of Public Service would like to see a systematic procedural approach. Such an approach should include the following components:

(1) Record, review, and analyze operating data to detect and prevent equipment failures and load reductions.

(2) Investigate and correct forced and partial outages; establish a framework to ensure that forced and partial outages are investigated and root cause identified.

(3) Devise a methodology for evaluating physical options for reducing outages. This methodology would involve evaluating alternative corrective actions in terms of technical feasibility. Project control, periodic review procedures, and feedback would also be evaluated.

The third part involves performing cost-benefit analysis of power replacement of each outage. The analysis considers several alternatives that include purchase of contingency power, use of spinning reserve, use of already operating facilities, at full power, and utilization of oil generation as well as long-range-planning options.

The fourth part of the program involves the development of procedures and policies. This is subcategorized into two areas of concentration: rate mechanism evaluation and monitoring procedures. In general, the utility is not penalized for poor power plant performance. Fuel adjustment clauses, such as the standard adopted by this state, tend to aggravate the situation by flowing through to the ratepayer any gain or loss of productivity of power plant operation on a monthly basis. Applicability of the fuel adjustment clause does tend to lessen the urgency of restoring a generating unit to service from an outage, forced or scheduled, since 
there is no penalty of unrecovered energy costs and an opportunity to avoid overtime charges. Conversely, the alleviation of this urgency is not necessarily undesirable if the end result is to promote more thorough maintenance and improve reliability.

Setting target levels against which actual productivity is judged for the purpose of administering rewards and penalties is a subject to be investigated. This is a very important area, but one that also requires great care to avoid oversimplification. Simple numerical criteria probably would not be adequate. A particular concern is that inappropriate criteria could lead to actions that are penny-wise and pound-foolish. Staff and consultant reviews of power plant reliability, to date, have provided evidence that some major problems were caused or exacerbated by lack of prompt response to trouble signals. Accepting an outage immediately may prevent a more serious outage later. A numerical index in rate setting may encourage the utility to delay maintenance that really should be done immediately until the next planned outage and take its chances for the future. Accepting an outage of increased length in order to make equipment modifications designed to reduce future outages should not absolutely be discouraged,

One of the challenges of this project will be to devise mechanisms that do not turn out to be counterproductive and do not, on the other hand, turn out to be totally subjective. Setting performance standards and requiring reporting to the Departinent of Public Service for evaluation of outages specifically identifiable as precautionary for discounting from the performance standard may constitute a fruitful approach.

Rewards and penalties should be meaningful to the utility, but penalties should not be sufficiently severe that they adversely impact the financial standing of the company, increasing interest rates and providing penalties to the consumer. Fuel adjustment penalties may have the disadvantage of being applied coincidentally with an adverse cash-flow situation occasioned by the outage, while a rate-of-return penalty has the disadvantage of being delayed. Rate of return is an easier mechanism of the reward side.

The monitoring procedures involve placing a qualified person in the field to collect on-site information. This individual assesses operator logs and outage forms in order to evaluate outage hours and reporting procedures better. One result of this program has been the development of reporting forms by the commission that better deliute the detalis of the outage problems. Additional details of the New York Power Plant Productivity Improvement Program may be found in appendix $D$ of this report.

\section{North Sarnlina}

The North Carolina Utilities Commission has instituted a procedure providing for hearings and review of power plant performance on a semiannual basis as part of the fuel cost adjustment mechanism. The expanded procedure is designed to incorporate outage experience at low-cost baseload generating stations into other performance and procurement evaluations existing in the commission's fuel cost monitoring program. The commission established a 60 percent minimum capacity factor as an objective for baseloaded nuclear plants, and it requires monthly reports from each electric utility showing details of the generation mix, outages, causes and remedial actions. Baseloaded fossil plants are also included, but no minimum capacity factor objective is specified.

The commission schedules semiannual hearings so that any company that fails to achieve the objective on a 6-month to 12-month moving average basis must justify the outages that prevented it from reaching the objective. If the commission finds from evidence at the hearings that failure to achieve the objective was caused by imprudent management, it may disallow some fuel adjustment charges. The amount of such disallowment will be based on time of outage, duration, magnitude of cost, prior performance of units, vintage of units, break-even level between nuclear-generating capacity and coal-fired generation capacity, general diligence of management, and other relevant factors suggested by the parties at the hearings. The commission believes that this procedure provides the utilities with a continuing incentive to ensure that their plant performance is maintained at high level and provides a proper data base for independent evaluation of outage experience by the commission public staff and other parties. 
In a separate but related proceeding, the commission requested the public staff to perform a detailed investigation of the causes of relatively higher rates of one utility operating in the state. The findings by the staff indicated that the major causes of higher rates were related to poor plant availability and efficiency (heat rate) experience resulting from inadequate maintenance practices. Recommendations for adjustments in the fuel cost adjustment charges to reflect the alleged inadequacies were adopted by the commission. Refunds were ordered, and similar adjustments are currently being made in each request for fuel cost adjustment.

A more detailed description of the North Carolina power plant performance evaluation mechanism is provided in appendix E.

Ohio

The Public Utilities Commission of Ohio has addressed the issue of power plant productivity in three major areas. First, a target thermal efficiency mechanism has been utilized in commission semiannual fuel cost adjustment clause hearings since December 1976; second, a PUCO/U.S. Department of Energy Cooperative Agreement to study the cost and benefits of improved power plant productivity is nearing completion; and third, the commission staff is currently formulating both short- and long-range procedures to introduce the issue into regulatory proceedings.

The Fuel Adjustment clause. The fuel cost of a utility is a combination of the cost of procurement and the efficiency with which its generating stations convert that fuel to electrical energy. Section 4905.69, Revised Code, requires the commission to establish a fuel adjustment clause that "establishes incentives, in terms of cost that may be recovered by electric light companies pursuant to a fuel cost adjustment clause for implementation and employment by such companies of efficient fuel procurement and utilization practices." Based upon this legislative directive, the commission included a thermal efficiency feature in its Revised Code of Rules and Regulations (4901:1-11). As delineated in the commission's Fuel Cost Adjustment Clause (FCA) (4901:1-11), the thermal efficiency feature is a reference measure of an electric utility's efficiency in operating its total system of electric-generating plants. The system target thermal efficiency is established by the commission for each electric utility within ohio based upon the utility's past system performance, future system additions, and other relevant factors.

In its most recent session, the Ohio General Assembly modified the 1975 statute that established the fuel cost adjustment clause. Among the many changes the commission staff is considering in order to comply with the new statute is the elimination of the thermal efficiency mechanism in favor of another efficiency measure. No final decision about the specifics of the new commission rule has been made.

PUCO/DOE Cooperative Agreement: The Costs and Benefits of Improved Power Plant productivity. This project utilizes existing analytical techniques to assess the costs and benefits of power plant productivity improvements. The project has been divided into five tasks:

Assessment of Power Plant Performance;

Cost/Performance Changes Associated with Specific Productivity Improvements;

(III) Benefits of Specific Productivity Improvements;

(IV) Incentives/Disincentives for Power Plant Productivity Improvements;

(V) Impact of Load shape Changes on Benefits of Improved Productivity.

Tasks I and IV have not been completed at the time of the writing of this report. The findings of Tasks II, III, and $V$, are described below. 
Task II utilized the DOE/MRI methodology [33] to assess its applicability and to estimate the costs and performance changes associated with eight specific problems at four Ohio power plants. The Energy Systems Planning Division of TRW supervised the implementation of the methodology. Table 4.1 presents a summary of the results of this analysis rounded to the nearest tenth [28].

In Tasks III and $V$, methods of probabilistic simulation of system operation were utilized to quantify the benefits associated with improving power plant performance with and without load management $[27]$. The benefits were quantified in terms of changes in loss-of-load probability (LOLP), unserved energy, and average fuel costs for six Ohio utilities based on actual system-operating data. The work performed was specific to the following six Ohio utilities: Dayton Power and Light, Toledo Edison, Ohio Edison, Cleveland Electric Illuminating, Columbus and Southern ohio Electric, and Cincinnati Gas and Electric.

TABLE 4.1

ESTIMATED IMPROVEMENT IN EQUIVALENT AVAILABILITY AND ASSOCIATED COST AND BENEFIT

\begin{tabular}{|c|c|c|c|}
\hline Unit Name & $\begin{array}{c}\text { Improvement in } \\
\text { Equivalent } \\
\text { Availability } \\
\text { (Percent } \\
\text { Points) }\end{array}$ & $\begin{array}{l}\text { Cost of } \\
\text { Improvement } \\
\text { (\$ millions })^{*}\end{array}$ & $\begin{array}{l}\text { Value of } \\
\text { Improved } \\
\text { Performance } \\
\text { Benefits } \\
\text { (\$ millions) }\end{array}$ \\
\hline $\begin{array}{l}\text { Mansfield Unit } 1 \\
\text { (1) Pulverizer } \\
\text { (2) I.D. Fan }\end{array}$ & $\begin{array}{l}0.2 \\
5.2\end{array}$ & $\begin{array}{l}1.5 \\
7.1\end{array}$ & $\begin{array}{r}2.1 \\
73.0\end{array}$ \\
\hline $\begin{array}{l}\text { Conesville Unit } 4 \\
\text { (1) Cooling water } \\
\text { Iimitations } \\
\text { (2) Economizers }\end{array}$ & $\begin{array}{l}0.2 \\
0.7\end{array}$ & $\begin{array}{r} \\
4.0 \\
.2\end{array}$ & $\begin{array}{r}8,5 \\
22.9\end{array}$ \\
\hline $\begin{array}{l}\text { Gavin Unit } 1 \\
\text { (1) Superheater } \\
\text { (2) F.D. Fans }\end{array}$ & $\begin{array}{l}1.7 \\
0.1\end{array}$ & $\begin{array}{l}2.6 \\
0.0\end{array}$ & $\begin{array}{r}28.2 \\
0.1\end{array}$ \\
\hline $\begin{array}{l}\text { Muskingum Unit } 3 \\
\text { (1) Superheater- } \\
\text { reheater } \\
\text { (2) Cyclones }\end{array}$ & $\frac{1.1}{0.7}$ & $\begin{array}{l}5.9 \\
4.4\end{array}$ & $\begin{array}{l}7.2 \\
6.0\end{array}$ \\
\hline
\end{tabular}

Source: Ohio Department of Energy.

*Present Value. 
Four cases of availability improvements were evaluated:

PI-0 No productivity improvements.

PI-l Equivalent forced outage rate of all baseloaded plants reduced by 5 percentage points over 10 years.

PI-2 Equivalent forced outage rate of all baseloaded plants reduced by 10 percentage points over 10 years.

PI-3 Equivalent forced outage rate of all baseloaded plants reduced by 10 percentage points and equivalent availability improved simultaneously to a maximum of 85 percent over 10 years. Minimum maintenance time was set to 20 days per plant per year.

These improvements were simulated on all baseloaded plants simultaneously. Improvements were phased in linearly over the period 1979-88 assuming a base year of 1978 .

Load management was simulated by modifying the load duration curve of each utility for each period of study. There were four three-month periods (seasons) of study in each year. The following cases of load management were evaluated:
LM-0 No load management.
LM-1 A 5 percent reduction of the peakload of the load duration curve, with 10 percent of the energy in the peak region shifted to the base and shoulder regions. (The peak region of the load duration curve was defined as the region in which the load exceeded 70 percent of the season's peak-hour load).
LM-2 A 5 percent reduction of the peakload of the load duration curve, with 20 percent of the energy in the peak shifted to the base and shoulder regions.
LM-3 A 10 percent reduction of the peakload of the load duration curve, with 40 percent of the energy in the peak shifted to the base and shoulder regions.

Simulations were run for each case of availability improvement by first assuming no load management and then assuming, each caseload management. A partial summary of results for the six ohio utilities is presented in table 4.2. The results show the computed percent improvements relative to the base case (PI-0, LM-0) in average fuel cost, LOLP, and expected unserved energy over the period 1979-88 for the extreme case of productivity improvements, PI-3, coupled with the case of no load management, LM-0, and with the extreme case of load management, LM-3. Results of additional cases, evaluating the effects of delaying capacity additions for one and two years, are presented in appendix $F$. The findings from this work indicate significant potential improvement in system reliability.

Current Action: Introducing Power Plant Productivity into the Regulatory Process. The staff of the PUCO is currently in the process of developing and implementing a two-phase plan to introduce the issue of power plant productivity into the regulatory process. The purpose of the first phase is to identify the issue in the rate case proceedings. In this phase, the staff will assess the status of the company's generating system, quantify potential system benefits, identify cost-effective examples of corrective actions for existing plants, and analyze current utility operations, maintenance, and data collection policies.

The purpose of the second phase of the program is to improve current commission procedures in the power plant productivity area. More specifically, the objective of this phase is to develop and document a comprehensive program for the inclusion of power plant productivity elements into existing procedures, in the areas of performance data collection, major capital improvements to existing units, preventive 
TABLE 4.2

THE EFFECTS CF PRODUCTIVITY IMPROVEMENTS AND LCAE- MANAGEMENT ON SYSTEM PARAMETERS OVER THE PERIOD 1C79-1988 ASSUMING TIMELY CAPACITY ADDITIONS

\begin{tabular}{|c|c|c|c|c|c|c|c|c|c|}
\hline Company Name & $\begin{array}{l}\text { Base } \\
\text { Case } \\
\text { (Days) }\end{array}$ & $\begin{array}{l}P I-3 \\
L M-0 \\
(8) \\
\end{array}$ & $\begin{array}{l}\text { EI-3 } \\
I M-3 \\
(8) \\
\end{array}$ & $\begin{array}{r}\text { Base } \\
\text { Case } \\
\left(10^{3} \mathrm{MWh}\right) \\
\end{array}$ & $\begin{array}{l}\text { PI-3 } \\
L M-0 \\
(8) \\
\end{array}$ & $\begin{array}{l}\mathrm{PI}-3 \\
\mathrm{LM}-3 \\
(8) \\
\end{array}$ & $\begin{array}{l}\text { Base } \\
\text { Case } \\
(\$ / M W h) *\end{array}$ & $\begin{array}{l}\mathrm{PI}-3 \\
\mathrm{LM}-0 \\
(8) \\
\end{array}$ & $\begin{array}{l}\mathrm{PI}-3 \\
\mathrm{LM}-3 \\
(\mathrm{q}) \\
\end{array}$ \\
\hline $\begin{array}{l}\text { Cincinnati Gas and } \\
\text { Electric }\end{array}$ & 63.15 & -71.7 & -82.1 & 340.5 & -78.3 & -87.5 & 8.691 & -2.1 & -2.4 \\
\hline $\begin{array}{l}\text { Cleveland Electric } \\
\text { Illuminating }\end{array}$ & 33.87 & -75.9 & -89.5 & 228.8 & -81.2 & -93.0 & 10.258 & -3.3 & -3.4 \\
\hline $\begin{array}{l}\text { Columbus and Southern } \\
\text { Ohio Electric }\end{array}$ & 54.35 & -60.1 & -73.0 & 233.4 & -66.8 & -79.7 & 9.149 & -1.4 & $-1 \cdot 5$ \\
\hline $\begin{array}{l}\text { Dayton Power and } \\
\text { Light }\end{array}$ & $271.6 \varepsilon$ & -54.5 & -68.5 & 1550.9 & -63.5 & -78.7 & 9.274 & -3.2 & -3.8 \\
\hline Ohio Edison & $177.5 \%$ & -55.5 & -66.3 & 1406.1 & -62.1 & -72.7 & 8.662 & -3.7 & -4.1 \\
\hline Toledo Edison & 194.74 & -40.8 & -47.6 & 707.0 & -44.2 & -52.9 & 8.023 & -6.8 & -7.6 \\
\hline
\end{tabular}


maintenance, and the tracking of benefits. This phase of the program is the subject of a second DOE/PUCO Cooperative Agreement; a consultant is scheduled to begin work on the new procedures in september 1980. It is expected that with the implementation of these new procedures, specifically commission verification of the assumptions, method, and benefits projected for major improvement programs and potential utility reimbursement for those programs, availabilities will increase for the state's power plants without the implementation of a more formal incentive mechanism.

Texas

The interest of the Texas Energy Advisory Council and the Center for Energy Studies at the University of Texas in power plant productivity was started and developed in response to a Department of Énergy Request for Proposal (RFP No. EP-78-F-01-6427).

The primary objective of that study is to examine the influence of the existing electric utility institutional framework on power plant productivity and to analyze both the short-run and long-run impacts of alternative regulatory incentives, designed to encourage improved power plant efficiency upon optimal capital mix and the cost of fuel.

The research project involves the determination of current levels and trends in power plant productivity in the state of Texas. Short-term costs of power plant outages will be computed using a production simulator that treats outages and system load in a probabilistic manner. The benefit to be derived from an improvement in outage rates (or other performance factor), therefore, can be determined by running the probabilistic simulator for the normal and improved outage (or other performance factor) levels and comparing the respective operating costs.

A more detailed description of this project and preliminary results are provided in appendix $G$.

\section{Virginia}

To varying degrees, utilities possess the potential of exercising control over each factor that influences and determines the total annual costs of providing electric service. The goals of the work performed by the Virginia commission staff are to assess each utility's effectiveness in the exercise of that control and the ultimate recognition of such success, or lack thereof, in the ratemaking process. In short, the purpose is to place the commission in a greater active rather than reactive regulatory position.

Although work has been undertaken to monitor and evaluate the principal areas that determine the total costs of providing electric service, major emphasis has been placed on fuel expenses. The primary reason for this emphasis is that the incurred fuel expenses, including interchange power, typically represent from 40 percent to over 100 percent of each utility's total annual costs.

So as to assure that the charges to customers only reflect a reasonable level of expenses, the automatic fuel adjustment clause was abolished. In its place, a procedure was established wherein fuel expenses are projected annually and rates set at the beginning of each calendar year that reflect the level of projected fuel expenses per $\mathrm{kWh}$.

Various tools were developed to assist the staff in its development and/or evaluation of the reasonableness of the assumption necessary to project expenses. These tools consist of the following:

(A) Fuel Price Index;

(B) Identification and establishment of generating unit performance measures;

(C) Production Cost Simulation (PCS) model.

(A) The Fuel Price Index requires monthly reporting by utilities of the costs of fuel purchased and consumed. The index permits the tracking of delivered fuel prices 
and comparison with regional averages of comparable quality fuels, and in addition, provides a basis for determining the reasonableness of projected delivered fuel prices as well as those actually incurred.

(B) With respect to generating unit performance, five factors were identified as being extremely good measures of performance. These are availability factor, equivalent availability factor, capacity factor, forced outage rate, and heat rate. Generating unit comparison groups were developed for each of the utility's units. The units in each comparison group consist of those which are the same (similar) fuel type, size, vintage, and design. The EEI data base and NRC Gray Book were the principal sources of information, supplemented and/or verified by each utility. From these comparison groups, zones of reasonableness were established with respect to the five factors listed above.

(c) The PC.S model provides the staft with the in-house capability of projecting fuel expenses and is used, among other things, to evaluate utility-sponsored forecasts and also to provide information necessary to monitor actual results, incurred expenses, and generating unit performance.

\subsection{Summary}

Industry action can be divided into the following categories: performance data, plant design, plant manufacture and construction, operations and maintenance, fuel quality and standardization.

Data-related activities focus primarily on programs to provide feedback data to design activities and to improve the quality of plant operation.

Present actions to improve the productivity aspects of design may be summarized as establishment of productivity in policy and organization arrangements, use of operating experience including both data and participation of operating personnel, feedback, testing and laboratory research to verify designs, and use of models to evaluate design. These actions have already led to important improvements and offer potential for even greater ones with wider implementation to the utilities themselves.

In the area of manufacture and construction, the use of plant models is expected to improve the understanding of each step of construction and thus improve plant reliability.

Operation- and maintenance-related programs include personnel training, improved spare-parts management, and improved outage planning and management. There is need for more utilities to undertake such programs.

Programs to improve fuel quality are currently under way in conjunction with the U.S. Department of Energy.

There is need for expanding plant design standardization projects.

The major federal programs are the power plant productivity lmprovement Program, the Light Water Reactor Technology Program, and the Fossil Energy Program.

The objectives of the Power Plant Productivity Improvement Program are to increase productivity awareness, encourage productivity improvement programs, highlight the cost-effectiveness and benefits of improved productivity, determine major causes of lost productivity and possible corrective actions, and publicize examples of improvements that are well documented. Projects within this program have been completed by General Electric, and others are currently under way by several states.

The objectives of the Light water Reactor Technology Program are (1) to improve performance of existing reactors and (2) to investigate the evolution of light-waterreactor technology and economics. Based on results of studies completed in 1978, a series of demonstration projects to improve refueling/maintenance outages is being planned for 1979 . 
The objectives of the Fossil Energy Program are to support research on physical and chemical coal-cleaning technology, flue gas cleanup, and on the development of boilers that can use a wide range of coals. The program also includes projects for coal liquefaction, coal gasification, and for gas and oil recovery. The timetable for this program extends into the 1980 s.

State activities include implementation of regulations aiming to promote power plant productivity improvements and studies in areas related to power plant productivity. The most notable states in this regard are California, Illinois, Michigan, New York, North Carolina, Ohio, Texas, and Virginia.

In California, the Public utilities Commission is using the energy cost adjustment mechanism to encourage attainment of higher levels of productivity. The California Energy Commission has recently completed a two-part guideline to ensure that the most cost-efficient levels of plant reliability and efficiency are obtained by proposed plants. As part of the same project, indices for assessing performance were developed, and ranges of performance for evaluating the productivity of proposed power plants were established.

The Illinois Commerce Commission is conducting a project in conjunction with the U.S. Department of Energy. The goals of this project are to increase the expertise of commission staff in the area of power plant productivity, examine current levels of power plant productivity in Illinois, and study possible methods of encouraging cost-beneficial improvements.

The Michigan Public Service Commission has established an availability incentive provision whereby the rate of return on equity is linked to system availability. $A$ task force on availability has also been formed and has identified availabilityrelated problems in Michigan. The task force is currently involved in developing recommendations aimed at improving availability, suggesting a revision in the existing availability-incentive plan, and developing regulatory techniques to improve power plant. availability.

The New York Public Service Commission has established a working group on power plant productivity comprised of commission staff and utility personnel. The program of the working group is to compile and analyze performance data for root-cause analyses of outages, to perform cost-benefit analyses of alternative ways to supply power for each case of outage and for the longer term, and to develop productivity monitoring and enforcement procedures.

The North Carolina Utilities Commission has instituted a procedure providing for hearings and review of power plant performance as part of the fuel cost adjustment mechanism. Failure to achieve set performance factor of 60 percent has been established for nuclear plants; the performance of baseloaded, coal-fired plants is also being monitored, but no minimum levels of performance have been set.

The Public Utilities Commission of ohio has established a target thermal efficiency program linking thermal efficiency to fuel cost adjustment. Additionally, projects are currently under way in conjunction with the U.S. Department of Energy to study the costs and benefits of improved power plant productivity and to formulate procedures to introduce the issue into regulatory proceedings.

The Texas Energy Advisory Council is conducting a project in conjunction with the U.S. Department of Energy to examine the influence of the existing electric utility framework on power plant productivity and to analyze impacts of alternative regulatory incentives for improved productivity upon ruel costs and optimal plant mix.

In Virginia, the commission staff has identified measures of plant performance suitable for use in the ratemaking process. Fuel expenses are projected, and rates are set assuming reasonable levels of performance. 
THIS PAGE

\section{WAS INTENTIONALLY LEFT BLANK}


Chapter 5.

\section{Recommendations}

\subsection{Introduction}

The potential benefits from improving the productivity of electric generating power plants have been discussed. In order to bring about productivity improvements, specific actions must be taken. Responsibility for service and therefore responsibility for productivity lies with the utility involved. However, responsibility for ascertaining that public interest is being served lies with the regulatory agency. Both responsibilities can be best discharged through a cooperative relationship. The Working Group recommendations that follow should be viewed as elements in a program designed to motivate utilities to take a broad-based approach to productivity. This involves two aspects: a multiattribute approach to productivity in which all measures of performance are considered, and a longitudinal approach to costing in which initial investment is combined with life-cycle performance to produce a total long-term productivity model. That model does not yet exist, except in bits and pieces. The total cost-benefit of productivity-enhancing decisions is not readily computed. However, this lack cannot be permitted to stand in the way of efforts to improve the productivity of electric-power-generating systems. To that end, then, the Working Group recommends that regulatory agencies and utilities combine efforts to improve power plant productivity. The following should be done by regulatory agencies:

- Adopt a policy statement that articulates a desire to enhance power plant productivity.

- Acquire the capability to perform independent in-house analyses of power plant performance.

- Participate in the establishment of productivity improvement programs.

- Establish a system of productivity improvement incentives.

- Coordinate efforts on a national basis to promote ongoing programs and develop new ones.

\subsection{Discussion of Recommended Actions}

\section{Policy Statement}

In many regulatory situations, utilities and agency staff experience difficulty in establishing working relationships because they lack a clear understanding of the commission's position. Power plant productivity is one such area. In some instances, a simple statement of commission concern will stimulate new or renewed utility efforts in this direction. In other cases, specific orders will have to be issued to overcome inertia. Regardless of the particular circumstances, the fact that the regulatory agency is assigning a priority to its concern that electrical-generating plants be as 
productive as. possible can serve as an important first step. Therefore, it is recommended that agencies develop and articulate a position encouraging utilities to improve the productivity of their power plants.

\section{Plant Data}

Regulatory agencies must obtain and maintain, or have access to, information about the performance. of power-plant-generating units. Data files should include date of outage, outage cause code, and outage duration, both for specific plants with the state's jurisdiction, and ideally, also for plants nationwide. Three reasons support data acquisition. First, such data help in the identification of causes of productivity losses; second, they are helpful in estimating costs and benefits associated with productivity improvement programs; and third, they enable the agency to monitor the implementation of productivity improvement measures. Therefore, it is recommended that regulatory agencies:

(1) initiate a program to acquire plant performance data on an ongoing basis; and

(2) support existing reporting programs, particularly NERC-Generating Availability Data Systems (GADS), making every effort to eliminate duplication, standardize formats, and ultimately establish a coherent national data base.

\section{In-House Capabilities}

Regulatory agencies should be capable of performing independent analyses to evaluate productivity, verify studies conducted by utilities, and promote, encourage, monitor, and/or enforce the implementation of productivity improvements. At the same time, it is recognized that staff acquisition is an expensive undertaking, and many state agencies are under pressure to reduce costs. It is recommended that regulatory. agencies acquire the capability for the following:

(1) auditing utility data, operations, and practices;

(2) analyzing the costs and benefits and assessing the impacts of regulatory policies and utility practices; and

(3) monitoring compliance and enforcing the achievement of productivity goals.

\section{Performance Programs and Goals}

State regulatory agencies should work with utilities to establish productivity improvement programs with explicit goals and to document the methods used to achieve such goals. To accomplish this, the requlatory agency should ensure that utilities:

(1) document the basis for the analyses undertiken to pstahlish prndurtivity improvement goals for existing plants and also document the i, plan of action;

(2) document their plans for vendor compliance/enforcement;

(3) establish performance objectives for new units, justify any custom design features, and establish reliability assurance plans for design innovations; and

(4) demonstrate that the productivity improvement goals are operational by documenting program elements and assigning responsibility for specific objectives to specific organizational units and identifying the persons who hold those responsibilities.

\section{Productivity Incentives}

To motivate the attainment of cost-effective higher productivity, it is recommended that state regulatory agencies establish a system of incentives. 
Certain states have established such systems. In Michigan, a provision has been established whereby the rate of return on common equity has been linked to availability. In North Carolina, capacity factor of nuclear units is considered in fuel cost adjustment proceedings. In New York, the response of utilities to forced and scheduled outage events is being evaluated. Rate of return and the fuel adjustment clause are possibilities being considered in that state as potential mechanisms to ensure productivi.ty improvements. In Virginia, the issue of power plant productivity is addressed in regulatory proceedings on a case-by-case basis. In addition to the above, other approaches include adjustments to the rate base and establishing a link between plant output and plant depreciation, fuel cost recovery, purchase power disallowance, and purchase power cost within pools. No particular incentive is recommended in this report. Regulatory agencies will have to work with utilities to determine what incentives are appropriate to their particular situations.

\section{Outreach Activities}

State regulatory agencies should notify the utilities of their interest and of programs to improve productivity. In addition, the following actions are recommended:

(1) All state agencies whose regulations impact on plant productivity should coordinate their actions.

(2) The NARUC Committee on Electricity should appoint a subcommittee on power plant productivity to exchange information and ideas among regulatory commissions.

(3) Communication among utilities and cooperative productivity-enhancing projects should be encouraged and promoted.

(4) Information and education activities should be undertaken between the regulatory agency and the utilities. Special programs might include studies with NRRI, DOE, in-house and in-utility studies, workshops, and publications. 


\section{THIS PAGE}

\section{WAS INTENTIONALLY LEFT BLANK}


REFERENCES

1. ANSI. "Report of the ANSI Steering Committee on Power Plant Data Systems." Publication SR-2l, December 1977 .

2. Balk, W. L., and Schafritz, J. M., Eds. "Public Utility Productivity Management and Measurement." Albany: New York Department of Public Service, 1975.

3. California Energy Resources Conservation and Development Commission. "Power Plant Performance Analysis and Guideline Study." Prepared by System Development Corporation, Santa Monica, California, 1978.

4. Claeson, E. U.; Inouye, S.; and Tully, J. E., Jr. "Standardized Fossil Power Plants--Feasibility, Advantages, Limitations." Proceedings of the American Power Conference, vol. 40, April 1978 .

5. Edison Electric Institute. "Report on Equipment Availability for the Ten-Year Periód 1966-75." Publication no. 76-85, December 1976.

6. EPRI. "Analysis of Utility Industry Data Systems." Prepared by Stone and Webster Engineering Corporation, Final Report, NP-1064, Research Project 771-1, April 1979.

7. EPRI. "Consolidating Power Plant Data Systems." EPRI-NP-836, July 1978.

8. EPRI. "Optimization of Reliability Data Systems." R-P-826, Phase I Report, July 1977.

9. EPRI. "Power Plant Data Systems." EPRI-NP-736, March 1978.

10. EPRI. "Power Plant Early Alert Reporting System." EPRI-NP-988, February 1979.

11. EPRI. "Proceedings EPRI Workshop on Availability Engineering." EPRI-NP-759-WS, 1978.

12. EPRI. "Proceedings: Workshop on Outage Planning." EPRI-WS-77-47, January 1978 .

13. Federal Energy Administration, Office of Fuels and Facilities. "Analysis of Benefits from Improved Productivity of Nuclear and Large Coal Power Plants." April 1976.

14. Federal Energy Administration. "A Report on Improving the Productivity of Electric Power Plants." FEA-263-6, March 1975.

15. Federal Energy Administration. "Summary Report FEA Regional Meeting on Improving Power Plant Productivity." FEA/G-76-272, August 1976.

16. Federal Energy Administration. "Summary Report on Three Power Plant Productivity Studies." FEA/G-76-328, August 1976. 
17. Hefter, C. L., and Bisck, J. M. "Building a Comprehensive Spare Parts Program." proceedings of the American Power Conference, vol. 39, April 1977.

18. Hilles, R. W.; Toth, C. P.; and Koh, B. "Using Nuclear Plant Operating Data to Improve Product Liability." Proceedings of the American Power Conference, vol. 38, April 1976.

19. IEEE, Plant Productivity Task Force, Applications of Probability Methods Subcommittee, Power Systems Engineering Committee. "Definitions for Use in Reporting Electric Generating Unit Reliability, Availability and Productivity." 1979.

20. Keller, Richard W., and Smith, Morton J. "Increasing Power Plant Productivity: A Status Report." Mechanics Research Inc., presented to the American Nuclear Society Winter Meeting, San Francisco, California, November 17, 1975.

21. Lapides, M. E. "Use of Nuclear Plant Operating Experience to Guide Productivity Improvement Programs." Nuclear Power Division, Electric Power Research Institute, EPRI-SR-26, November 1975.

22. Michigan Public Service Commission. "Report on Power Plant Availability." Lansing, Michigan, March 1979.

23. National Association of Regulatory Utility Commissioners. "The Battle to Increase the Capacity Factor of Electric Generation Equipment." Proceedings of the $88 \mathrm{th}$ Annual Convention, 1976.

24. Niebo, R. J. "Power Plant Productivity Trends and Improvement Possibilities." ASME Joint Power Conference, Long Beach, California, September 1977.

25. Niebo, R. J. "Transition of Equipment Availability Data to NERC." 1979 Reliability Conference for the Electric Power Industry, April 19-20, Miami Beach, Florida.

26. Poseidon, C. "Development of Methodologies and Evaluation of the Effects of Load Management and Plant Availability Improvements on the Fuel Cost and Reliability of an Electric Utility System." Ph.D. Dissertation, The Ohio State University, March 1979 .

27. Poseidon, C. et al. "Task 3: Benefits of Specific Productivity Improvements," and "Task 5: Impact of Load Shape Changes to Benefits of Improved productivity." Final Report to the Public Utilities Commission of ohio, The Ohio State University, Nuclear Engineering Program, Department of Mechanical Engineering, June 1979.

28. Public Utilities Commission of Ohio. "Study of the Cost/Benefit of Improved Power Plant Productivity, Task E, Report." Prepared by TRW, Energy Systems Planning Division, McLean, Virginia, June 1979.

29. Regional Seminars on Availability Engineering and Power Plant Productivity Improvement. Sponsored by U.S. Department of Energy, EPRI, NERC, EEI, June 1978 ; workshops, March 1979.

30. Simard, R. L. "An Assessment of Anomalies in the EEI Data Base on Power Plant Performance." Oak Ridge National Laboratory, ORNL/TM-6601, February 1979.

31. U.S. Department of Agriculture, Rural Electrification Administration, Power Supply and Engineering Standards Division. "Preventive Maintenance Management Manual for Fossil Fuel Steam Electric Generating Plants." February 1980.

32. U.S. Department of Energy, Economic Regulatory Administration, Division of Power Supply and Reliability. "Interim Report on the Performance of 400 Megawatt and Larger Nuclear and Coal-Fired Generating Units: Performance through 1975." DOE.ERA-0007, April 1978 . 
33. U.S. Department of Energy, Economic Regulatory Administration, Division of Power Supply and Reliability. "Power Plant Productivity Improvement Study: Summary Report." HCP/B60830-01.

34. U.S. Department of Energy, Economic Regulatory Administration, pivision of Power Supply and Reliability. "Study of Benefits of Improved Power Plant Reliability and Productivity. Phase I Report: Factors Considered in Planning Generation." Prepared by General Electric for DOE, HCP/B60792-01, February 1978.

35. U.S. Department of Energy, Economic Regulatory Administration, Division of Power Supply and Reliability. "Study of Benefits of Improved Power Plant Reliability and Productivity. phase II Report: Analysis of Two Utility Systems and Regions." Prepared by General Electric for DOE, HCP/B60792-02, February 1978.

36. U.S. Department of Energy, Economic Regulatory Administration, Division of Power Supply and Reliability. "Study of Benefits of Improved Power plant Reliability and Productivity. Phase III Report: National Analysis." Prepared by General Electric for DOE, December 1977.

37. U.S. Department of Energy, Federal Electric Utility Program Task Force. "Working Group Report on Improving Base Load Power Plant Performance: Main Report." Prepared by Systems Development Corporation for DOE, January 1978.

38. U.S. Department of Energy, Federal Electric Utility Program Task Force. "Working Group Report on Improving Base Load Power Plant Performance: Appendix G, Data "Availability and Adequacy." Prepared by Systems Development Corporation for DOE, January 1978 .

39. U.S. Department of Energy, Office of Program Control and Support. Fossil Energy Program Summary Document, DOE/ET-0087. March 1979.

40. U.S. Department of Energy, Office of Nuclear Energy Programs. "Light Water Reactor (LWR) Technology Program." March 1979. 
50

THIS PAGE

\section{WAS INTENTIONALLY LEFT BLANK}




\section{CURRENT ACTIVITIES RELATED TO IMPROVED POWER PLANT PRODUCTIVITY IN THE STATE OF CALIFORNIA}

(Power Plant Performance Analysis and Guidelines Study)

\section{A. I Introduction}

Responsibility for regulation of electric utilities is shared in California principally between the Public Utilities Commission and the Energy Commission. Each commission is seeking ways to improve power plant productivity. The following pages outline the most ambitious project to date, the Energy Committee's "Power Plant Performance Analysis and Guidelines study" for use as a part of new power plant applications [23].

One of the responsibilities of the Energy Resources Conservation and Development Commission is to establish minimum standards of reliability and efficiency during its approval for siting new power-generating facilities. The present study was undertaken by the commission in cooperation with the FEA (now DOE) to develop a uniform and systematic approach to the review and evaluation of the performance of new power plants.

The stated purpose and the intent of the "Power Plant Performance Analysis and Guidelines Study" were to accomplish the following: (1) identify power plant performance indices and data sources; (2) tabulate the historical performance of power plants on a national and California basis; (3) assess the impact of plant design and construction procedures, site and regulatory factors, contract procedures, plant operation and maintenance factors, and other factors that affect power plant reliability and efficiency; (4) determine issues that must be addressed by utilities in proposing the most cost-effective levels of reliability and efficiency in power plants; and (5) recommend guidelines and follow-up procedures that might be implemented by the commission to assess and bring about improvements in the performance of new plants.

The scope of the study was extremely broad in that it encompassed (1) assessing national data systems, (2) literature searches, (3) in-depth review and evaluation of the many possible indicators of electrical-generating unit reliability and efficiency, (4) interviews with California utilities, and (5) on-site investigations. In addition, the selection of performance measures had to consider the variability in indicators in terms of direct and indirect impact of operating philosophies, maintenance strategies, design concepts, unit-loading order, regulatory effects, and other categories on the indicator. In this effort, the study concentrated primarily on seven (coal-fired, geothermal, combined cycle, nuclear, oil, gas, and combustion turbines) discrete unit fuel types, five of which were known to be projected for possible siting in the state of California (coal, geothermal, combined cycle, nuclear, and combustion turbine).

The following include additional elements that influenced the scope of this nine-month study: (1) the degree to which historical data accurately reflects common power plant performance indicators; (2) the depth, quality, and availability of 
historical data; and (3) the degree to which the California utilities openly could discuss institutional as well as management and technical factors affecting power plant costs and performance.

The technical approach employed relied heavily on the work of previous researchers, including special studies and data from the Federal Power Commission (FPC), the Federal Energy Administration, and the Electric Power Research Institute. The Edison Electric Institute provided many special analyses of their data for the evaluation of specific unit types and indicators of performance. In addition, five major California utilities were contacted for (1) access to their in-house data systems, (2) interviews with utility and unit personnel on factors and institutional barriers affecting cost-effective levels of reliability and efficiency, (3) review and comment of interim reports and analyses, and (4) their perspective of cost-effective methods of implementation of guidelines.

In section A.2 of this appendix, the results and conclusions from this study are outlined. Recommendations are made for future work in section A. 3 .

\section{A. 2 Results and Conclusions}

This study provides six major results:

(1) Four (4) indices of unit reliability and efficiency for use in the siting proness:

Capacity Factor, Equivalent Availability, Operating Availability, Heat Rate.

(2) A meaningful definition and method of computation of each index.

(3) Recommendations for application of each index during the siting process.

(4) Analysis of historical data to arrive at averages and ranges of averages of the four indices for seven (7) fuel types (coal, nuclear, geothermal, combined cycle, combustion turbine, oil, and gas plants) for use by the commission to assese the level or rangcu of rcliability and cefieiency proposed for new units.

(5) A two-part guideline that presents a standard aqenda of key issues for assessing the optimality and attainability of the reliability and efficiency levels or ranges proposed.

- Impieñentation of the tirst part of the guideline will provide assurance to the commission that levels or ranqes of reliability and efficiency proposed for the new facility are the most cost-effective levels or ranges.

- Implementation of the second part of the guideline will provide assurance to the commission that specific actions will be taken by the applicant to ensure that the levels or ranges of reliability and efficiency proposed will be achieved in accordance with the cost estimates and accounts of the first part of the guideline.

(6) Outline of a monitoring and reporting system to track key elements associated with unit costs, unit operation, and maintenance and utility action to achieve the most cost-effective levels of performance.

The approach to determining a set of indices of power plant reliability and efficiency that would be of greatest use to the Energy Commission in the evaluating of utility "Application for Certification" (AFC) submittals was based upon two separate evaluations; namely, (1) an evaluation of the indicators presently used to assess the 
performance of power plants with special emphasis on plant reliability and efficiency; and (2) identification of indices of reliability and efficiency that could be used for siting decision information requirements.

Historical performance data was formatted and analyzed to arrive at the ranges and averages of the recommended reliability and efficiency indices. The available literature was surveyed along with visits to the participating utilities for face-to-face interviews, and with plant design, construction, operation, and management organization personnel to identify the key issues impacting plant reliability and efficiency.

The recommended indices, their attributes and limitations, and a summary of data are presented in tables A.1, A.2, A.3, and A.4.

The results of the data analysis, shown in tables $A .3$ and $A .4$, present an overview of the historical performance of the indices from a perspective quite different from that which may be achieved by reviewing individual fuel types and size classifications separately. In addition to illustrating the average performance levels, the table identifies the worst level and best level achieved by distinct fuel types and size classes. Since these are all annual averages, they illustrate more than one-time lows or highs and for this reason are believed to represent the feasibility of achieving specific performance levels better.

Virtually all levels are feasible for all plant or fuel types and sizes. The attainability of any level is a function of the deliberate action that a utility takes. These actions encompass the life cycle of the plant and can be summarized under six distinct categories: design, procurement, construction, operation, maintenance, and management organization. The actions that a utility can take under each of these categories are constrained by the requirements of the utility generation system and the cost incurred in implementing each action. For an individual plant, the utility strikes a balance among (1) the energy demand on the units (for example, its loading order), (2) the target level of each index, and (3) the cost of achieving the targets. The historical level actually achieved is the result of trade-offs a utility is required to make amony the above [actors.

The three elements of plant age, plant design, and utility experience influence the achievable levels of each of the four indices. Immaturity in any of these elements can cause significant decreases in capacity factor, equivalent availability, and operating availability or increase in heat rate. A review of the data did not - provide strong evidence that all of these elements had acquired a significant degree of maturity for the historical data to provide significant insight into future utility design or operational processes. Also, expected future design changes such as addition of pollution equipment and compliance with new regulations will influence the achievable levels of reliability and efficiency.

The recommended guideline is issued in two parts. The first part, titled "Establishing the Most Cost-Effective Levels or Ranges of Reliability and Efficiency "for New Power Plants," is to be used for ensuring that the maximum levels of reliability and efficiency that are technically and economically feasible for the operation of a new power-generating unit within the electrical supply system are met. The second part, "Applicant Action to Ensure the Achievement of Established Reliability and Efficiency Levels or Ranges," is to be used to ensure that specific actions will be taken by the applicant to achieve the established cost-effective reliability and efficiency levels.

The establishment of the most cost-effective reliability and efficiency levels requires analysis of the impact of the new unit upon the existing power generation and distribution system. This analysis shall be based upon the applicant's costs of bringing a new power plant on-line, and operating, maintaining, and managing it to achieve the proposed reliability and efficiency levels through the useful life of the new plant. The uncertainties involved in such an analysis shall be specifically discussed by the applicant to assure the commission of its awareness of future technical, environmental, socioeconomic and sociopolitical issues, and the best estimate of their effect on plant life-cycle costs. 
TABLE A.I

RELIABILITY AND. EFFICIENCY INDICES RECOMMENDED IN REF • [3]

CAPACITY FACTOR (CF) = Actual Net Generation

$\because-$

$=\overline{\text { Period Hours } x \text { Design Electrical Rating }}$

, .

OPERATING AVAILABILITY (OA) = $\frac{\text { Service Hours + Reserve Shutdown Hours }}{\text { Period Hours }}$

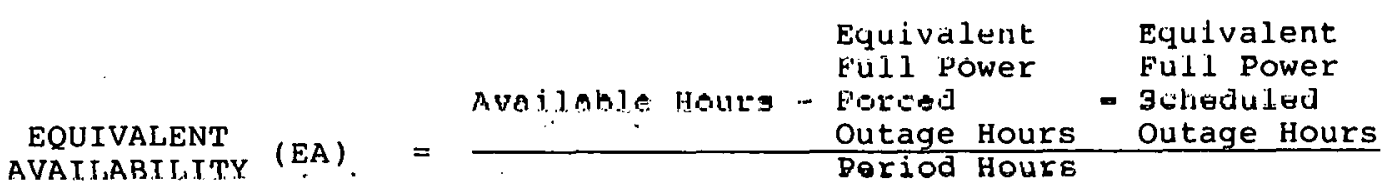

HEAT'RATE (HR) = $\frac{\text { Fuel Bnergy Demand }}{\text { Total Electrical Electric Energy. }}$

Energy Generated - Used by Plant 
TABLE A. 2

ATTRIBUTES AND LIMITATIONS OF INDICES RECOMMENDED IN REF. [3]

\section{Capacity Factor}

\section{Attributes}

- Quantifies production utilization

- Useful for establishing energy planned for distribution

- Provides systematic accounting method of power production

- Useful in evaluating costeffectiveness of proposed facilities

\section{Limitations}

- Inconsistency of historical data base

- Subject to load demand and many other influences

Operating Availability

Attributes

- Establishes production requirement (time)

- Bounds time available for full forced and planned outages

- Provides method for determining effectiveness of programs to control unavailability

- Measure of reliability

\section{Limitations}

- Inconsistency of historical data base

- Power level available upon demand unknown 
TABLE A. 2

ATTRIBUTES AND LIMITATIONS OF INDICES RECOMMENDED IN REF. [3] (continued)

$\checkmark$

Equivalent Availability

\section{Attributes}

- Establishes full power production capabil1ty

- Bounds time available for full and partial outages

- Provides method for determining effectiveness of programs to control outages

- Measures of reliability

\section{Heat Rate}

\section{Attributes}

- Measure of thermodynamic efficiency

- Indicator of cost-effectiveness of alternate fuel types and production rates

- Useful for evaluating loading order

\section{Lillilations}

- Inconsistency of historical data base

- Nut uniformly recoraed fur: individual units

- Measurement accuracy 
TABLE A. 3

SUMMARY OF RELIABILITY INDEX ANALYSIS

\begin{tabular}{|c|c|c|c|c|c|c|c|c|c|}
\hline \multirow[t]{2}{*}{$\begin{array}{l}\text { Unit Size } \\
\text { Type Range } \\
\text { (MW) }\end{array}$} & \multicolumn{3}{|c|}{$\begin{array}{l}\text { Capacity } \\
\text { Factor }\end{array}$} & \multicolumn{3}{|c|}{$\begin{array}{c}\text { Operating } \\
\text { Availability }\end{array}$} & \multicolumn{3}{|c|}{$\begin{array}{c}\text { Equivalent } \\
\text { Availability } \\
\text { Annual Averages }(\&) \text { * }\end{array}$} \\
\hline & LOW & Mean & High & LOW & Mean & High & LOW & Mean & High \\
\hline $\begin{array}{l}\text { Coal } \\
60-89 \\
90-129 \\
130-199 \\
200-389 \\
390-599 \\
600 \& \text { above } \\
600-699 \\
700-799 \\
800-899 \\
900 \& \text { above }\end{array}$ & $\begin{array}{l}60.1 \\
61.0 \\
57.2 \\
63.9 \\
60.8 \\
55.4 \\
56.8 \\
57.8 \\
52.0 \\
48.5 \\
55.4\end{array}$ & $\begin{array}{l}65.5 \\
70.0 \\
63.6 \\
69.6 \\
66.0 \\
60.5 \\
59.8 \\
60.9 \\
60.8 \\
56.4 \\
60.6\end{array}$ & $\begin{array}{l}68.9 \\
73.3 \\
67.5 \\
73.1 \\
69.0 \\
63.2 \\
63.4 \\
65.1 \\
65.9 \\
60.7 \\
66.0\end{array}$ & $\begin{array}{l}79.4 \\
82.7 \\
82.8 \\
82.7 \\
78.4 \\
73.3 \\
72.2 \\
66.3 \\
71.2 \\
53.6 \\
67.2\end{array}$ & $\begin{array}{r}82.4 \\
. \quad 85.2 \\
85.2 \\
85.6 \\
82.5 \\
75.8 \\
73.9 \\
75.8 \\
72.8 \\
70.8 \\
72.8\end{array}$ & $\begin{array}{l}85.4 \\
88.5 \\
87.4 \\
88.6 \\
85.3 \\
79.8 \\
76.0 \\
77.3 \\
73.9 \\
75.7 \\
80.5\end{array}$ & $\begin{array}{l}75.5 \\
79.8 \\
80.4 \\
80.4 \\
74.1 \\
68.3 \\
66.3 \\
63.8 \\
65.3 \\
52.5 \\
56.4\end{array}$ & $\begin{array}{l}79.4 \\
83.5 \\
83.6 \\
83.9 \\
78.8 \\
70.9 \\
67.5 \\
68.0 \\
65.3 \\
62.5 \\
64.5\end{array}$ & $\begin{array}{l}83.3 \\
87.7 \\
86.2 \\
87.4 \\
83.0 \\
75.9 \\
70.1 \\
71.6 \\
66.8 \\
65.9 \\
74.9\end{array}$ \\
\hline $\begin{array}{l}\text { Nuclear } \\
400 \& \text { below } \\
400-499 \\
500-599 \\
600 \& \text { above } \\
600-699 \\
700-799 \\
800-899 \\
900-999 \\
1000 \& \text { above }\end{array}$ & $\begin{array}{l}58.1 \\
53.8 \\
63.3 \\
35.5 \\
54.9 \\
63.3 \\
41.6 \\
39.6 \\
45.7 \\
47.3\end{array}$ & $\begin{array}{l}59.1 \\
57.7 \\
71.8 \\
59.7 \\
58.3 \\
67.0 \\
67.5 \\
54.9 \\
53.1 \\
47.7\end{array}$ & $\begin{array}{l}61.6 \\
61.5 \\
83.6 \\
73.1 \\
72.1 \\
80.8 \\
82.1 \\
59.4 \\
68.0 \\
48.0\end{array}$ & $\begin{array}{l}66.2 \\
63.9 \\
77.1 \\
67.2 \\
64.9 \\
67.8 \\
46.7 \\
58.4 \\
54.2 \\
55.3\end{array}$ & $\begin{array}{l}70.0 \\
70.7 \\
80.2 \\
75.6 \\
67.5 \\
75.3 \\
73.3 \\
66.0 \\
68.9 \\
58.4\end{array}$ & $\begin{array}{l}74.6 \\
74.2 \\
84.6 \\
87.9 \\
74.3 \\
79.9 \\
85.2 \\
70.6 \\
98.4 \\
62.1\end{array}$ & $\begin{array}{l}62.6 \\
59.4 \\
76.0 \\
65.1 \\
57.6 \\
69.4 \\
46.7 \\
43.4 \\
50.3 \\
46.6\end{array}$ & $\begin{array}{l}64.8 \\
61.0 \\
79.3 \\
73.4 \\
61.3 \\
69.9 \\
69.6 \\
59.2 \\
66.3 \\
51.1\end{array}$ & $\begin{array}{l}69.8 \\
62.7 \\
83.4 \\
87.9 \\
67.9 \\
84.1 \\
84.5 \\
65.0 \\
98.4 \\
56.4\end{array}$ \\
\hline $\begin{array}{l}\text { Geothermal } \\
55 \\
110\end{array}$ & $\begin{array}{l}36.8 \\
36.8 \\
68.5\end{array}$ & $\begin{array}{l}74.5 \\
74.8 \\
68.5\end{array}$ & $\begin{array}{l}83.4 \\
85.9 \\
68.5\end{array}$ & $\begin{array}{l}49.0 \\
49.0 \\
75.6\end{array}$ & $\begin{array}{l}83.3 \\
83.6 \\
75.6\end{array}$ & $\begin{array}{l}89.9 \\
91.6 \\
75.6\end{array}$ & $\begin{array}{l}42.5 \\
42.5 \\
69.1\end{array}$ & $\begin{array}{l}76.8 \\
77.1 \\
69.1\end{array}$ & $\begin{array}{l}83.0 \\
85.3 \\
69.1\end{array}$ \\
\hline $\begin{array}{l}\text { Gas Turbine } \\
\text { below } 25 \\
25 \& \text { above }\end{array}$ & $\begin{array}{l}5.5 \\
4.6 \\
7.8\end{array}$ & $\begin{array}{r}9.7 \\
9.4 \\
10.4\end{array}$ & $\begin{array}{l}16.4 \\
17.7 \\
46.1\end{array}$ & $\begin{array}{l}77.9 \\
80.6 \\
70.1\end{array}$ & $\begin{array}{l}81.3 \\
84.4 \\
73.3\end{array}$ & $\begin{array}{l}91.3 \\
92.6 \\
81.4\end{array}$ & $\begin{array}{r}-77.7 \\
80.5 \\
69.5\end{array}$ & $\begin{array}{l}81.2 \\
84.5 \\
73.0\end{array}$ & $\begin{array}{l}91.3 \\
92.6 \\
81.4\end{array}$ \\
\hline
\end{tabular}

*Annual averages over the period 1971-75. 
TABLE A. 4

SIJMMARY OF EFFICTENCY INDEX RESULTS

\begin{tabular}{|c|c|c|c|}
\hline \multirow[t]{2}{*}{$\begin{array}{c}\text { Unit Size Type } \\
\text { Range (MW) }\end{array}$} & \multicolumn{3}{|c|}{$\begin{array}{c}\text { Heat Rate } \\
\text { Annual Averages (Net) }\end{array}$} \\
\hline & LOW & Mean & $\mathrm{High}$ \\
\hline $\begin{array}{l}\text { Coall } \\
60-89 \\
90-129 \\
130-199 \\
200-389 \\
390-599 \\
600 \& \text { above } \\
600-699 \\
700-799 \\
800-899 \\
900 \& \text { above }\end{array}$ & $\begin{array}{r}10168 \\
11490 \\
10723 \\
10206 \\
9951 \\
9739 \\
9584 \\
9788 \\
9520 \\
10190 \\
9267\end{array}$ & $\begin{array}{r}10303 \\
11899 \\
10762 \\
10265 \\
10000 \\
9943 \\
9792 \\
9914 \\
9555 \\
10190 \\
9337\end{array}$ & $\begin{array}{r}10403 \\
121145 \\
10789 \\
10320 \\
10035 \\
9948 \\
9797 \\
10022 \\
9590 \\
10190 \\
9460\end{array}$ \\
\hline $\begin{array}{l}\text { Nuclear } 2 \\
400 \& \text { below } \\
400-499 \\
500-599 \\
600 \& \text { above } \\
800 \& 50 \\
700-799 \\
800-899 \\
900-999 \\
1000 \& \text { above }\end{array}$ & $\begin{array}{r}10897 \\
11239 \\
10517 \\
10452 \\
10400 \\
10988 \\
10699 \\
10376 \\
11593\end{array}$ & $\begin{array}{r}11220 \\
11628 \\
10764 \\
11013 \\
10600 \\
11487 \\
11316 \\
10376 \\
12322\end{array}$ & $\begin{array}{r}11336 \\
12359 \\
10944 \\
11168 \\
10661 \\
12851 \\
11843 \\
10376 \\
14146\end{array}$ \\
\hline $\begin{array}{c}\text { Geotherma } \perp^{3} \\
55 \\
110\end{array}$ & $\begin{array}{l}21989 \\
22128 \\
21156\end{array}$ & $\begin{array}{l}26826 \\
22895 \\
21156\end{array}$ & $\begin{array}{l}26060 \\
25056 \\
21156\end{array}$ \\
\hline $\begin{array}{c}\text { Gas Turbine } \\
\text { below } 25 \\
25 \& \text { above }\end{array}$ & $\begin{array}{l}12328 \\
12328 \\
12356\end{array}$ & $\begin{array}{l}16918 \\
16364 \\
17753\end{array}$ & $\begin{array}{l}23680 \\
23680 \\
22702\end{array}$ \\
\hline
\end{tabular}

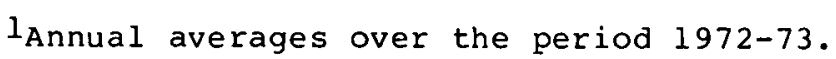

2Annual averages over the period 1971-74.

${ }^{3} 1973$ average.

${ }^{4}$ Annual averages over the period 1971-75. 
For the purpose of this guideline, the proposed reliability and efficiency levels of the new plant shall be cost-effective if the costs of addition of the new plant and its planned operation result in reduced or minimized individual consumer cost.

It is the intent of the recommended guideline that the establishment and subsequent justification of the most cost-effective reliability and efficiency levels or ranges and the utility plan of action to achieve the levels or ranges proposed by the applicant be expressed in, and be measured by the Capacity Factor, Operating Availability, Equivalent Availability, and Heat Rate.

The guideline provides a standard agenda for the applicant and energy commission to assess the cost-effectiveness and attainability of levels of reliability and efficiency proposed by the applicant in the facility-siting process. This is accomplished, in part, in the guidelines by the following:

identifying commission review and acceptance criteria,

identifying key issues to be addressed by the applicant,

identifying methods for use by the applicant for acceptable responses to the guidelines.

The recommended key issues are listed in table A.5. It is recognized that individual applicants, when complying with the requirements, may propose alternates to the recommendations. These alternates need not be consistent with the recommendations of this guideline. It is recommended that the justification for these alternates be reviewed by the energy commission staff and their acceptability be determined on a case-by-case basis during individual AFC submittal reviews. The recommended guidelines, thus, define the items that the utility monitoring and reporting system is required to address. It is recommended that the monitoring and reporting system be applied in a step-by-step time-staged process. It is anticipated that the applicant utility shall define this process. The objective is to brinq new capacity into commercial operation, within the time period available, with minimal impact (cost, manpower, and so forth) upon the applicant utility. The reporting procedures and requirements should be consistent with current Federal Power Commission, California Public Utilities Commission, and so forth, guidelines to minimize the amount of new information generated. The suitability and acceptability of the process shall be judged by the commission and used to develop the regulatory process required to overview the recommended utility monitoring and reporting system.

\section{A. 3 Recommendations for Further Work}

The background, purpose, objectives, range, and results of the "Power Plant Performance Analysis and Guidelines Study" provided the basis for recommendations for further work in the development of improved criteria and guidelines for application in the siting process. The recommendations provided for continuity between the results of this study and their application in the siting process. In particular, these recommendations call for the following: (1) the development of a single performance (cost-effective reliability and efficiency) index; (2) the establishment of a comprehensive data base; (3) the creation of incentives for better utilization of existing resources; (4) the development of methods to quantify the cost-effectiveness of improved productivity; (5) the establishment of a regulatory environment that does not inhibit advances in the state of the art of plant technology and engineering. $A$ brief discussion of each recommendation is listed below.

(1) Recommendation for the Development of a single Performance Index: The four reliability and efficiency indices recommended for use in the siting process were specifically developed to apply at the unit level. The results of this study, however, indicate that decisions with respect to cost-effectiveness of proposed levels and ranges of reliability and efficiency must be made with respect to the performance of the total power generation and supply system, viewed in terms of the needs and demands imposed upon the system. To aid in the assessment of the reliability and efficiency levels that are cost-effective and those which are not, it is recommended 
TABLE A. 5

ILY' I3GUES

\section{objective}

Escablishing móst cost-ettective

levels or ranges of reliability and efficiency.

Applicant actions to ensure the achievement of established reliability and efficiency levels and ranges.
Rernmmented by Issue

1. Validity of the projected impact of the new facility on the system.

2. Optimality of the balance obtained between facility considerations.

1. Adequacy of plant design.

2. Quality of plant construction.

3. Effectiveness of procurement.

4. Emphasis of personnel training and relláininy.

5. Assurance of maintenance effeativencos.

b. Oiyainizallun and plant management. 
that a single index be developed that is sensitive to changes in the power generation ahd supply system (the demands on the system, the manner of meeting the demand) and also to change each and every unit that makes up the system. It is recommended that as far as possible, the single index be comprised of existing system level indices (system heat rate, loss-of-load probability, system load factor, and so forth) and the four recommended unit level indices (capacity factor, operating availability, equivalent availability, and heat rate). The single index should also be considerate of the consumer base that bears the total cost of generating and supplying electric power. It is also recommended that the development of the single index result in the planned conclusion that the numerical value of the index be directly proportional to the cost incurred by each individual customer in the customer base.

(2) Recommendation for the Establishment of a Comprehensive Data Base: Historical performance data are indicative of the reliability and efficiency levels of existing plants. For the commission to base key elements of the siting decision process upon historical performance data, it is necessary that the data be authentic, its proper interpretation be documented, and the data be current, up-to-date, and readily accessible. There are three recommendations to accomplish this: (1) the problems (missing data, unvalidated data, conflicting data, and so forth) with the current data bases be evaluated thoroughly; (2) the manner of data collection and documentation be rigorous to ensure proper interpretation of compiled data; and (3) efforts be directed toward keeping the data base current and up-to-date. The first recommendation may be accomplished by a thorough statistical analysis; the second may be accomplished by collecting and formatting the data with the expected future use in mind; and the third may be accomplished by establishing a continuous data collection program.

(3) Recommendation for the Creation of Incentives for Better Utilization of Existing Resources: The underlying objective of the commission siting decision process is to provide an environment conducive to the best utilization of existing resources. Increase in existing electric plant capacity requires a commitment of increased resources. To ensure that the addition of new capacity to meet increases in energy demand is the proper utilization of the state's finite energy resources, it is recommended that the commission provide incentives either to controi the demand of energy or the manner in which it is supplied. The commission can address two incentive areas that have been identified during the course of this study:

- The consumer should have an incentive either to reduce his total power consumption or to stagger his power utilization to time periods of low demand. The incentive has to be more cost-effective for him to do so. This in turn will help reduce increases in the average and peakload.

- An incentive for the electric power supplied to minimize the need for new generating capacity is that it has to be more cost-effective for him to improve the productivity of his existing generation capacity than to install more new capacity.

Modifying both the demand and supply of electrical power, thus, requires cost incentive for both the consumer and the supplier. A detailed study of rate structures (rate base, allowable rate of return) is recommended to determine how both groups can be accommodated in a cost-effective manner.

(4) Recommendation for the Development of Methods to Quantify the CostEffectiveness of Improved Productivity: This study has defined a commission action or a utility action to be cost-effective if implementation of the action(s) results in either a reduced cost or a minimum increase in cost to the individual customer. The most cost-effective action is one that results in the most reduction or a minimum increase in cost to the individual customers. To ascertain if an action is merely cost-effective or most cost-effective, it is necessary to be able to quantify the cost impact of an action. Also, choosing between alternative courses of action requires a quantitative evaluation of the costs of the alternate course. It is recommended that the commission explore the development of rigorous methods to assess the cost impact of actions. It is recommended that in the early stages of the method development the commission identify its anticipated actions and those of the electric supplier and 
develop rigorous methods to quantify the cost of these actions. It is expected that the method development will entail a study of, among others, the utility rate structure, its costs, and performance.

(5) Recommendation for Establishing an Environment That Does Not Inhibit Advances in the State of the Art of Plant Technology and Engineering: The recommended guidelines have been developed for application by utilities under the jurisdiction of the commission. The guidelines identify the key issues that an applicant for new capacity should address but do not identify the step-by-step procedure to be followed in justifying the need for new capacity, of "the cost-effectiveness of proposed reliability and efficiency levels or ranges for the new unit(s), "or in substantiating that proposed actions will assure the attainment of the proposed reliability and efficiency levels or ranges. This provides the utilities with a forum for presenting new ideas and developments. It is recommended that the form of this guideline and future guidelines be maintained to provide this forum. It is aloo paramount to ensure that in the application of these recommended guidelines and future guidelines by the commission, this forum is not eliminated. 


\author{
APPENDIX B \\ CURRENT ACTIVITIES RELATED TO IMPROVED POWER .PLANT \\ PRODUCTIVITY IN THE STATE OF ILLINOIS
}

\title{
B.I Introduction
}

Historically, the Illinois Commerce Commission took note of power plant productivity when the issue arose on a case-by-case basis. Two instances are cited below as examples, followed by brief descriptions of recent studies and current activities.

In 1976, the commission ordered a management audit of Central Illinois Public Service Company (CIPS) by Ernst and Ernst. One of the major recommendations was to establish a productivity strike force at the CIPS Coffeen Plant. Improved maintenance practices and the setting of availability improvement goals were also encouraged. The report acknowledged the complexity of the problem and the efforts undertaken by the company but stated that the approach has been fragmented and lacked direction and force. The commiceion monitored the activities of CIPS in rarrying nut. the recommendations of Ernst and Ernst.

Power plant productivity was also an issue in a 1976 Iowa-Illinois Gas and Electric (IIGE) rate case. The utility petitioned the commission for a purchased power adjustment clause due to low productivity at the Quad Cities nuclear station. The plant is 25 percent owned by IIGE, and when it is not available, much more expensive purchased power must be obtained. The commission recognized the disincentive effects of such a clause in this case, and the request was denied.

Cases such as these and rapidly rising fuel prices alerted the commission and staff to the growing importance of power plant productivity. In November 1977 , the Illinois Commerce Commission and the U.S. Department of Energy entered into a cooperative agreement to perform a Powerplant Productivity Improvement study in Illinois. The primary focus of the study was on improvements in the availability of existing coal and nuclear baseload units in the state. Subsequently, a second cooperative agreement was signed to perform a Future Powerplant Availability Improvement study that addressed the technical and economic feasibility of obtaining cost-effective levels of power plant reliability at the design stage. In parallel with these studies, an investigation was initiated to identify methods and measures that could be used by the commission to assess utility efficiency or performance in other areas in addition to power plant productivity. Simultaneously, various regulatory incentive mechanisms are being examined that could be adopted by the commission for the purpose of promoting improved utility performance in power plant productivity as well. as in other performance categories. The study of performance measures and incentives is scheduled for completion in December 1980.

In the following sections, the objectives and major tasks of the studies are summarized. 


\section{B.2 Power Plant Productivity Improvement Study}

- Purpose:

Exploration of methods for improving the productivity of baseload-generating units in Illinois.

- Execution Period:

November 1977 to June 1979 .

- Participants:

U.S. Department of Energy (Sponsor)

Illinois Commerce Commission (Cosponsor)

Energy Resources Center, University of Illinois, Chicago

Trident Engineering Associates

Four large electric utilities in Illinois

- Major Tasks:

The study consisted of six major tasks that are outlined below.

Task 1--Cuitenl Ptaclices in Illinois Utilities toward power Plant Productivity

Identification and documentation of approaches and practices of Illinois electric utilities in improving plant productivity. Management philosophy toward productivity, performance measures, analytical tools and procedures, internal organization for productivity, and representative case studies were examined for the four largest investor-owned electric utilities in Illinois.

Task 2--Demonstration of DOE Methodology

The systematic methodology developed by DOE was applied to the analysis of eight plant improvement projects at the Illinois Power wood River 5 coal unit and the Commonwealth Edison Quad Cilies 1 and 2 nuclear units. Estimates of improved unit equivalent availability were calculated for each project.

Task 3--Analysis of Costs and Benefits for Eight Power Plant Proniritivity Improvement Projecte

Estimated improvements in unit equivalent availability from Task 2 above were translated into economic benefits resulting from rediren replarement power costs. Project costs were estimated, and benefit-to-cost ratios and net present values were calculated for each project.

Task 4--Historical Performance of Illinois Investor-owned Electrical-generating Power Plants over $200 \mathrm{MW}$

Equivalent availability of large generating units in Illinois was reported and compared with national performance data.

Task 5--Benefits of Improved Reliability

The procedures developed by General Electric for estimating the potential . benefits of improved productivity were applied to the Commonwealth Edison and Illinois Power systems. Four scenarios of improvements in planned and forced outage rates were examined to determine benefits (exclusive of costs) in terms of savings in generation costs and oil and gas consumption.

'l'ask 6--Policy Analysis and Incentive Assessment

Current regulatory practice in Illinois was examined to identify any existing incentives or disincentives to the undertaking of plant improvement projects 
by electric utilities. Other state public utility commissions were contacted to determine their experiences with productivity improvement incentives, and candidate incentive mechanisms were identified and analyzed.

- Summary of Key Findings and Conclusions.

1. The historic performance (equivalent availability) of large generating units in Illinois is below national average performance. Some units and some companies perform above national averages however.

2. Cost-effective opportunities to improve performance exist, and utilities pursue many of these.

3. There are no strong regulatory disincentives to the undertaking of productivity improvement projects, but no strong incentives either.

4. Current utility practices, procedures, and management philosophy toward improved productivity are being strengthened.

5. Areas in which immediate attention is warranted include application of reliability-engineering tools to the analysis of power plant availability and more vigorous pursuit of opportunities for performance improvements.

6. The U.S. Department of Energy systematic methodology for the analysis of productivity improvement projects was demonstrated at three units in Illinois and found to be a useful approach.

7. The potential for improved productivity was estimated by Commonwealth Edison and Illinois Power to be on the order of 2 percent points in planned and forced outage rates. If Illinois utilities attained national average performance, the potential would be closer to 5-percent-points.

8. If a 5-percent-point improvement is obtained, cumulative (through 1990) constant dollar benefits would be approximately $\$ 500$ million. Cumulative oil savings could equal the total consumption of oil in Illinois in 1974 . Benefits for a 2-percent-point improvement would be proportionally less.

9. Based on a survey of state public utility commissions, it was determined that "formula" regulation incentive mechanisms are presently in a developmental or experimental phase. Results of these activities should be monitored closely, but adoption by the state of Illinois does not appear warranted at this time.

10. The Illinois Commerce Commission can encourage improved power plant productivity by explicitly considering recent unit performance during normal rate case proceedings.

\section{B. 3 Future Power Plant Availability Improvement Study}

- Purpose:

Examination of the technical and economic feasibility of incorporating high levels of reliability in new unit designs and analysis of regulatory policies to promote cost-effective utility investments in new unit availability.

- Execution Period:

November 1978 to September 1980 .

- Participants:

U.S. Department of Energy (Sponsor)

Illinois Commerce Commission (Cosponsor)

Energy Resource Center, University of Illinois, Chicago

Commonwealth Edison Company 
- Major Tasks:

Task 1--Determine Impact of Current Policies

The objective of this task is to document and assess current Illinois

Commerce Commission and utility practices concerning reliability planning for future units, land to identify any existing incentives, and/or disincentives and their mode of operation.

Task 2--Determine Potential Uses of Existing Mechanisms

Under this task, there were a number of candidate actions that the Illinois Commerce Commission could implement through the existing regulatory framework and that would have a positive impact on the reliability of future generating units.

\section{'lask 3--Development of New Mechanisms}

The objective of this task is to develop candidate regulatory policies, procedures, and practices that will promote cost-effective levels of reliability for future generating units. These candidate policies could fall outside the traditional regulatory approaches.

Task 4--Assess Engineering and Economic Potential for Improving Reliability of Future Generating Units

The objective of this task is to provide information on the cost-effective levels of new unit reliability that are available to utilities in the design and selection process.

Preparation of the final report on this study is now in progress. 


\author{
APPENDIX C \\ CURRENT ACTIVITIES RELATED TO IMPROVED POWER PLANT \\ PRODUCTIVITY IN THE STATE OF MICHIGAN

\section{I Introduction}

The following is a short summary of programs and activities that the Michigan Public Service Commission and its staff are pursuing in order to improve power plant availability in Michigan. Included are the original Availability Incentive Provision, Proposed Modifications to the Original Availability Incentive provision, and the Power. Plant Availability Project.

\title{
C. 2 The Original Availability Incentive Provision
}

In its option for Case U-5108, dated May 27, 1977, and Case U-5331 dated July 31, 1978, the Michigan Public Service Commission established system availability incentive provisions for the Detroit Edison Company and Consumers Power Company, respectively. l'he incentlve provistun dlluws edcl vilipainy lo adjust its rate of return on oommon equity according to the scale listed in table C.l.

The Detroit Edison Company's total system annual availability was to be calculated using the East Central Area Reliability (ECAR) method, and to file testimony and exhibits supporting this computation during the first week of April for the preceding calendar year filed. Consumers Power was required to furnish a similar computation and supporting evidence during the first week of May for the preceding calendar yeaṛ.

TABLE C.I

THE ORIGINAL SCALE OF AVAILABILITY ADJUSTMENT

System Availability (ECAR)

$$
\begin{aligned}
100.08 & =85.18 \\
85.08 & =80.18 \\
80.08 & =70.18 \\
70.08 & =08
\end{aligned}
$$

\section{Common Equity Adjustment}

$$
\begin{array}{r}
+.508 \\
+.258 \\
08 \\
-.258
\end{array}
$$

\section{C.3 Proposed Modification to the Original system Availability Incentive Provision}

In Detroit Edison's Case No. U-6006 and Consumers Power's Case No. U-5979, the staff of the Michigan Public Service Commission proposed to modify the original System Availability Incentive Provision by expanding both the system availability (ECAR) and common equity adjustment ranges. One advantage of this modification is that it provides a more continuous incentive to increase system availability once the 
80.1 percent availability is obtained. It also reduces the neutral zone from 10 percent to 6 percent and encourages operation of the generating system in a higher availability range. The net effect of this modification is to provide smaller incremental incentives for smaller incremental changes in system availability. The proposed expanded scale of availability adjustment is listed in table C.2.

TABLE C. 2

THE PROPOSED EXPANDED SCALE OF AVAILABILITY ADJUSTMENT

System Availability (ECAR)

$1008-85.018$
$85.008-83.768$
$83.758-82.518$
$82.508-81.268$
$81.258-80.018$
$80.008-74.018$
$74.008-73.018$
$73.008-72.018$
$72.008-71.018$
$71.008-70.018$
$70.008-0$

Common Equity Adjustment

$$
\begin{gathered}
+.508 \\
+.408 \\
+.308 \\
+.208 \\
+.108 \\
0 \\
-.058 \\
-.108 \\
-.158 \\
-.208 \\
-.258
\end{gathered}
$$

A second modification is the inclusion of a projected nominal periodic or scheduled maintenance factor in the determination of the ECAR availability scale. For a given year, system performance would then be determined by adding the actual system periodic or scheduled maintenance factor to the system ECAR availability as is currently computed. By using this summation as the measure of system performance, the potential to manipulate the amount of periodic or scheduled maintenance to achieve the incentive is eliminated. System performance can only be improved by reducing random outages. The current scale of availability adjustment, including the periodic maintenance factor, and the proposed expanded scale, including periodic maintenance factor, are listed in tables C. 3 and C. 4 .

The Michigan Public Service Commission, on March 14, 1980, in Detroit Edison's Case No. U-6006, ordered a revision of the original system Availability Incentive. The revision reflects both proposed staff modifications, namely, expansion of the System Availability (ECAR) and common equity adjustment ranges and inclusion of the periodic maintenance factor as depicted in table C. 4.

\section{4 The Power plant Avallab1l1ty Project}

The purpose of the Power Plant Availability Project is to develop regulatory techniques to improve power plant availability. The goals of the project are as follows: (1) establish baseline data on the performance of power plants in Michigan; (2) evaluate the current production maintenance process for Detroit Edison and Consumers Power; (3) evaluate the Michigan Public Service Commission's present regulatory policies and techniques as they impact power plant productivity; (4) analyze the impact of major productivity improvement projects for large baseload power plants in Michigan; and (5) develop recommendations for improvement in present regulatory policies and techniques and develop new regulatory policies and techniques that could be implemented by the Michigan Public Service Commission to improve power plant availability. 
TABLE C. 3

ORIGINAL SCALE OF AVAILABILITY ADJUSTMENT INCLUDING PERIODIC MAINTENANCE FACTOR

System Availability (ECAR)

Plus Periodic Factor

$$
\begin{aligned}
1008 & -92.18 \\
92.08 & -87.18 \\
87.08 & =77.18 \\
77.18 & -U
\end{aligned}
$$

\section{Equity Return Incentive}

$$
\begin{gathered}
+.508 \\
+.258 \\
0 \\
-.258
\end{gathered}
$$

TABLE C. 4

THE PROPOSED EXPANDED SCALE OF AVAILABILITY ADJUSTMENT INCLUDING PERIODIC MAINTENANCE FACTOR

System Availability (ECAR) Plus Periodic Factor

Equity Return Incentive

$$
\begin{gathered}
1008-92.018 \\
92.008-90.768 \\
90.758-89.518 \\
89.508-88.268 \\
88.258-87.018 \\
87.008-81.018 \\
81.008-80.018 \\
80.008-79.018 \\
79.008-78.018 \\
78.008-77.018 \\
77.008-0
\end{gathered}
$$

$$
\begin{array}{r}
+.508 \\
+.408 \\
+.308 \\
+.208 \\
+.108 \\
0 \\
-.058 \\
-.108 \\
-.158 \\
-.208 \\
-.258
\end{array}
$$


C. 5 The Report on Power Plant Availability

On December 1, 1977, the Executive Management Committee of the Michigan Public Service Commission formed an Availability Task Force composed of commission staff members to initiate a study to determine the causes and impacts of the general decline in power plant availability [22].

The study was issued in March 1979 and has addressed the advantages of high-system availability, how availability is measured, the availability trends experienced by Consumers Power and Detroit Edison since 1970, and the identification of key factors and constraints that affect availability. These factors and constraints include the following: increasing system age, lower operating and availabilities of new units, declining coal quality, environmental equipment modifications, nuclear refueling, governmental warranty and insurance requirements, statistical-reporting improvements, maintenance constraints, spare parts, shape of the load curve, and the impact of regulation.

The study also incluaes a review of the production maintenance process of both Consumers Power and Detroit Edison focusing on organization, scheduling techniques, budgeting., and spare-parts philosophies.

The general findings of the study are summarized below.

Michigan's two major electric utilities have experienced a general decline in power plant availability for the greater part of this decade. The term "availability" is defined as the means of having some resource accessible, obtainable, ready for use, or at one's disposal. When used by the electric utility industry, availability refers to the status of any generating unit or piece of equipment within a specific system.

During this decade, Consumers Power and Detroit Edison experienced highest system. equivalent availabilities of 80.5 percent and 83.6 percent in 1970 . For this same period, system equivalent availabilities hit lows of 70.0 percent for Consumers Power in 1974 and 66.7 percent for Detroit Edison in 1975. In response to this decline, both companies began accelerated preventive maintenance programs, and as a result, each company improved its system equivalent availability to slightly over 74 pereent in 1977.

The primary cause of this decline, at least on a statistical basis, was a steady increase in the number of random mechanical failures occurring within each system. There are numerous reasons for this increase, many of which are complex and interrelated.

One reason is the increasing age of existing generating units within the system. As is true with any mechanical device, the older a unit gets and the more it is used, the more prone it is to wearing out or breaking down. Further complicating this situation is the fact that most mature coal-fired-generating units are burning coal with different characteristics than that which they were designed to burn. This situation can be attributed primarily to environmental restrictions on sulfur dioxide emissions and the declining quality of coal burned by utilities in this country. Another factor is environmental equipment modifications that were mandated by the imposition of strict environmental requirements. The additions or modifications to existing plants rarely result in improved capability and, in most cases, cause. increases in station power use and losses in overall plant efficiency. Adding equipment to an already functional unit increases the complexity of its operation and the probability that something can malfunction and force the unit out of service.

New units are not immune to this trend of lower availability. These units are usually more complex in design, physically larger, and subject to more severe operating stresses than smaller and older units. As a result, they tend to incur a higher incidence of random outages and require more maintenance time than smaller units of equivalent age. An extensive preventive maintenance program is utilized by both utilities in an attempt to reduce random outage occurrences and improve system availability. For a preventive maintenance program to be effective, a utility must have sufficient time as well as adequate financial resources to perform maintenance. 
In addition, the existence of adequate spare-parts resources is also necessary to maintain and improve power plant availability. In periods of reduced or insufficient revenue, production maintenance expenditures are usually reduced thus almost surely resulting in an increase in system random outages.

Over the past three years, production maintenance expenses have increased for Consumers Power and Detroit Edison. Inflation aside, the increase is the result of an attempt by both companies to reverse the trend of falling availability and make up for maintenance projects that were postponed or deferred because of earnings and cash-filow problems in the first half of this decade.

The responsibility for improving the availability of electric power plants lies with the utility management, but regulatory bodies must allow for the necessary financial requirements. Both are concerned with providing the consumer with an adequate and reliable source of electricity at the lowest possible cost. It is evident that a high level of power plant availability is a necessary ingredient in the fulfillment of these concerns. 
12

THIS PAGE

\section{WAS INTENTIONALLY \\ LEFT BLANK}




\title{
APPENDIX D
}

\author{
CURRENT ACTIVITIES RELATED TO IMPROVED POWER PLANT \\ PRODUCTIVITY IN THE STATE OF NEW YORK
}

\section{1 Introduction}

New York State utilities presently consume close to $90 \mathrm{million}$ barrels of oil annually in the generation of power. At this rate of consumption, coupled with the Organization of Petroleum Exporting Countries' (OPEC) continual escalation of oil prices, the annual fuel cost to the ratepayer from oil-fired generation will eclipse the $\$ 2$ billion mark soon.

In addition to costs, the state of New York is vulnerable to the political vagaries of OPEC that would result in supply interruptions similar to those experienced during the 1973-74 oil embargo. The state's dependence on oil, in terms of generation capability and energy production, are 59 percent and 43 percent.

To reduce this dependence, the state of New York must increase its use of nonoil power generation sources. Reclaimed and small hydrogeneration may help; however, much has to be done to reconcile the economic realities with state potential. Cogeneration schemes explored to date, while utilizing oil more efficiently, are still related.to the continued dependence on oil. Fuel cells are also efficient but like cogeneration are linked to oil or natural gas.

The obvious solution is to install additional coal and nuclear generation as quickly as possible. The present generation mix for New York state shows approximately $3,5.00 \mathrm{MW}$ of coal and $3,600 \mathrm{MW}$ of nuclear generation installed with 2,000 $\mathrm{MW}$ of nuclear generation under construction and 3,250 MW of coal and 7,200 MW of nuclear generation planned in the next 15 years. Thus, the potential savings of oil for New York state utilities are tremendous, both in the near term and the future. The magnitude of these oil savings is highly dependent on the productivity of the nuclear and coal units in operation, under construction, and planned for New York state. In the near term, it is estimated that a 10 percent improvement in capacity factor for the existing coal and nuclear units in New York state could save the United states over $10 \mathrm{million}$ bbl. of oil annually.

The New York Department of Public Service has been dedicated to power plant productivity improvement for some time as indicated in section D. 2 on our capabilities and commitment. The commission staff is of the opinion that power plant productivity can be improved and has set up a separate analysis and engineering group responsible for the achievement of this goal. The United States Department of Energy is funding a portion of this group's start-up costs through their Power Plant Productivity Improvement Program.

The Department of Public Service also believes that the initial analysis of productivity and the setting of goals is not enough, and that continued follow-up and monitoring of utility practices affecting productivity will be required. To accomplish this, the commission has established a compliance and monitoring section that will have this responsibility as part of its overall charge. 
D. 2 State of New York Department of Public Service Existing Procedures Related to Power Plant Productivity Improvement

For the past eight years, it has been the policy of the Department of Public Service to hire technically qualified people in its Power Division/System Planning Section with specialized skills in the area of power plant equipment design, operation and maintenance, as well as people with experience in electric utility system planning and engineering economics. Most of the engineers in the Power Division/System Planning section have come to the department from electric utilities, architect-engineering companies, and manufacturers. The Department of Public Service's capability and commitment to improved power plant productivity can be demonstrated by a summary review of the following commission procedures:

(1) Case 26937--Proceeding on motion of the commission as to the plans and procedures of Electric Corporations for load shedaing in times of cmergency.

(2) Casc 27123--ordẹ institutinq Proceedinq to investigate the prolongen nutage of Indian Point No. 2 Nuclear Generating Plant.

(3) Case 27137--order establishing generic proceedings to investigate fuel adjustment clauses of electric utilities (issued February 1977).

(4) Case 8ưử--l'estimony of Ur. Martin Becker in the proposed siting of two $1150 \mathrm{MW}$ Nuclear Units at Jamesport, Long Island.

(5) Case 80003--Testimony of John H. Koubek in the proposed siting of two 1150 MW Nuclear Units at Jamesport, Long Island.

In Case 26937, the Department's Power Division/System Planning Section staff made a thorough survey and analysis of all the New York utilities' maintenance organization and procedures. Maintenance questionnaires were sent out to each utility followed up by field trips and meetings with the utility's maintenance managers and supervisory personnel. The result of this analysis was a commission order requiring Consolidated Edison to put a more comprehensive preventive maintenance program into effect.

Case 27123 was concerned with determining if Consolidated Edison Company of New York, Inc.'s (Con Edison) fuel adjustment account should be adjusted as a consequence of a prolonged refueling outage of Indian Point No. 2 in 1976. In this proceeding, staff presented a detailed analysis of 12 tasks where delays were encountered and sought to establish that the outage was needlessly delayed by 60.5 days. Staff not only made an analysis of these 12 tasks but evaluated the organizational and planning mechanisms of the refueling outage.

The State of New York Public Service Commission concluded that the refueling shutdown was extended unnecessarily for at least 54 days within the company's control and that the "avoidable delay" had cost Con Edison's customers some $\$ 15 \mathrm{mill}$ ion in higher fuel costs.

In Case 27137, the Power Division/Rates and Valuation Section is involved in a generic evaluation of the entire concept of fuel adjustment clause. A facet of this case involves the incentives a utility has for achieving high productivity of low-fuel-cost coal and nuclear-generating units.

The commission staff is also in a unique position in that it is charged with evaluating the engineering and design characteristics of proposed generating units for New York State. This responsibility comes from Article VIII of the Public Service Law that makes the Department of Public Service the lead agency for evaluating power-plant-siting applications.

In Article VIII cases, the Power Division/System Planning Section has developed considerable testimony on projecting nuclear and coal generation productivity and hac 
explored root causes of failure and their contribution to reduced productivity. Staff has also cross-examined the utilities' witnesses with regard to selection of vendors, component materials (titanium versus copper-based condenser tubes), cycle selection (supercritical versus subcritical), number of feedwater heaters, selection of turbine back ends for efficiency consideration, and so forth.

\section{3 Power Plant Productivity Improvement Program}

\section{3.1 General}

The Department of Public service has established a working group consisting of the project team (Department of Public Service staff and consultants) and key individuals from each major utility in the state (the Power Authority of the state of New York has been invited to participate even though the Department of Public Service has no regulatory jurisdiction over it). This working group serves as a vehicle for obtaining information as well as for discussing and evaluating information obtained and suggestions made for future improved procedures and productivity. It is expected that if found effective, this working group will be maintained in the future. The following is a list of specific tasks contained in the United states Department of Energy and the State of New York Department of Public Service cosponsored Power Plant Productivity Improvement Program.

\section{3.2 Task 1--Power Plant Outage Events and Performance}

\section{Task 1A--Outage Event Data Analysis}

With the assistance of the working group, data for individual units have been, are being, and will be obtained in suggested categories (planned, maintenance, forced, and partial outages) from individual utilities, the Edison Electric Institute (EEI), the Electric Power Research Institute (EPRI), the United States Department of Energy (DOE), the New York Power Pool (NYPP), the United States Nuclear Regulatory Commission (NRC), and so forth. In addition, attention is given, to potential subtleties, for example, the degree to which maintenance outages extend beyond a weekend (or off-peak time) to a tille when reserve requirements are affected.

With respect to partial outages, attention is given to identification of extended basic problems such as regulatory (as experienced with early operation of some nuclear units) and design (as experienced with some supercritical coal units). In other words, effort is devoted to distinguish basic, generic problems from random malfunction problems and to avoid masking singular effects in the data categorized by utility, fuel type, and plant size.

The above data are compiled and aggregated by the following categories:

(i) individual utility

(ii) unit type--Nuclear: Pressurized or Boiling Water Reactor Coal: $\quad$ Supercritical, drum type

(iii) fuel type: that is, coal and nuclear

(iv) coal characteristics: sulfur and ash content

(v) plant size: that is, 0-400 MW, 401-800 MW, $801 \mathrm{MW}$ and up

(vi.) contributions of individual components to performance indices: that is turbine, boiler, recirculation pump

In addition to gathering the statistical data, the working group reviews maintenance and outage practices at similar plants. Where differences are observed, reasons behind alternate procedures will be examined to determine if these may lead to improved procedures at other stations (see Task 3). 
Task 1B--Performance Data Analysis

In addition to the four indices cited (equivalent availability, availability factor, capacity factor, forced outage rate) to be given in the categories requested, effort is made to distinguish the singular effects noted in Task lA from the general, random failures.

The Department of Public Service personnel and their consultants perform component root-cause analysis for each outage or derating of each unit involved in this program. This detailed root-cause analysis focuses on causes and solutions of outages or deratings, similar outages or deratings at other plants, corrective actions by individual utilities, procedures and policies of each utility to prevent outages or deratings, and so forth. The depth of this root-cause analysis will depend upon actual available information from the operating, maintenance, and engineering personnel of each utility.

\section{3.3 Task 2--Costs and Other Impacts Associated with Outage/Derating Events}

Task 2Ä-Utility Response to Outage/Derating Events

The working group reviews procedures for responding to outages/deratings of units at several utilities. Attention is given to variations in these responses as a function of time of day, time of year, and so forth, and to differences between "average" response and response at crucial times.

In addition, the working group reviews procedures for deciding on scheduling maintenance outages. This is deemed to be important because maintenance outages could result in avoiding major problems later, but excessive conservatism could lead to excessive downtime. In effect, utility response to instrumentation signals may be as important as utility response to actual outages once they occur.

Task 2B--Short-Term Cost Impacts

The working group performs cost-benefit analyses of power replacement of each outage considering the following alternatives:

(i) purchase of contingency power

(ii) use spinning vestive

(iii) increased output of operating plants that are not fully loaded to maintain reserve requirement

(iv) brinqinq oil-fired units on-line for the duration of the nutages tn maintain reserve equipment

(v) increase system reserve margins by adding new generation (long-range planning)

(vi) increase interconnection capacity by adding new transmission line (long-range planning)

(vii) increase purchase power commitments from out of state.

The above cost will include capital cost, operation and maintenance cost, interest, escalation, and fuel differential cost, in terms of $\$ / \mathrm{kW}$ and/or $\$ / \mathrm{kWh}$.

Task 2C--Long-Term Impacts on Consumer Costs, Oil Consumption, Capacity, and Capital Requirements

Long-term impacts will relate to alternate assumptions about system expansion. If expansion is to minimize additional capacity, subject to maintaining reliability, 
then the major impact may be in the requirements for additional capacity. If expansion is to reduce oil consumption, then the major impact may be on the degree to which oil consumption is actually reduced. Subtleties that have to be addressed exist in this area.

\section{D.3.4 Task 3--Documentation and Development of Regulatory Policies and} Procedures

Task 3A--Impact of Current Policies

Current regulation is not conducive to providing incentives for improving power plant operation. A high level of inflation makes rate revision almost an annual affair for most utilities; revenues are continuously matched to expenses thus removing from the utility any productivity benefits achieved through plant operation. Conversely, the utility is also not penalized for poor operation. Fuel adjustment clauses, such as the standard adopted by this state, tend to aggravate the situation by flowing through to the ratepayer any gain or loss of productivity of power plant operation on a monthly basis. The condition is somewhat alleviated by permitting the full cost of economy power in the average fuel cost consumption; buyers break even while sellers realize a markup over fuel costs. Thus, full operation of nuclear and coal-fired plants tends to be encouraged.

Applicability of the fuel adjustment clause does tend to lessen the urgency of restoring a generating unit to service from an outage, forced or scheduled, since there is no penalty of unrecovered energy costs and an opportunity to avoid overtime charges. The alleviation of this urgency is not necessarily undesirable; it may well promote more thorough maintenance and improve reliability.

Task 3B--Potential Uses of Existing Mechanisms

The commission is concerned that the automatic flow-through of fuel costs does not tend to promote improvement of generation productivity and has instituted a generic proceeding to explore the various aspects of fuel adjustment clauses including the folluwing:

1. whether there is a need for a mechanism within the fuel adjustment clause to encourage optimum availability, utilization and efficiency of production facilities, including the question of whether the cost of unnecessarily prolonged outages of generating units should be shared between stockholders and ratepayers;

2. whether existing fuel adjustment clause procedures provide an adequate incentive for utilities to seek the lowest prices for the fuel they purchase; and

3. whether the existing fuel adjustment clause should be modified in view of the emergence of rates based on marginal running costs.

Task 3C--Development of New Mechanisms

1. Identification of Physical options. Considerable emphasis will be placed on physical options, technical and procedural, in recognition of the fact that an outage results from a physical failure or required physical maintenance of certain equipment and that an outage can be extended if the physical procedures followed are inefficient or ineffective. The mechanism of the working group will be utilized to enhance cognizance among all utilities of means available for improvement in productivity.

a. From the comparisons of procedures followed in similar facilities (Task 1), suggestions may arise for productivity improvement.

b. Specific choices will be postulated for evaluation. Some options below for pressurized water reactors are illustrative. 
Should pump seals be replaced at refueling outages, as a precaution (at significant expense), even though no defect is observed, to avoid pump seal failure outages?

Should investment be made to install demineralization equipment for the secondary water system for plants not so equipped to provide long-term steam generator protection?

Should procedures be instituted to provide effective blanketing during refueling of moisture separator reheaters to avoid corrosion problems?

Should water chemistry specifications be followed very strictly, that is, shutdown if any specification is exceeded for any significant period of time?

Should fuel-cycle length be extended to improve average capacity factor, consistent with sound malntenance jiacilice?

2. Target Performance Levels--Rewards and Penalties. This is an area that is very important but that also requires great care to avoid oversimplification. Simple numerical criteria on availability probably would not be adequate. A particular concern is that inappropriate criteria could lead to actions that are penny-wise and pound-foolish. Staff and consultant reviews of power plant reliability, to date, have provided evidence that some major problems were caused or exacerbated by lack of prompt response to trouble signals. Accepting an outage immediately may prevent a more serious outage later. A numerical index in rate setting may encourage the utility to delay maintenance that really should be done immediately until the next planned outage and take its chances for the future. Accepting an outage of increased length in order to make equipment modifications designed to reduce future outages should, also, not absolutely be discouraged.

One of the challenges of this project is to devise incentive mechanisms that do not turn out to be counterproductive and do not, on the other hand, turn out to be totally subjective. Setting performance standards and requiring reporting to the Department of Public Service for evaluation of outages specifically identifiable as precautionary for discounting from the performance standard may constitute a fruitful approach.

3. Rewards and Penalties and Their Impacts. The mechanisms for setting rewards and penalties must be examined carefully to recognize subtlc implications. possibilities that exist include adjustment of the rate of return a utility receives during a rate hearing and adjustment of its fuel adjustment clause.

Rewards and penalties should be meaningful to the utility, but penalties should not be sufficiently severe that they impact adversely on the filldicial slarling of the company, increasing interest rates and providing penalties to the customer. Fuel adjustment penalties may have the disadvantage of being applied coincidentally with an adverse cash-flow situation occasioned by an outage, while a rate-of-return penalty has the disadvantage of being delayed. Rate of return appears to be an easier mechanism on the reward side.

Consideration also must be given to the criteria for the selection of base data points against which actual productivity is judged for the purpose of imposing rewards and penalties - national averages, best-run utilities, and so forth. Another question is whether these norms should be fixed or moving targets, for example, whether a level of performance to be rewarded in 1980 should be considered simply acceptable by 1985 . 
APPENDIX E

CURRENT ACTIVITIES RELATED TO IMPROVED POWER PLANT PRODUCTIVITY IN THE STATE OF NORTH CAROLINA

(Description of North Carolina Power Plant Performance Evaluation Mechanism)

The electric power companies in North Carolina are authorized by the North Carolina General statutes and by the rule of the North Carolina Utilities Commission to seek periodic rate adjustments based solely upon the increased cost of fuel. During such periodic fuel adjustment hearings in 1977 for three major electric power companies, the public staff recommended a modification in the method used to determine periodic adjustments to fuel charges. In essence, the modification introduced the concept of generating plant performance as one of the factors in determining an appropriate fuel charge adjustment.

Fuel costs vary from month to month as a function of three basic components: procured fuel costs, the efficiency of units (heat rate), and plant performance (generation mix).. Currently used procedures were adequate to allow the commission to monitor the first two of these components. However, the original procedures did not adequately monitor changes in fuel costs resulting from changes in generation mix arising from poor individual plant performance.

Generation mix refers to the proportionate utilization of the coal, oil, and nuclear plants (hydro is minimal) on the system that provides the total generation. These three types of plants have different fuel costs; and consequently, the burned cost of fuel at any given time will depend on which plants are being used to produce power. Nuclear plants are the most expensive to install, but once built, they are the least expensive to operate. Large baseload coal plants are the next most expensive to install and the next least expensive to operate. Nuclear fuel costs considerably less than coal or oil; and therefore, the more total kWhs produced by nuclear plants, the lower the total system fuel costs. Due to the high cost of building nuclear plants and due to their low-fuel costs, the efficient dispatch of power requires that nuclear plants run at all times consistent with sound safety and operational practices. When available, large nuclear plants are normally run 24 hours a day at the upward founds of their capacity. For that reason, they are generally referred to as "baseloaded" plants. Similarly, each utility presently has one or more large coal-fired units that are normally operated as baseloaded plants. However, due to their lower capacity costs and operational considerations, these baseloaded fossil plants may also be flexibly operated to carry intermediate loads from time to time.

When a nuclear plant suffers an outage, the kWhs it would have produced must be replaced by coal-fired or oil-fired units that have fuel costs considerably greater than nuclear units. During certain past periods when fuel prices have been relatively stable, fluctuations in monthly fuel adjustment charges have been due, primarily, to such changes in generation mix.

The previously used fuel formula and procedures largely provided financial insulation for the companies against changes in generation mix. If a large nuclear 
unit was out for six weeks during a peak season, the required supply of electricity would typically be provided by a coal-fired unit. The company simply burned more coal, and the increased cost was passed to the consumers in the form of an increased fuel surcharge.

Other than the incentive to do a good job in the face of regulation and audits by regulatory bodies, together with the lag that normally delayed fuel cost recovery, the companies had little financial incentive to guarantee that generation mix was at all times the most economical possible.

The public staff proposed that the commission adopt a procedure that would establish an automatic evaluation of power plant performance so that only fuel costs resulting from "acceptable" performance would be charged through the fuel factor, but that costs resulting from "substandard" operation could be passed along only with specific commission approval. Essentially, the public staff recommended a procedure whereby the companies would be expected to operate their baseload plants, both fossil and nuclear, at predetermined minimum capacity factors. If the companies failed to achieve the minimum factors, then these capacity factors would be reformulated into a Euel adjustment recovery formula, unless the companies could present evidence sufficient to convince the commission to allow the full recovery of expenses.

The companies opposen the public etaff proposal on groulids lliat lite peopused formula contained an unwarranted presumption of mismanagement; usurped management's prevogative to make decisions, created operating disincentives, placed too much reliance on capacity factors as valid measures of efficiency, created unmanageable regulatory requirements, and alarmed investors.

The commission decided that its current review procedures should include a means to provide additional incentives for better plant performance. Simply stated, the commission believes that even the best management is subject to being less diligent in saving costs if automatically shielded from any mistakes that might be made.

The commission decided that its current review procedures and evaluation should continue for the purpose of monitoring all those fuel costs that were attributable to factors other than plant performance, and that an additional procedure providing for hearings and review of plant performance should be instituted on a semiannual basis. The commission decided that an effective procedure for review should forus on the establishment of a commission objective for plant performance, and that a detailed revlew should be mandated semiannually only for a company that fails to meet this objective. The objective serves two purposes: (1) it serves notice to the companies of the commission's expectations for plant performance under normally expected operating conditions; and (2) it serves as a trigger, or flag, for review. Such a procedure gives the companies a continuing incentive to ensure that their plant performance is maintained at a high level. The commission made it clear that no presumption of inadequate performance would arise from a failure to achieve the objective. The objective established serves only as a flag that further investigation is necessary, and any findings of inadequate performance must be based on evidence given at a hearing.

The commission also concluded that the companies can be reasonably expected to seek, as an objective, to operate baseloaded nuclear plants at a minimum 60 percent capacity factor on a systemwide basis. The commission concluded that this objective is reasonable and attainable in that 60 percent is near the nationwide average capacity factor for nuclear plants.

The commission chose to limit the capacity factor objective that triggers examination to baseloaded nuclear plants, because it is convinced that for the particular mixes of the utilities under consideration, setting of a predetermined minimum capacity objective for the fossil baseloaded plants might create a disincentive for efficient operation of the overall system. Reporting requirements and a review mechanism for the baseloaded fossil plants were, however, required. 
The commission saw a major difference between the operation of baseloaded fossil and nuclear plants in that economic dispatch of the system generally dictated that nuclear units be operated to the maximum extent possible. It believed that exceptions to this general practice would be rare and would affect the average capacity factor only by a slight amount.

The commission concluded that semiannual hearings should be scheduled so that companies failing to achieve the objective on both a 6-month and 12-month moving average basis could be examined in detail as to the outages that prevented it from reaching the objective. The commission made it clear that once a hearing was triggered and scheduled, the hearing would not be limited to investigating and determining possible remedial measures for poor plant performance. If the commission finds from the evidence that any outage was caused by imprudent management, it will determine to what extent any resulting excess fuel expenses will be disallowed as an adjustment to the fuel costs to be charged in subsequent periods. In determining the amount of this adjustment, the commission considers the following as relevant factors: the time of the outage, its duration, the magnitude of the cost, the minimum capacity level at which nuclear generation "breaks even" with coal-fired generation on an economic basis, prior performance of the unit, the vintage of the units, and the general diligence and responsibility of management. The commission also considers other relevant factors suggested by the parties. Examination of outages is limited to the most recent 6-month period, and this period serves as the test period for any adjustments made to rates in the event imprudent management has been shown.

In summary, the commission's present method for determining periodic adjustments to fuel charges includes a system for review of nuclear power plant performance. The system includes a trigger mechanism, automatic utility reporting, a public staff review, plus the burden of proof on the utility to support its actions in a hearing before the commission and provides for a potential adjustment for recovery of some or all of the subject expenses should imprudent management be determined. The trigger mechanism recognizes that plant performance will vary from time to time as part of normally expected operations and does not operate each time performance level drops for a short period of time.

The mechanics for review of power plant performance are contained in North Carolina Utilities Commission Rule R8-46, as follows:

Rule R8-46. Base Load Power Plant Performance Review Plan.

(a) Every electrical public utility which uses fossil or nuclear fuel, or both, in the generation of electrical power shall, on or before the $25 \mathrm{th}$ day of each month, file a Base Load Power Plant Performance Report as required in paragraph (e) below.

(b) The Public staff should review the base load unit operating performance.

(c) If the nuclear capacity factors for the six months and the 12 months ending with october or April, as appropriate, are less than 60 percent, or upon Motion by the Commission, the Public Staff, or another party, the commission will review the performance of the system's base load generating plants during the next semi-annual fuel adjustment hearing, December or June, as appropriate.' Both the public staff and the affected utility will be required to present to the commission an explanation and comments concerning the causes of the low performance and concerning any remedial actions taken.

(d) If the commission finds that responsibility for some or all of the poor performance lies with the utility because of management practices deemed to be imprudent, the commission may disallow some or all of the cost of below minimum performance, as appropriate. In determining the amount of this adjustment, the commission considers the following as relevant factors: the time 
of the outage, its duration, the magnitude of the cost, the minimum capacity level at which generation "breaks even" with coal-fired generation on an economic basis, prior performance of the unit, the vintage of the units, and the general diligence and responsibility of management. The commission will also consider other relevant factors suggested by the parties.

(e) Requirements for Base Load Power Plant Performance Report. The following shall be separately reported for fossil generation and nuclear generation.

(1) List each outage during the monthly period and include:

(i) Duration of each outage;

(ii) Cause of out.age;

(iii) Explanation for uccuklellce of cause, 11 known;

(iv) Remedial action to prevent recurrence of outage, if any.

Note: List scheduled outages before forced outages.

(2) Provide the following information for the monthly period and provide a summary for the three-month, six-month, and the 12 -month periods ending with the eulkent month:

(i) Maximum dependable capacity (MDC) in Megawatts (MW);

(ii) Hours in period;

(iii) Megawatt-hours (MWH) generated in the period;

(iv) MWH not generated due to scheduled outages;

(v) MWH not generated due to forced outages;

(vi) MWH not generated due to economic dispatch or other causes; and

(vii) Total MWH possible in period [(i) $x$ (ii)].

Note: Provide (i) through (vii) in the units required and provide ( $i i i)$ through (vi) as a percent of (vii).

(3) The base load plants to be included in the report are the following: CP\&L - Roxboro, Robinson \#2, Brunswick; Duke Belews Creek, Oconee; VEPCO - Mt. Storm, Surry, North Anna. Subsequent base loaded plants shall be reported beginning with their first full calendar month of commercial operation. 


\section{APPENDIX F}

CURRENT ACTIVITIES RELATED TO IMPROVED POWER PLANT PRODUCTIVITY IN THE STATE OF OHIO

\section{F.1 Introduction}

The Public Utilities Commission of Ohio has addressed the issue of power plant productivity in three major areas. First, a target thermal efficiency mechanism, based on a heat rate measure, has been utilized in commission semiannual fuel cost adjustment clause hearings since December 1976; second, a PUCO/U.S. Department of Energy Cooperative Agreement to study the costs and benefits of improved power plant productivity is nearing completion; and third, the commission staff is currently formulating both short- and long-range procedures to introduce the issue into regulatory proceedings.

\section{F.2 The Fuel Cost Adjustment Clause}

The fuel cost of a utility is a combination of the cost of procurement and the efficiency with which its generating stations convert that fuel to electrical energy. Section 4905.69, Revised Code, requires the commission to establish a fuel adjustment clause that "establishes incentives, in terms of costs that may be recovered by electric light companies pursuant to a fuel cost adjustment clause for implementation and employment by such companies of efficient fuel procurement and utilization practices." Based on this legislative directive, the commission included a thermal efficiency feature in its Revised Code of Rules and Regulations (4901:1-11).

As delineated in the commission's fuel cost adjustment clause (FCA) (4901:1-11), the thermal efficiency feature is a reference measure of the electric utility's efficiency in operating its total system of electric-generating plants. The system target thermal efficiency is established by the commission for each electric utility within Ohio based upon the utility's past system performance, future system additions, and other relevant factors.

In its most recent session, the Ohio General Assembly modified the 1976 statute that established the fuel cost adjustment clause. Among the many changes that the commission staff is considering in order to comply with the new statute is the elimination of the thermal efficiency mechanism in favor of another efficiency measure. No final decision about the specifics of the new commission rule has been made.

\section{F. 3 PUCO/DOE Cooperative Agreement:} The Costs and Benefits of Improved Power Plant Productivity

This project utilizes existing analytical techniques to assess the costs and benefits of power plant productivity improvements. The project has been divided into five tasks; the purpose and status of each task is explained below. 


\section{F.3.1 Task I--Assessment of Power Plant Performance}

This task was originally scheduled as the initial phase of the project, but it was delayed due to data discrepancies discovered in the principal data base (NERC/EEI). Ohio utilities have verified and updated the data, and the analysis is under way.

This task will assess the historical power plant performance in ohio in terms of capacity factor, operating availability, equivalent availability, and forced outage rate. These parameters will be presented by unit fuel type, size, and age on an individual unit, utility, and state level.

\section{F.3.2 Task II--Cost/Performance Changes Associated with Specific Productivity Improvements}

In 'lask II, the applicability of the DOE/MRT methodology [33] was assessed, and the cost and performance changes associated with eight specific problems at four ohio power plants were estimated [28]. The Energy Systems Planning Division of TRW supervised the implementation of the methodology.

Four power plants were selected for study. Two major problem areas in each plant were investigated, and the root causes of the problems were identified. Data for the unit selected for study and the two major problem areas identified for each unit are listed in table F.1.

For each root cause, corrective actions and equipment or operational modifications were suggested. The capital, operating, and maintenance related costs associated with the suggested modifications were calculated. Next, the participants constructed analytical models for their respective units in accordance with the DOE methodology. From these models, the predicted benefits in terms of improved equivalent availability (EA) were quantified for each unit. The estimated improvement in equivalent availability and the associated costs and benefits are listed in table F.2.

The TRW Planning Division reached the following conclusions regarding the DOE/MRI methodology:

- The methodology is valid and appropriate frir use by electrio utilities and regulatory agencies.

- The methodology is beneficial to plant engineers. It provides them with a method of communicating the impact of a power plant improvement to management.

- The methodology can be used in regulatory pronesdinge to ovaluate opecifie productivity improvements and their impact on utility operations.

- The level of effort required from a utility to apply the methodology is not disproportionate to potential benefits that can be accrued.

The following items should be addressed to improve the existing methodology:

- The methodology does not require a separate justification of alternative corrective actions, only for the corrective action selected. This may result in selection of a less attractive option.

- The methodology is incapable of taking concurrent plant outages into account.

- The methodology does not include a rigorous test of the model's ability to monitor future plant performance.

- The methodology should be expanded to include cost variance analysis, to describe a range of uncertainty for plant improvement cost factors and the cost sensitivity of the overall improvement program. 
TABLE F.1

UNITS AND PROBLEM AREAS SELECTED FOR STUDY

\begin{tabular}{|c|c|c|c|c|c|}
\hline Unit Name & $\begin{array}{l}\text { Principal Owner } \\
\text { (Operator) }\end{array}$ & $\begin{array}{l}\text { Date of } \\
\text { Commercial } \\
\text { Operation }\end{array}$ & $\begin{array}{l}\text { Unit } \\
\text { Rating } \\
(M W)\end{array}$ & & Problem Area \\
\hline $\begin{array}{l}\text { Mansfield } \\
\text { Unit } 1\end{array}$ & $\begin{array}{l}\text { Ohio Edison co. } \\
\text { Pennsylvania } \\
\text { Power Co. }\end{array}$ & $\begin{array}{l}\text { April } \\
1976\end{array}$ & 825 & 1) & $\begin{array}{l}\text { Pulverizer } \\
\text { failures } \\
\text { Induced draft } \\
\text { fan casing } \\
\text { failure }\end{array}$ \\
\hline $\begin{array}{l}\text { Conesville } \\
\text { Unit } 4\end{array}$ & $\begin{array}{l}\text { Columbus \& } \\
\text { Southern } \\
\text { Ohio Electric } \\
\text { Co. }\end{array}$ & $\begin{array}{l}\text { June } \\
1973\end{array}$ & 800 & 2) & $\begin{array}{l}\text { Cooling water } \\
\text { temperature } \\
\text { limitation } \\
\text { Economizer } \\
\text { tube leaks and } \\
\text { pluggage }\end{array}$ \\
\hline $\begin{array}{l}\text { Gavin } \\
\text { Unit } 1\end{array}$ & $\begin{array}{l}\text { Ohio Electric } \\
\text { (Subsidiary of } \\
\text { AEP) }\end{array}$ & $\begin{array}{l}\text { October } \\
1974\end{array}$ & 1300 & 2) & $\begin{array}{l}\text { Secondary } \\
\text { superheater } \\
\text { tube leaks } \\
\text { and slagging } \\
\text { Forced draft } \\
\text { fan inlet } \\
\text { valve linkage } \\
\text { arm failure }\end{array}$ \\
\hline $\begin{array}{l}\text { Muskingum } \\
\text { River } \\
\text { Unit } 3\end{array}$ & $\begin{array}{l}\text { Ohio Power } \\
\text { (Subsidiary of } \\
\text { AEP) }\end{array}$ & $\begin{array}{c}\text { December } \\
1975\end{array}$ & 215 & $\begin{array}{l}\text { 1) } \\
\text { 2) }\end{array}$ & $\begin{array}{l}\text { Superheater- } \\
\text { reheater } \\
\text { tube leaks } \\
\text { Cyclone tube } \\
\text { leaks }\end{array}$ \\
\hline
\end{tabular}


TABLE F. 2

ES'I'LMA'I'ED IMPROVEMENT IN EQUIVALENT AVAILABILITY AND ASSOCIATED COST AND BENEFIT

\begin{tabular}{|c|c|c|c|}
\hline Unit Name & $\begin{array}{l}\text { Improvement in } \\
\text { Equivalent } \\
\text { Availability } \\
\text { (Percent } \\
\text { Points) }\end{array}$ & $\begin{array}{l}\text { Cost of } \\
\text { Improvement } \\
(\$ \text { millilions })^{*}\end{array}$ & $\begin{array}{l}\text { Valuc of } \\
\text { Improved } \\
\text { Performance } \\
\text { Benefits } \\
\text { (\$ millions )* }\end{array}$ \\
\hline $\begin{array}{l}\text { Mansfield Unit } 1 \\
\text { (1) Pulverizer } \\
\text { (2) I.D. Fan }\end{array}$ & $\begin{array}{l}0.2 \\
5.2\end{array}$ & $\begin{array}{l}1.5 \\
7.1\end{array}$ & $\begin{array}{r}2.1 \\
73.0\end{array}$ \\
\hline $\begin{array}{l}\text { Conesville Unit } 4 \\
\text { (1) Cooling water } \\
\text { limitations } \\
\text { (2) Economizers }\end{array}$ & $\begin{array}{l}0.2 \\
0.7\end{array}$ & $\begin{array}{r}4.0 \\
.2\end{array}$ & $\begin{array}{r}8.5 \\
22.9\end{array}$ \\
\hline $\begin{array}{l}\text { Gavin Unit } 1 \\
\text { (1) Superheater } \\
\text { (2) F.D. Fans }\end{array}$ & $\begin{array}{l}1.7 \\
0.1\end{array}$ & $\begin{array}{l}2.6 \\
0.0\end{array}$ & $\begin{array}{r}28.2 \\
0.1\end{array}$ \\
\hline $\begin{array}{l}\text { Muskingum Unit } 3 \\
\text { (1) Superheater- } \\
\text { reheater } \\
\text { (2) Cyclones }\end{array}$ & $\begin{array}{l}1.1 \\
0.7\end{array}$ & $\begin{array}{l}5.9 \\
4.4\end{array}$ & $\begin{array}{l}7.2 \\
6.0\end{array}$ \\
\hline
\end{tabular}

*Present Value in 1978 discounted over the life of each unit. 
- Utility company engineers should use a fixed charge rate (FCR) in estimating the cost of capital expenditures. However, the components of the FCR must be detailed.

In conclusion, the study indicated that the following recommendations, if implemented, would improve the overall effectiveness of studies such as this and the DOE/MRI methodology.

- The problems associated with use of the current EEI cause code structure should be brought to the attention of the National Electric Reliability Council (NERC).

- Each utility should develop a plant reliability data base that expands upon the existing EEI system as an interim solution to the data base problem.

- Utilities should make current engineering, design, and maintenance information records easily accessible to plant engineers.

- An independent, automated, utility-operated data base for reporting plant outages should be developed for application in power plant productivity improvement programs.

- Utilities should rigorously apply a cost benefit methodology of this type to avoid drawing inaccurate conclusions.

F.3.3 Task III--Benefits of Sperific Productivity Improvements

Task V-- Impact of Load Shape Changes on Benefits and Improved Productivity

The work performed in these tasks was specific to the following six ohio utilities: Dayton Power and Light, Toledo Edison, Cleveland Electric Illuminating, Columbus and Southern Ohio Electric, Cincinnati Gas and Electric, and Ohio Edison. The benefits were quantified in terlls of change in the system luss-of-10ad probability, expected unserved energy, and average fuel cost [20]. Calculations were made using probabilistic simulation of system operation [19].

The cases of productivity improvements evaluated were as follows:

PI-O No productivity improvements.

PI-l Equivalent forced outage rate of all baseloaded plants reduced by 5 percentage points over 10 years.

PI-2 Equivalent forced outage rate of all baseloaded plants reduced by 10 percentage points over 10 years.

PI-3 Equivalent forced outage rate of all baseloaded plants reduced by 10 percentage points and equivalent availability improved simultaneously to a maximum of 85 percent over 10 years. Minimum maintenance time was set to 20 days per plant per year.

These improvements were simulated on all baseloaded plants simultaneously. Improvements were phased in linearly over the period 1979-88 assuming a base year of 1978.

Load management was simulated by modifying the load duration curve of each utility for each period of study. There were four three-month periods (seasons) of study in each year. The following cases of load management were evaluated: 
LM-0 No load management.

LM-1 A 5 percent reduction of the peakload of the load duration curve, with 10 percent of the energy in the peak region shifted to the base and shoulder regions. (The peak region of the load duration curvc was defined as the region in which load exceeded 70 percent of the season's peak hour load.)

LM-2 A 5 percent reduction of the peakload of the load duration curve, with 20 percent of the energy in the peak shifted to the base and shoulder regions.

LM-3 A 10 percent reduction of the peakload of the load duration curve, with 40 percent of the energy in the peak shifted to the base and shoulder regions.

Two sets of scenarios were evaluated. In the first set, it was assumed that future capacity additions were brought on-line as specified by the expansion plans of each utility. Simulations were run for each case of productivity improvement by first assuming no load management and then assuming each case of load management. A partiai summary of results for the six Ohio utilities studied is presented in table F. 3 . Table F.3 compares loss-of-load probability, expected unserved energy, and average fuel costs as estimated for the extreme case of load mangement and productivity improvements (LM-3, PI-3), with the extreme case of productivity improvements without load management (LM-0, PI-3), and with the base case (LM-0, PI-0). The results show the computed percent improvements relative to the base case (PI-0, LM-0) in average fuel cost, LoLP, and expected unserved energy over the period 1979-88 for 3 of the 16 cases investigated. The findings from this work indicate significant improvement in system reliability. The expected reduction in average fuel cost is small because most of the energy in Ohio is generated from coal-fired plants and only a small fraction from oil.

In the second set of scenarios, it was assumed that plant delays did occur and that productivity improvements and load management were implemented. These evaluations were made in order to investigate whether productivity improvements and load management could alleviate capacity shortages. The following cases of plant deferralc werc cpcoified.

(1) All capacity additions after 1981 were delayed by one year (Plan 1 ).

(2) All capacity additions after 1981 were delayed by two years (Plan 2).

Each of the above plans was evaluated with no productivity improvement nor load management ( $P I-U, L M-U$ ) and also with the most extreme case of productivity improvement in combination with the most extreme case of load management (PI-3, LM-3).

A summary of the results from these evaluations is shown in Tables F.4 and F.5. The results show the computed percentage changes relative to the base case in average fuel cost, LOLP, and expected unserved energy over the period $1979-88$ for Plan 1 and for Plan 2 .

There are three general conclusions that were reached from this work:

(1) Productivity improvements and load management can increase system reliability and reduce fuel costs.

(2) Productivity improvements in conjunction with load management results are more significant in improving system reliability and reducing fuel costs than productivity. improvements alone. However, the cost of implementation of productivity improvements and load management was not considered in this work. For this reason, cost benefit results are not presented in this report. 
TABLE F. 3

THE EFFECTS OF PRODUCTIVITY IMPROVEMENTS AND LOAD MANAGEMENT ON SYSTEM PARAMETERS OVER THE PERIOD 1979-1988 ASSUMING TIMELY CAPACITY ADDITIONS

\begin{tabular}{|c|c|c|c|c|c|c|c|c|c|}
\hline \multirow[b]{2}{*}{ Company Name } & \multicolumn{3}{|c|}{ LOLP } & \multicolumn{3}{|c|}{ Unserved Energy } & \multicolumn{2}{|c|}{ Average Fuel } & \multirow{2}{*}{$\begin{array}{l}\text { Cost } \\
\qquad \begin{array}{l}\text { PI-3 } \\
\text { LM-3 } \\
(8)\end{array}\end{array}$} \\
\hline & $\begin{array}{l}\text { Base } \\
\text { Case } \\
\text { (Days) }\end{array}$ & $\begin{array}{l}P I-3 \\
L M-0 \\
(8)\end{array}$ & $\begin{array}{r}P I-3 \\
L M-3 \\
(8)\end{array}$ & $\begin{array}{c}\text { Base } \\
\text { Case } \\
\left(10^{3} \text { MWh }\right)\end{array}$ & $\begin{array}{r}P I-3 \\
L M-0 \\
(8)\end{array}$ & $\begin{array}{r}P I-3 \\
L M-3 \\
(8)\end{array}$ & $\begin{array}{c}\text { Base } \\
\text { Case } \\
(\$ / M W h) *\end{array}$ & $\begin{array}{r}P I-3 \\
L M-0 \\
(8)\end{array}$ & \\
\hline $\begin{array}{l}\text { Cincinnati Gas and } \\
\text { Electric }\end{array}$ & 63.15 & -71.7 & -82.1 & 340.5 & -78.3 & -87.5 & 8.691 & -2.1 & -2.4 \\
\hline $\begin{array}{l}\text { Cleveland Electric } \\
\text { Illuminating }\end{array}$ & 33.87 & $-7,5.9$ & -89.5 & 228.8 & -81.2 & -93.0 & 10.258 & -3.3 & -3.4 \\
\hline $\begin{array}{l}\text { Columbus and South- } \\
\text { ern ohio Electric }\end{array}$ & 54.35 & -60.1 & $-73: 0$ & 233.4 & -66.8 & -79.7 & 9.149 & -1.4 & -1.5 \\
\hline $\begin{array}{l}\text { Dayton. Power and } \\
\text { Light }\end{array}$ & 271.68 & $-54 \cdot 5$ & -68.5 & 1550.9 & -63.5 & -78.7 & 9.274 & -3.2 & -3.8 \\
\hline Ohio Edison & 177.57 & -55.5 & -66.3 & 1406.1 & -62.1 & -72.7 & 8.662 & -3.7 & -4.1 \\
\hline Toledo Edison & 194.74 & -40.8 & -47.6 & 707.0 & $-44 \cdot 2$ & -52.9 & 8.023 & -6.8 & $-7 \cdot 6$ \\
\hline
\end{tabular}




\section{TABLE F. 4}

THE EFFECTS OF PRODUETIVITY IMPROVEMENTS AND JOAD MANAGEMENT ON SISTEM PARAMETERS OVER THE PERIOD 1979-1988 ASSUMIMG

DNE-YEAR DEL.GY IN ALL FUTURE CAPACITY ADDITIONS

\begin{tabular}{|c|c|c|c|c|c|c|c|c|c|}
\hline \multirow[b]{2}{*}{ Company Name } & \multicolumn{3}{|c|}{ LOL? } & \multicolumn{3}{|c|}{ Unserved Energy } & \multicolumn{2}{|c|}{ Average Fuel } & \multirow{2}{*}{$\begin{array}{l}\text { Cost } \\
\qquad \begin{array}{l}\mathrm{PI}-3 \\
\mathrm{LM}-3 \\
(8)\end{array}\end{array}$} \\
\hline & $\begin{array}{l}\text { Base } \\
\text { Case } \\
\text { (Days) }\end{array}$ & $\begin{array}{l}P I-0 \\
L M-0 \\
(8)\end{array}$ & $\begin{array}{r}P I-3 \\
L M-3 \\
(8)\end{array}$ & $\begin{array}{c}\text { Base } \\
\text { Case } \\
\left(10^{3} \text { MWh! }\right.\end{array}$ & $\begin{array}{r}P I-1) \\
L M-1) \\
(8)\end{array}$ & $\begin{array}{r}\mathrm{PI}-3 \\
\mathrm{LM}-3 \\
(8)\end{array}$ & $\begin{array}{c}\text { Base } \\
\text { Case } \\
(\$ / M W h) *\end{array}$ & $\begin{array}{r}P I-0 \\
L M-0 \\
\left(\frac{8}{3}\right)\end{array}$ & \\
\hline $\begin{array}{l}\text { Cincinnati Gas and } \\
\text { Electric }\end{array}$ & 63.15 & +36.9 & -66.9 & 340.5 & +36.3 & -76.0 & 8.691 & -1.7 & -0.9 \\
\hline $\begin{array}{l}\text { Cleveland Electric } \\
\text { Illuminating }\end{array}$ & 33.87 & +39.6 & -81.7 & 228.8 & +41.5 & -87.2 & 10.258 & $\div 2.8$ & -0.3 \\
\hline $\begin{array}{l}\text { Columbus and South- } \\
\text { ern Ohio Electric }\end{array}$ & 54.3 .5 & +34.0 & -60.4 & 233.4 & +35.1 & -69.6 & 9.149 & -1.1 & -0.4 \\
\hline $\begin{array}{l}\text { Dayton Power and } \\
\text { Light }\end{array}$ & 271.6 .3 & +33.5 & -48.7 & 1550.9 & +33.2 & $-64 \cdot 0$ & .9 .274 & $\div 2.9$ & -1.3 \\
\hline Ohio Edison & 177.57 & +69.2 & -38.8 & 1406.1 & +86.3 & -47.1 & 8.662 & -5.0 & +0.8 \\
\hline Toledo Edison & 194.74 & +63.5 & -12.7 & 707.0 & +77.8 & -17.1 & 8.023 & -8.5 & -0.3 \\
\hline
\end{tabular}


TABLE F. 5

THE EFFECTS OF PRODUCTIVITY IMPROVEMENTS AND LOAD MANAGEMENT ON SYSTEM PARAMETERS OVER THE PERIOD 1979-1988 ASSUMING TWO-YEAR DELAY IN ALL FUTURE CAPACITY ADDITIONS

\begin{tabular}{|c|c|c|c|c|c|c|c|c|c|}
\hline \multirow[b]{2}{*}{ Company Name } & \multirow[b]{2}{*}{$\begin{array}{l}\text { Base } \\
\text { Case } \\
\text { (Days) }\end{array}$} & \multirow{2}{*}{$\begin{array}{l}\text { LOLP } \\
\text { PI-0 } \\
\text { LM-0 } \\
\text { (8) }\end{array}$} & \multirow[b]{2}{*}{$\begin{array}{r}P I-3 \\
L M-3 \\
(8)\end{array}$} & \multicolumn{3}{|c|}{ Unserved Energy } & \multicolumn{2}{|c|}{ Average Fuel } & \multirow{2}{*}{$\begin{array}{l}\text { Cost } \\
\qquad \begin{array}{l}\text { PI }-3 \\
L M-3 \\
(8)\end{array}\end{array}$} \\
\hline & & & & $\begin{array}{c}\text { Base } \\
\text { Case } \\
\left(10^{3} \text { MWh }\right)\end{array}$ & $\begin{array}{r}P I-0 \\
L M-0 \\
(8)\end{array}$ & $\begin{array}{l}\mathrm{PI}-3 \\
\mathrm{LM}-3 \\
(8)\end{array}$ & $\begin{array}{c}\text { Base } \\
\text { Case } \\
(\$ / M W h) *\end{array}$ & $\begin{array}{r}P I-0 \\
L M-0 \\
(8)\end{array}$ & \\
\hline $\begin{array}{l}\text { Cincinnati Gas and } \\
\text { Electric }\end{array}$ & 63.15 & +92.0 & -45.8 & 340.5 & +95.5 & -59.4 & 8.691 & +1.7 & +0.7 \\
\hline $\begin{array}{l}\text { Cleveland Electric } \\
\text { Illuminating }\end{array}$ & 33.87 & +113.0 & -67.0 & 228.8 & +128.7 & $-75 . \varepsilon$ & 10.258 & +5.6 & -1.6 \\
\hline $\begin{array}{l}\text { Columbus and South- } \\
\text { ern Ohio Electric }\end{array}$ & 54.35 & +86.5 & -41.1 & 233.4 & +305.8 & -53.1 & 9.149 & +2.3 & +0.6 \\
\hline $\begin{array}{l}\text { Dayton Power and } \\
\text { Light }\end{array}$ & 271.68 & +66.8 & -19.6 & 1550.9 & +86.4 & -41.3 & 9.274 & +5.9 & +1.5 \\
\hline Ohio Edison & 177.57 & +155.2 & -0.1 & 1406.1 & +210.1 & -8.0 & 8.662 & +9.6 & +5.3 \\
\hline Toledo Edison & 194.74 & +140.9 & +31.5 & 707.0 & +186.8 & +31.0 & 8.023 & +16.7 & +7.0 \\
\hline
\end{tabular}


3. In certain cases, productivity improvements and load management may alleviate the effects of delaying capacity installations. In other cases, however, they may only reduce the impact of capacity shortages.

\section{F.3.4 Task IV - Incentives/Disincentives for Power Plant Productivity Improvements}

The purpose of this task, to be completed by members of the commission staff, is to examine current regulatory and nonregulatory policies and procedures in order to assess the existing incentives and disincentives affecting power plant productivity. Following this initial assessment of the current situation, alternative incentive proposals will be developed if necessary.

\section{F. 4 Current Action: \\ Introducing Power Plant Productivity into the Regulatory Process}

The results from the cooperative agreement provided the basis for the development and implementation of a cooperative long-term program for the improvement of power plant productivity. The first phase of this program, the identification of the issue in the rate case area, is already in progress; the issue has been considered in four rate cases to date for half of the ohio electric utilities. This phase has formally notified each utility considered of the commission's interest in the issue and has mandated the formation of a state-specific power plant productivity data base to provide the commission with current information about the status of the state's power plants.

The purpose of the second. phase of the program is to improve current commission procedures in the power plant productivity area. More specifically, the objective of this phase is to develop and document a comprehensive program for the inclusion of power plant productivity elements into existing procedures, in the areas of performance data collection, major capital improvements to existing units, preventive maintenance, and the tracking of benefits. This phase of the program is the subject of a second DOE/PUCO Cooperative Agreement; a consultant is scheduled to begin work on the new procedures in September 1980. It is expected that with the implementation of these new procedures, specifically commission verification of the assumptions, method; and benefits projected from major improvement programs and potential uellity reimbursement for those programs, availabilities will increase for the state's power plants without the implementation of a more formal incentive mechanism. 


\section{APPENDIX G}

CURRENT ACTIVITIES RELATED TO IMPROVED POWER PLANT PRODUCTIVITY IN THE STATE OF TEXAS (Power Plant Productivity Study)

\section{G.1 Introduction}

The interest of the Texas Energy Advisory Council and the Center for Energy Studies at the University of Texas in topics such as power plant productivity stems from the common objective of both groups to encourage efficient utilization of all energy resources. The involvement with the specific topic of power plant productivity was started and developed in response to a Department of Energy request for proposal (RFP No. EB-F-01-6427).

The primary objective of this study is to examine the influence of the existing electric utility institutional framework on power plant productivity, and to analyze both the short-run and long-run impacts of alternative regulatory incentives designed to encourage improved power plant efficiency upon optimal capital mix and the cost of fuel.

The research project involves the determination of current levels and trends in power plant productivity in the state of Texas. Short-term costs of power plant outages will be computed using a production simulator that treats outages and system load in a probabilistic manner. The benefit to be derived from an improvement in outage rates (or other performance factor), therefore, can be determined by running the probabilistic simulator for the normal and improved outage (or other performance factor) levels and comparing the respective operating costs.

The estimation of long-run costs will be implemented by means of the University of Texas Regional Electricity Model. As in the case of the short-run, the long-run benefits associated with alternative improvement strategies can be estimated by iterating the Regional Electricity Model for standard and improved performance levels for all relevant years. The Regional Electricity Model has the capability of determining a cost minimal capital and fuel mix as well as final price to the consumer and other balance sheet entries, given a multitude of parameters, some of which include outage rate (or other performance factor) and regulated rate-of-return. This facet permits the examination of the impact of alternative combinations of performance and rate-of-return levels upon future generation expansion and fuel usage.

The regulatory section of this project contains a number of critical tasks. First, a review of relevant economic literature is made and then combined with engineering evidence to support the general methodology of the study. Second, existing and planned incentive provisions instituted by state level regulatory agencies (including Texas) are summarized and compared. Third, several alternative incentive strategies are developed and discussed in detail (in reference to their possible effects on power plant productivity and the efficient allocation of resources). The final step is to use the production simulator and the Regional Electricity Model to measure the feasible range of economic impacts associated with the incentive provisions. 
In section G.2, preliminary findings of the study of performance level of Texas utilities are discussed. In section G.3, preliminary findings on the long-term impacts from improved productivity are discussed.

\section{G.2 Performance Levels of Texas Utilities--Preliminary Findings}

The following utilities were studied in this analysis: Central Power and Light, Dallas Power and Light, Houston Lighting and Power, Texas Electric Service, and Texas Power and Light. Analyses were made using data from EEI.

In general, the representative utilities of Texas had an equivalent availability factor that was greater than the national average. The only utility that averaged less than the national average for the equivalent availability factor was Dallas Power and right. Similarly, all the utilities investigated had a lower (or better) forced outage rate than the national average. However, the uillilies' cajacity factor did not compare guite as well to the natlonal averaye as the cquivalent availability $\mathrm{nr}$ the equivalent forced outage rate. Unly two uf lhe utilitics' avcrages were as gnnd or better than the national average for capacity factor. Houston Lighting and power had an average capacity factor of about 10 percent greater than the national average for the same period of years. Texas Electric Service showed a similar average over the same perlod, although not as high as the Houston lighting and Power average. The other utilities all averaged below the national average; some by quite a percentage. Central Power and Light averaged 10-15 percent lower than the national average.

These conclusions are not final because additional data have been requested from the five utilities.

\section{G. 3 Long-Term Impacts from Improved Power Plant Productivity-- Preliminary Findings}

\section{G.3.1 Scenarios of Study}

The objective of this part of the study is to evaluate long-term potential benefits of improved nuclear and coal power plant productivity. Analysis has been made for the Electric Reliability Council of Texas region (ERCOT). Nuclear and coal nnwer plant productivity improvement has been simulated by a 5-percent-point improvement in the forced outage rate (FOK) over an elght-ycal perivo (1080 87 ).

The present results are based on sillullaneous improvement in nuclear and rnal units by 5-percent-points. Other cases of interest would be an improvement in only nuclear or only coal plants.

Two scenarios can be considered:

(1) Fixed Planned Expansion

This case of study holds the future planned expansion fixed while improving power plant productivity. The benefits are principally in the form of savings in oil and gas consumption.

(2) Variable Expansion

As power plant productivity is improved, effective capacity of existing plants increases; therefore, there would be less need of new additional generation capacity. This means construction of new plants can be deferred. The benefits would be in the form of less capital investment.

Presently, we are concentrating on the Fixed Expansion Case. The following are the results obtained with a simultaneous improvement in nuclear and coal plant FOR while keeping future generation expansion fixed. We are planning to look into the Variable Expansion Case after evaluation of the Fixed Expansion Case is complete. (REM).

The simulation tool used in the study is the Regionalized Electricity Model 


\section{G.3.2 Results}

Fixed Planned Expansion

In this part of the study, coal and nuclear power plant forced outage rates are improved simultaneously by 5 percent points over an eight-year period (1980-87), and future planned generation expansion has been kept fixed. The new coal and nuclear power plants that come on-line after 1987 have the improved forced outage rates incorporated in them.

The potential benefits obtained by keeping future generation expansion $f$ ixed and improving FOR are reduced oil and gas consumption. Considering the tight supply market for imported oil and gas and continuous price increases by OPEC makes this saving of real value. Reduction in consumption of expensive and scarce. oil and gas benefits the consumer, the utility, and the nation. The benefits to the consumer are in the form of lower electricity cost. The utility benefits by being in the better position in the event of shortage or price increase of oil and gas, and the nation pays a rediced energy bill.

Table G.l presents some of the results. Since no significant oil-fired generation exists in the ERCOT region, the major fuel saving is in gas consumption. Column 2 presents reduction in gas consumption in MCF for the corresponding years indicated in column 1. The gas saving nearly remains constant over the 15-year period. This is due to the fact that no new gas plants are to be constructed in this period.

Column 3 shows percent increases in the generation from nuclear. These increases are expected because nuclear fuel cost is the lowest, and as productivity of nuclear plants is improved, more electricity is generated from nuclear.

Column 4 shows changes in coal consumption. There is a slight increase in coal consumption as cheaper coal replaces gas. In the year 2000, nuclear, the cheapest fuel, rejlaces a jait of the cual, so the coal consumption drops slightly.

Column 5 presents reductions in production expenses. The major portion of this saving is in fuel costs.

Column 6 is the reduction in the cost of electricity, and column 7 is the benefit to the consumers. Comparing columns 5 and 7 , we can conclude that almost all the saving in generation goes to the consumer.

It can be concluded at this state that if utilities decide to continue their generation expansion as it is planned, even after improving forced outage rates of nuclear and coal plants, the benefits would be in the form of expensive fuel savings, and the major portion of the dollar benefits go to the consumer. 
TAELE G.1

F-XED ELANNED CAPACITY EXPANSION - ERCOT REGION

5-Percent-Foint Improvement in Coal and Nuclear Plant's For over Eight Years (1980-87)

\begin{tabular}{|c|c|c|c|c|c|c|c|}
\hline \multirow[b]{2}{*}{ Year } & \multicolumn{2}{|c|}{$\begin{array}{l}\text { Reduction in } \\
\text { Gas Consumption }\end{array}$} & \multirow{2}{*}{$\begin{array}{l}\quad \text { En- } \\
\text { crease in } \\
\text { Generation } \\
\text { from } \\
\text { Nuclear }\end{array}$} & \multirow{2}{*}{$\begin{array}{c}\text { Change } \\
\text { in Coal } \\
\text { Consumption } \\
\text { Short Tons/Yr } \\
\text { (Million) }\end{array}$} & \multirow{2}{*}{$\begin{array}{l}\text { Feduction } \\
\text { in } \\
\text { Froduction } \\
\text { Expenses } \\
10^{9} \$\end{array}$} & \multirow{2}{*}{$\begin{array}{l}\text { Reduction } \\
\text { in } \\
\text { the Cost of } \\
\text { Electricity } \\
\text { Mills/kWh }\end{array}$} & \multirow{2}{*}{$\begin{array}{l}\text { Benefit to } \\
\text { Consumers } \\
10^{9} \mathrm{~S}\end{array}$} \\
\hline & $M C F / Y r$ & (3) & & & & & \\
\hline 1985 & 47.77 & 3.3 & 4.56 & +1.64 & 0.0271 & 0.1391 & 0.0257 \\
\hline 1990 & 66.1 & 19 & 6 & +1.85 & 0.0648 & 0.2147 & 0.0508 \\
\hline 1995 & 60 & 25 & 6 & +0.99 & 0.1223 & 0.2743 & 0.0817 \\
\hline 2000 & 54.16 & 310 & 6 & -0.04 & 0.228 & 0.4047 & 0.1509 \\
\hline
\end{tabular}


BIBLIOGRAPHY

1. ANSI Steering Committee Meeting on Power Plant Data Systems. "The General Electric Company's Component Information Retrieval Systems." June 1976.

2. ARINC Research Corporation. "Survey of Performance Assurance Concepts Applicable to Baseload Electric Power Plants." November 1977.

3. Anderson, R. C., and Shor, S. W. W. "Coordinated Design Reviews to Improve Access and Reduce Radiation Exposure." Nuclear Engineering International 23 (1978).

4. Basin, S. L.; Fullwood, R. R.; and Lavalle, W. L. "A Summary of Nuclear Power Plant Operating Experience for 1975." Electric Power Research Institute, EPRI-NP-263, October 1975.

5. Billington, R., and Krasnodebski, J. "Practical Application of Reliability and Maintainability Concepts to Generating Station Design." IEEE Transactions on Power Apparatus systems, vol. PAS-92, November/December 1973 .

6. Breen, Bernard P., and Sotter, J. George. "Reducing Inefficiency and Emissions of Large Steam Generators; Progress in Energy and Combustion Science," vol. 4, no. 3,1978 .

7. Bridenbaugh, D. G., and Burdsall, G. D. "Application of Plant Outage Experience to Improve Plant Performance." Proceedings of the American Power Conference, vol. 36, April 1974 .

8. Burge, Don. "Utilities Shift Training Emphasis to Maintenance Men," Electric Power and Light, June 1979.

9. California Energy Resources Conservation and Development Commission. "Assessment of Quality Assurance in Non-Nuclear Power Plants." Prepared by Nuclear Services Corporation, Juiy 1978.

10. California Energy Resources Conservation and Development Commission. "Power Plant Performance Analysis." Prepared by System Development Corporation, June 1978.

11. Chittenden, W. A. "Improving Power Plant Reliability--Needs and Direction." American Nuclear Society Executive Conference, September 1976.

12. Claeson, E. U.; Inouye, S.; and Tully, J. E., Jr. "Standardized Fossil Power Plants--Feasibility, Advantages, Limitations." Proceedings of the American Power Conference, vol. 40, April 1978.

13. Comey, David D. "Nuclear Power Plant Reliability: The 1973-1974 Record Not Man Apart." April 1975 . 
14. Corey, Gordon R. "Cost Comparison of Nuclear and Conventional Electric Generation." Public Utilities Fortnightly, April 22, 1976.

15. Davis, C. M.; Haller, K. H.; and Weiner, M. "Large Utility Boilers--Experience and Design Trends." Proceedings of the American Power Conference, vol. 38, April 1976 .

16. Davis, C. N., and Herring, R. F. "AEP's 1300 MW Coal-Fired Steam Generating UMB Designed for Reliability." ASME, July 1972.

17. Davis, C. N., and Herring, R. F. "AEP Succeeds with Large New Units." Electric World, August 1976.

18. Deddens, J. C., and Clark, R. H. "Increasing Reliability and Availability of B\&W Nuclear steam systems." Proceedings of the Amerlcan Power Conference, vol. 38 , npril 1976.

19. Deddens, J. C., and Fahland, F. R. "Increasing Reliability of Nuclear Steam Systems Utilizing Operating Experience Feedback." Proceedings of the American Power Conference, vol. 39, April 1977.

20. Detroit Edison. "Evaluation of the Functional and Economic Feasibility of Employing Diagnost1c Vibration Frequency Analysis to Identify Defecls in Power Plant Operating Equipment." May 1977.

21. Edison Electric Institute. "Boiler Comparison (Drum vs. Supercritical) of Coal Units 390-599 MW and $600 \mathrm{MW}$ and Above." Equipment Availability Task Force of the Prime Movers Committee, 76-85-A, 1976.

22. Edison Electric Institute. "EEI Equipment Availability Quarterly Report for 600 MW and Larger Fossil Units." 1976.

23. Edison Electric Institute. "Report on Equipment Availability for the Ten-Year Period 1966-75." Publication no. 76-85, December 1976.

24. Egy, Joseph E. "Economic Life Span for Power Production Units." Public Utilites Fortnight1y, September 11, 1976.

25. Electric Power Research Institute. "Analysis of Utility Industry Data Systems." Prepared by Stone and Webster Engineering Corporation, Final Report, NP-1064, Research Project 771-1, April 1979.

26. Electric Power Research Institute. "Availability of Fossil-Fired Steam Power Plants." EPRI-FP-422 SR., June 1977.

27. Electric Power Research Institute. "Characteristics of Instrumentation and Control System Failures." EPRI-NP-443, August 1977.

28. Electric Power Research Institute. "Characteristics of Pipe System Failures in Light Water Reactors." EPRI-NP-438, August 1977.

29. Electric Power Research Institute. "EPRI Reliability Data Base Studies." May 1976.

30. Electric Power Research Institute. "Nuclear Unit Productivity Analysis." SR-46, August 1976.

31. Electric Power Research Institute. "Optimization of Reliability Data Systems." RP-826, Phase I Report, July 1977.

32. "ERDA Program to Reduce Outage Time--Fort Calhoun Project." Combustion Engineering, December 1976. 
33. Federal Energy Administration. "Impact of Load Management Strategies upon Electric Utility Costs and Fuel Consumption." FEA/D-77/208, June 1977.

34. Federal Energy Administration, Office of Fuels and Facilities. "Analysis of Benefits from Improved Productivity of Nuclear and Large Coal Power Plants." April 1976.

35. Federal Energy Administration. "A Report on Improving the Productivity of Electric Power Plants." FEA-263-6, March 1975.

36. Federal Energy Administration. "Summary Report FEA Regional Meeting on Improving Power Plant Productivity." FEA/G-76-272, August 1976.

37. Federal Energy Administration. "Summary Report on Three Power Plant Productivity Studies." FEA/G-76-328, August 1976 .

38. Federal Power Commission. "Electric Generating Plant Availability." Bureau of Power staff Report, May 1975 .

39. Federal Power Commission. "Factors Affecting the Electric Power Supply, 1980-85." Bureau of Power, December 1976.

40. Felmus, N. L., and Elhof, W. C. "BWR Operating Experience and Outage Services." Proceedings of the American Power Conference, vol. 38, April 1976.

41. Felmus, N. L., and Willett, D. K. "Nuclear Plant Performance Improvement programs: Progress and Results." Proceedings of the American Power Conference, vol. 40, April 1978 .

42. Flashburg, A. L., and Rodriquez, R. "System Heat Rate Improved with Computerized Overhaul Scheduling." Power Engineering, September 1977.

13. Fricdland, Gordon D. "Gtandardized Generating Plantsì" Electrical World, April. 15,1979 .

44. Garrick, B. J. "Reliability Engineering Guide--Sun Desert Nuclear Plant." Pickard, Lowe and Garrick, Inc., October 1976.

45. Garver, L. L. "Adjusting Maintenance Schedules to Levelized Risk." IEEE Transactions on Power Apparatus and Systems, vol. PAS-91:5, September/October 1972 .

46. Gordian Associates, Inc. "Economics of Power Plant Productivity Improvement and Load Management Benefits." 1976.

47. Hamann, J. R. "Steam Generator Performance Evaluation and Improvement." Presented at the AEIC Conference, January 1974.

48. Hamilton, D. E., and Koh, B. "Upgrading of PWR's to Enhance Plant Availability." proceedings of the American Power Conference, vol. 39, April 1977.

49. Haveter, Robert L. "Nuclear Power Plant Reliability." Proceedings of the American Power Conference, vol. 36, April 1974.

50. "Heat Rate Improvement Program Boosts Power Plant Efficiency." Electric Power and Light, July 1977.

51. Hefter, C. L., and Bisck, J. M. "Building a Comprehensive Spare Parts Program." proceedings of the American Power Conference, vol. 39, April 1977.

52. Hilles, R. W.; Toth, C. P.; and Koh, B. "Using Nuclear Plant Operating Data to Improve Product Liability." Proceedings of the American Power Conference, vol, 38, April 1976. 
53. "How to Save Five Days From a Nuclear Refueling Outage." Electric Light and Power, October 1977.

54. IEEE, Plant Productivity Task Force, Applications of Probability Methods Subcommittee, Power Systems Engineering Committee. "Definitions for Use in Reporting Electric Generating Unit Reliability, Availability and productivity." 1979.

55. Johnson, J. P. "Low-frequency Ultrasonic Testing." Sonic Instruments, Inc., 1977.

56. Keller, Richard W., and Smith, Morton J. "Increasing Power Plant Productivity: A Status Report." Mechanics Research Inc., presented to the American Nuclear Society Winter Meeting, San Francisco, California, November 17, 1975.

57. Kohn, Harold w. "Reactor Performance Evaluation." Power Engineering, December 1975.

58. Kohn, Harold w. "Evaluating Nuclear Reactor Capacity Factors." Power Engineering, January 1978.

59. Kohn, Harold W. "Capacity Factor Evaluation of Fossil-Fired Power Plants." Power Engineering, October 1978.

60. Komanoff, Charles. "Power Plant Performance--Nuclear and Coal Capacity Factors and Economics." New York: Council on Economic Priorities, Publication Number S6-1, 1976 .

61. Komanoff, Charles, and Boyer, Nancy. "Nuclear Plant Performance/ Update: Data Through December 31, 1976." New York: Council on Economic Priorities, 1977.

62. Lapides, M. E. "Nuclear Unit Productivity Analysis." Flectric Power Research Institute, EPRI-SF-46, August 1976.

63. Lapides, M. E., and Zebroski, E. L. "Evolving Incentives and Technical programs for Attaining Higher Plant Productivity." Proceedings of the American Power Conference, vol. 37, April 1975.

64. Lapides, M. E., and Zebroski, E. L. "Use of Nuclear Plant Operating Experience to Guide Productivity Improvement Programs." Nuclear Power Division, Electric Power Research Institute, EPRI-SR-26, November 1975.

65. Lawrence, C. C.; Graf, D. V.; and Honey, J. A. "Lessons Learned at Calvert Cliffs." Proceedings of the American Power Conference, vol. 38, April 1976.

66. Lehr, R. F., and llartley, F. W. "Refuoling Shutdown Management." Proceenings of the American Conference, vol. 35, April 1973.

67. Long, R. L., and Cleveland, E. B. "Engineering for Availability." Power Engineering, July 1978 .

68. Lyons, D. E., and Blackburn, S. S. "Design for Availability--An Update." proceedings of the American Power Conference, vol. 39, April 1977.

69. Lyons, James w. "Optimizing Designs of Fossil-Fired Generating Units." Power Engineering, February 1979.

70. McFarren, R. D., and Simard, R. L. "Analyzing Future Power Plant Performance." Public Utilities Fortnightly, April 28, 1977.

71. Michigan Public Service Commission. "Report on Power Plant Availability." Lansing, Michigan, March 1979. 
72. Mitre Corporation. "Proceedings of Workshop on Increasing, Efficiency and Effectiveness in Electric Power Generation." MTR-7032, 1976.

73. Mooney, J. T., and Miskimin, P. A. "Unique Design Features of the South Texas Project." Proceedings of the American Power Conference, vol. 38, April 1976.

74. Moraw, G., and Szeless, A. "Availability of Nuclear Power Plants." Power Engineering, December 1977.

75. Morong, T. M., and Patterson, R. L. "Designing for Plant Availability at the Navajo Generating Station." Proceedings of the American Power Conference, vol. 37, April 1976.

76. MPR Associates Inc. "Assessment of Industry Valve Problems." November 1976.

77. National Association of Regulatory Utility Commissioners. "The Battle to Increase the Capacity Factor of Electric Generation Equipment." Proceedings of the 88th Annual Convention, 1976.

78. National Association of Regulatory Ut1lity Commissioners. "Productivity and Public Utilities Regulation." Economic Paper no. 5, Staff Subcommittee on Economics, Proceedings of the 86 th Annual Convention, 1974.

79. Niebo, R. J. "Power Plant Productivity Trends and Improvement Possibilities." ASME Joint Power Conference, Long Beach, California, September 1977.

80. Nuclear Regulatory Commission. "Operating Units Status Report." (Annual Publication).

81. Nuclear Services Corporation. "Power Plant Productivity." November 1975.

82. Owen, W. H. "Design for Reliability." Proceedings of Topical Meeting on Reliable Nuclear Power Today, ISBN: 0-89448-102-9, American Nuclear Society, 1978.

83. Parker, W. D. "Operating Reliability of Oconee Nuclear Station." Proceedings of the American Power Conference, vol. 39, April 1977.

84. Petrick, N. "SNUPPS-The Multiple Utility Standardization Project." Nuclear Engineering International, November 1975.

85. Poseidon, C. "Development of Methodologies and Evaluation of the Effects of Load Management and Plant Availability Improvements on the Fuel cost and Reliability of an Electric Utility System." Ph.D. Dissertation, The Ohio State University, March 1979.

86. Poseidon, C. et al. "Task 3: Benefits of Specific Productivity Improvements," and "Task 5: Impact of Load Shape Changes to Benefits of Improved Productivity." Final Report to the Public utilities Commission of onio, The Ohio State University, Nuclear. Engineering Program, Department of Mechanical Engineering, June 1979.

87. Public Utilities Commission of ohio. "Study of the Cost/Benefit of Improved Power Plant Productivity, Task E, Report." Prepared by TRW, Energy Systems Planning Division, McLean, Virginia, June 1979.

88. Renshaw, E. F. "Productivity and the Demand for Electricity." Public Utilities Fortnightly, May 6, 1976.

89. Rittenhouse, R. C. "Vibration Monitoring and Control in Power Plants." Power Engineering, June 1980 .

90. Rowsome, F. H. III. "The Role of System Reliability Prediction in Power Plant Design." Power Engineering, February 1977. 
91. Savage, Jack. "Load Management Planning Needs--A Disciplined Approach." Electric Light and Power, May 1979.

92. Schwieger, Bob. "Design Concepts and Operating Techniques Focus on Improving Plant Performance." power, July 1979.

93. Seith, w. "Productive Efficiency in the Steam Electric Generating Industry." Journal of Political Economy 79 (1971): 4 .

94. S. M. Stoller Corporation. "Performance Characteristics of Nuclear Power Plants in the United States." 1976.

95. Stanley, R. J.; Randazzo, T.; McBeth, J. P.; and Hastings, L. W. "Availability of Large Fossil Power Plant Equipment." Proceedings of the American Power Conference, vol. 38, April 1976.

96. Stello, Victor, Jr. "Some Bases for a Systematic Program to Enhance Nuclear Plant Reliability." American Nuclear Society Executive Conference, September 1976.

97. Thomas, E. F.; Holmes, J. G.; and Schonoff, C. C. "Operating Experience with Largo Cupcroritioal units." Eombustinn, April 1971.

98. Thompson, C. A., and Clothier, W. A. "SNUPPS Power Block Modeliny." Nuclear Engineering International, November 1975.

99. Trident Engineering Associates, Inc. "Power Plant Productivity: An Assessment of Outages at Two Coal-Fired and Two Nuclear Un1ts." November 1975.

100. U.S. Department of Agriculture, Rural Electrification Administration, Power Supply and Engineering Standards Division. "Preventive Maintenance Management Manual for Fossil Fuel Steam Electric Generating Plants." February 1980.

101. U.S. Department of Energy, Economic Regulatory Administration, Division of Power Supply and Reliability. "Interim Report on the Performance of 400 Megawatt and Larger Nuclear and Coal-Fired Generating Units: Performance through 1975." DOE.ERA-0007, April 1978.

102. U.S. Department of Energy, Economic Regulatory Administration, Division of Power Supply and Reliability. "Power Plant Productivity Improvement Study: Appendices 1-4." Prepared by MRI for DOE, HCP/B60830, February 1978.

103. U.S. Department of Energy, Economic Regulatory Administration, Division of Puwer 3upply and Reliability. "Power Plant Productivity Improvement Study: Summary Report." Prepared by MRI for DOE, HCP/B60830-01.

104. U.S. Department of Energy, Economic Regulatory Administration, Division of Power Supply and Reliability. "Power Plant Productivity Improvement Study: Volumes I-IV." Prepared by MRI for DOE, HCP/B60830-02, February 1978.

105. U.S. Department of Energy, Economic Regulatory Administration, Division of Power Supply and Reliability. "Study of Benefits of Improved Power plant Reliability and Productivity. Phase I Report: Factors Considered in Planning Generation." Prepared by General Electric for DOE, HCP/B60792-01, February 1978 .

106. U.S. Department of Energy, Economic Regulatory Administration, Division of Power Supply and Reliability. "Study of Benefits of Improved Power Plant Reliability and Productivity. Phase II Report: Analysis of Two Utility Systems and Regions." Prepared by General Electric for DOE, HCP/B60792-02, February 1978. 
107. U.S. Department of Energy, Economic Regulatory Administration, Division of Power Supply and Reliability. "Study of Benefits of Improved Power Plant Reliability and Productivity. Phase III Report: National Analysis." Prepared by General Electric for DOE, December 1977.

108. U.S. Department of Energy, Federal Electric Utility Program Task Force. "Working Group Report on Improving Base Load Power Plant Performance: Appendix A, Status of Power Plant Performance." Prepared by Systems Development Corporation for DOE, January 1978 .

109. U.S. Department of Energy, Federal Electric Utility Program Task Force. "Working Group Report on Improving Base Load Power Plant Performance." Prepared by Systems Development Co'rporation for DOE, January 1978.

110. U.S. Department of Energy, Federal Electric Utility Program Task Force. "Working Group Report on Improving Base Load Power Plant Performance: Appendix $C$, Benefits and Costs of Improving Power Plant Performance." Prepared by Systems Development Corporation for DOE, January 1978.

111. U.S. Department of Energy, Federal Electric Utility Program Task Force. "Working Group Report on Improving Base Load Power Plant Performance: Appendix D, Industry Actions Being Taken." Prepared by Systems Development Corporation for DOE, January 1978 .

112. U.S. Department of Energy, Federal Electric Utility Program Task Force. "Working Group Report on Improving Base Load Power Plant Performance: E, Existing Government Programs and Activities to Improve Power Plant Performance." Prepared by Systems Development.Corporation for DOE, January 1978 .

113. U.S. Department of Energy, Federal Electric Utility Program Task Force. "Working Group Report on Improving Base Load Power Plant Performance: Appendix F, Constraints to Industry Initiatives." Prepared by Systems Development Corporation for DOE, January 1970.

114. U.S. Department of Energy, Federal Electric Utility Program Task Force. "Working Group Report on Improving Base Load Power Plant Performance: Appendix G, Data Availability and Adequacy." Prepared by Systems Development Corporation for DOE, January 1978 .

115. U.S. Department of Energy, Federal Electric Utility Program Task Force. "Working Group Report on Improving Base Load Power Plant Performance: Main Report." Prepared by Systems Development Corporation for DOE, January 1978.

116. U.S. Department of Energy, office of Nuclear Energy Programs. "Light Water Reactor (LWR) Technology Program." March 1979.

117. U.S. Department of Energy, Office of Program Control and Support. Fossil Energy Program Summary Document, DOE/ET-0087. March 1979.

118. Wall, T. F.; Lowe, A., Wibberly, L. J.; and MaStewart, J. "Mineral Matter in Coal and the Thermal Performance of Large Boilers." Progress in Energy and Combustion Science 5 (1979).

119. Zebroski, E. L. "Some Technical and Institutional Directions for Improving - Plant and Equipment Productivity." Mitre Corporation, MTR-7032, February 1976. 